\title{
A synoptic review of the family Dendronotidae (Mollusca: Nudibranchia): a multilevel organismal diversity approach
}

\author{
Tatiana Korshunova \\ Koltzov Institute of Developmental Biology, Vavilova str. 26, 119334 Moscow, Russia
}

Torkild Bakken

NTNU University Museum, Norwegian University of Science and Technology, Trondheim, Norway

Viktor V. Grøtan

Ørland Froskemannsklubb (Ørland Diveclub), Postboks 197, 7129 Brekstad, Norway

Kjetil B. Johnson

Ørland Froskemannsklubb (Ørland Diveclub), Postboks 197, 7129 Brekstad, Norway

Kennet Lundin

Gothenburg Natural History Museum, Box 7283, 40235, Gothenburg, Sweden

Gothenburg Global Biodiversity Centre, Box 461, 40530, Gothenburg, Sweden

\author{
Alexander Martynov \\ Zoological Museum of the Moscow State University, Bolshaya Nikitskaya Str. 6125009 \\ Moscow, Russia \\ martynov@zmmu.msu.ru
}

\begin{abstract}
A synoptic review of the family Dendronotidae is presented based on morphological and molecular data. Three genera are recognized: Dendronotus, Pseudobornella, and Cabangus gen. nov. Two new Dendronotus species are described, D. yrjargul sp. nov. and D. nordenskioeldi sp. nov., which reveal fine-scale differences. Dendronotus yrjargul sp. nov. from mid-Norway and the Arctic regions is a sister species to the North Pacific $D$. kalikal. These two species are showing clear morphological and ontogenetic differences but are close in genetic distance. In contrast, Dendronotus nordenskioeldi sp. nov. from the Laptev Sea is externally similar to the white morphs of $D$. lacteus or $D$. frondosus, but according to the molecular data and radular


morphology it is distinct from any of its congenerics. Comparison of molecular and morphological data of $D$. niveus from the type locality (White Sea) and material from other localities with those from the American North Atlantic coast (type locality of D. elegans) reveals their substantial similarity. Therefore, $D$. niveus is considered a junior synonym of $D$. elegans. The present review of the family Dendronotidae contributes to a general discussion on the species concepts and on a recent proposal of multilevel organismal diversity.

\section{Keywords}

Cabangus - Dendronotus - Pseudobornella - molecular phylogeny - species problem - taxonomy

Zoobank: http://urn:lsid:zoobank.org:pub:5E6F2529-E533-4A89-9EE4-5677865C5468

\section{Introduction}

The evolutionary process is traditionally considered to be continuous (Darwin, 1859) and this concept prevails despite many years of controversial discussions (Eldredge \& Gould, 1972; Mayr, 1982; Mallet et al., 20o9; Coates et al., 2018). However, the species itself is supposed to be an unavoidably separate unit according to the nomenclature of current taxonomic practice, which in zoology is governed by the ICZN (1999). This is one of the greatest contradictions between the evolutionary processes and taxonomic classification, which has not been solved satisfactorily (Zachos, 2018). In many cases it has been shown that it is very difficult to assign a particular specimen to a particular species. Until now there are no unequivocal and universal criteria for species delimitations when the underlying evolutionary processes and phylogenies are taken into consideration (e.g., Zachos et al., 2013; González et al., 2018; Stanton et al., 2019; Platania et al., 2020), and even for the existence of species at all (Ereshefsky, 1998; Willis, 2017; Reydon \& Kunz, 2019). At the conceptual level, more than 26 different species concepts have been suggested (Zachos, 2016) but at a practical level even the most widely acclaimed criterion of reproductive isolation (Mayr, 1969,1982 ) is not robust as has been shown on numerous occasions (e.g., McDonald and Koehn, 1988; Mallet, 2005; Kijewski et al., 2006; Harrison \& Larson, 2014; Jančúchová-Lásková et al., 2015; Crossman et al., 2016; Fraïsse et al., 2016; Potkamp \& Fransen, 2019).

With the dawn of the molecular era in taxonomy, the problem of hidden diversity emerged when molecularly divergent groups of specimens were discovered within morphologically highly similar species as defined in the traditional way (Bickford, 2007; Korshunova et al., 2017a, 2019a). The discordant development of morphological structures and genetic apparatus per se is also a sign of evolutionary processes in progress. However, it is still possible to separate such cases by using molecular data and if there are extensive genetic differences, we may assume that evolutionary divergence has occurred among such species. Relatively rarerely noticed and much more interesting are those cases when despite relatively low genetic differences some species exhibit distinct morphological features (Mayer \& Helversen, 2001; Wiemers \& Fiedler, 2007). The current practice of defining potential species by using molecular markers depending on various distances 
and factors (e.g., Ratnasingham \& Hebert, 2013) referred to as "operational taxonomic units" (оTUs) does not consistently correspond to taxa at the species level. There is an unfortunate discordance in how the taxonomic practice currently works because it is based on a classification system consisting of rigid names that does not fully reflect information of the underlying evolutionary processes. A solution for the species problem using the separation between metapopulation lineages potentially without any distinguishing characters (de Queiroz, 2006, 2007) contradicts available biological evidence, e.g., that even clones show minor but detectable morphological and epigenetic differences. Therefore, to avoid an artificial contrast between "cryptic" and "non-cryptic" species in a classification and to encompass various available data, the concept of the multilevel organismal diversity was proposed (Korshunova et al., 2019a). In the present study we apply this approach to the nudibranch family Dendronotidae.

Currently there is an accelerating discovery of fine-scale species-level diversity within the genus Dendronotus. In the last decade, 10 of 12 new Dendronotus spp. were described by our research group using both morphological and molecular data (Martynov 2015a, 2020a; Ekimova et al. 2015; Lundin et al., 2017; Korshunova et al. 2016a, b, 2017b, 2019b). In this study, we present a modern taxonomic synopsis of the family Dendronotidae, which together with molecular phylogenetic analyses demonstrates both lower and higher degrees of evolutionary separations as a reliable example of multilevel organismal diversity. For instance, a newly discovered species from Norway (Dendronotus yrjargul sp. nov.) already has developed definite signs of morphological and molecular divergence. This highlights the importance of considering broadly ontogenetic data in the framework of multilevel organismal diversity (Korshunova et al., 2019a). We therefore develop a general taxonomic framework for phylogeny and taxonomy of the family Dendronotidae, which for the first time presents a synoptic review of all currently known species of the genus Dendronotus. Its also confirms the validity of the genus Pseudobornella Baba, 1932 and supports the proposal of the new genus Cabangus (see details in Synopsis).

\section{Materials and methods}

\section{Collecting data}

Specimens were collected by Viktor V. Grøtan and Kjetil B. Johnson in the vicinities of Trondheim, Norway $\left(63^{\circ} 41^{\prime} 8.66^{\prime \prime} \mathrm{N}\right.$ $9^{\circ} 39^{\prime} 58.79 " \mathrm{E}$ ), and also in the Arctic waters during vessel expeditions, and for comparative purposes by scuba diving in NE Atlantic, NW and NE Pacific. Specimens studied are deposited in the collections at Zoological Museum, Moscow State University (ZMMU), and the Norwegian University of Science and Technology, NTNU University Museum (NTNU-VM) (Bakken et al., 202O).

\section{Morphological analysis}

External and internal morphology was studied under a stereomicroscope using a Nikon D-81o digital camera and scanning electron microscopes. The buccal mass of each specimen was extracted and processed in 10\% sodium hypochlorite solution to extract the radula and the jaws. The jaws of each species were analysed under a stereomicroscope and then photographed. The jaws and radulae were coated, then examined and photographed using a scanning electron microscope (CamScan, JSM). The reproductive systems were also examined using a stereomicroscope. 


\section{Molecular analysis}

Eleven specimens were sequenced for the mitochondrial genes cytochrome $\mathrm{c}$ oxidase subunit I (COI) and $16 \mathrm{~S}$ rRNA, and the nuclear genes $28 \mathrm{~S}$ rRNA (C1-C2 domain). Small pieces of tissue were used for DNA extraction with Diatom ${ }^{\mathrm{mm}}$ DNA Prep 100 kit by Isogene Lab, according to the producer's protocols. Standard PCR amplification options, and sequence obtainment were applied (for details, see Korshunova et al., 2016a, 2017a). COI sequences were translated into amino acids to verify coding regions and avoid errors. All new sequences were deposited in GenBank (Appendix, table A1, highlighted in bold). Publicly available sequences COI, 16S rRNA, 28S rRNA, and additionally the nuclear gene Histone $3\left(\mathrm{H}_{3}\right)$ of Dendronotus species plus several outgroup taxa (Tritonia, Marionia, Doto, Scyllaea, Crosslandia, Tethys and Notobryon) were also included in the molecular analysis. Phylogenetic analysis was performed using 91 specimens of the genus Dendronotus, three Pseudobornella orientalis Baba, 1932 specimens, and 12 outgroup specimens (Appendix, table A1). Sequences were aligned with the MAFFT algorithm (Katoh et al., 2002). Separate analyses were conducted for COI (658 bp), $16 \mathrm{~S}$ (442 bp), $28 \mathrm{~S}$ (349 bp), $\mathrm{H}_{3}$ (328 bp), and the concatenated dataset $(1777 \mathrm{bp})$. Gblocks o.91b (Talavera and Castresana 2007) was applied to discard poorly aligned regions for the $16 \mathrm{~S}$ data set (using less stringent options; in total, $5 \%$ of the positions were eliminated). The GTR $+\mathrm{I}+\mathrm{G}$ model was chosen for the COI, $16 \mathrm{~S}$, and concatenated datasets; the $G T R+G$ model was chosen for the $28 \mathrm{~S}$ and $\mathrm{H}_{3}$ datasets using MrModelTest 2.3 (Nylander et al., 2004).

Two different phylogenetic methods, Bayesian Inference (BI) and Maximum Likelihood (ML), were used to infer evolutionary relationships. Bayesian estimation of posterior probability was performed in MrBayes 3.2
(Ronquist et al., 2012). Four Markov chains were sampled at intervals of 500 generations. Analysis was started with random starting trees and $5 \times 10^{6}$ generations. Maximum Likelihood-based phylogeny inference was performed using RAxML 7.2.8 (Stamatakis et al., 2008)) with 1000 bootstrap replicates. Final phylogenetic tree images were rendered in FigTree 1.4.2. Nodes in the phylogenetic trees with Bayesian posterior values $>0.96 \%$ and bootstrap values $>90 \%$ were considered 'highly' supported. Nodes with $0.90-0.95 \%$ and $80-89 \%$ accordingly were considered 'moderately' supported (lower support values were considered not significant).

The program MEGA7 (Kumar et al., 2016) was used to calculate the uncorrected p-distances between all the sequences as well as mean intragroup and intergroup genetic distances. Automatic Barcode Gap Discovery (ABGD) (Puillandre et al., 2012) (https://bioinfo.mnhn.fr/abi/public/abgd/abgdweb.html) was used to estimate Dendronotus species divergence. Alignment from the COI marker were submitted and processed in ABGD using the Jukes-Cantor (JC69) and Kimura (K8o) models with the following settings: a prior for the maximum value of intraspecific divergence between 0.001 and $0.1,10$ recursive steps within the primary partitions defined by the first estimated gap, and a gap width of 1 .

A multi-locus species delimitation analysis was performed using BPP v.3.1 (Yang 2015) for COI, $16 \mathrm{~S}$, and $28 \mathrm{~S}$ genes. Two analyses (A and $\mathrm{B}$ ) with different population size $(\theta s)$ and divergence time ( $\tau \circ)$ priors were preformed, using the same settings and priors as in Martinsson

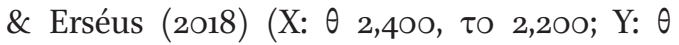
$2,1000, \tau 02,200$ ). All analyses were performed three times to confirm consistency between runs. We considered species delimited with a PP $\geq 0.90$ in all analyses to be well supported. For clusters with a PP $<0.90$, we accepted the best-supported more inclusive species. 


\section{Results}

\section{Molecular phylogenetic relationships} amongst species of the genus Dendronotus

Bayesian Inference (BI) and Maximum Likelihood (ML) analyses based on the combined dataset for the mitochondrial COI and $16 \mathrm{~S}$, and the nuclear $28 \mathrm{~S}$ and $\mathrm{H}_{3}$ genes yielded similar results (fig. 1). The family Dendronotidae formed a highly supported clade with BI and ML (BS = 100, PP = 0.96). Dendronotus elegans Verrill, 1880 from Newfoundland and Greenland (close to the type locality of this species) nested together with $D$. elegans (= D. niveus Ekimova et al., 2015 syn. nov.) from the White, Barents, Kara, and Laptev seas in a maximum-supported separate clade $(\mathrm{PP}=1, \mathrm{BS}=100)$. Dendronotus nordenskioeldi sp. nov. shows a sister position with the D. europaeus Korshunova et al., 2017 clade and the clade including D. rufus O'Donoghue, 1921 and D. lacteus (Thompson, 1840), but without good node support. Evolutionary ties for D. nordenskioeldi sp. nov. are not fully clarified. Dendronotus kalikal Ekimova et al., 2015 and D. yrjargul sp. nov. clustered in separate clades. Node support for the $D$. yrjargul sp. nov. clade is moderate ( $\mathrm{PP}=0.93, \mathrm{BS}=78)$. Support for the D. kalikal clade is highly supported with BI and moderately supported with ML ( PP = 0.99, BS $=83)$.

Individual gene trees showed similar trends, however the position of Pseudobornella orientalis and Cabangus regius (Pola \& Stout, 2008). varied (fig. 2). The cor single tree placed $C$. regius $(\mathrm{PP}=0.99)$ as sister to the genus Dendronotus, and $P$. orientalis as sister to these together. The $16 \mathrm{~S}$ single tree showed that $P$. orientalis forms a weakly supported polytomy $(\mathrm{PP}=0.6)$ with the clade containing D. robustus, D. patricki Stout et al., 2011 and $D$. velifer, and the clade including other Dendronotus species. C. regius was sister to all these clades $(\mathrm{PP}=0.98)$. The $28 \mathrm{~S}$ single tree placed $P$. orientalis $(\mathrm{PP}=0.99)$ as sister to the genus Dendronotus. The $\mathrm{H}_{3}$ single tree shows polyphyly in genus Dendronotus if Cabangus regius would be classified as Dendronotus. For $P$. orientalis, the minimal mean COI intergroup genetic distance was found between $P$. orientalis and D. velifer (15.6\%), and maximal between P. orientalis and D. lacteus (18.3\%). For $C$. regius, the minimal mean intergroup genetic distance was found between $C$. regius and $D$. kalikal $(16.2 \%)$, and the maximal between $C$. regius and $D$. frondosus (18.4\%). The mean intergroup genetic distance within the clade including $D$. robustus, $D$. patricki and $D$. velifer ranged from 7.2 to $16.8 \%$. The mean intergroup genetic distance within the clade "other Dendronotus" ranged between 2.1 and 14.2\% (Appendix, table A2).

To define species, we used an integrative approach, including phylogenetic tree topologies, ABGD and BPP analyses, pairwise distances as well as the haplotype network for the molecular data reconstructed using Population Analysis with Reticulate Trees (PopART).

To delimit the species based on single locus sequence data (COI), species delimitation was performed with the ABGD tool. In the full data set (88 Dendronotus specimens), results from initial partitions show 20 potential species: 16 reputed Dendronotus species $+D$. elegans from the type geographic region (North Atlantic), combined together with $D$. elegans ("as $D$. niveus") from the Arctic region $+D$. rufus, combined with $D$. lacteus $+D$. nordenskioeldi sp. nov. + D. yrjargul sp. nov., combined with D. kalikal. Generally, recursive partitions have more groups than initial partitions that are typically stable. Results from recursive partitions show 22 potential species, corresponding the potential Dendronotus species clades on the phylogenetic tree (fig. 1): 16 reputed Dendronotus species in additon to separate clades for D. nordenskioeldi sp. nov., D. yrjargul 
Dendronotus elegans White Sea

Dendronotus elegans White Sea

Dendronotus "niveus" White Sea (h)

Dendronotus "niveus" White Sea (p)

Dendronotus "niveus" Barents Sea (p)

Dendronotus "niveus" Barents Sea (p)

Dendronotus "niveus" Barents Sea (p)

Dendronotus elegans White Sea

Dendronotus "niveus" Barents Sea (p)

Dendronotus elegans Kara Sea

Dendronotus elegans Newfoundland

100 Dendronotus elegans Kara Sea

Dendronotus elegans Laptev Sea

Dendronotus elegans Kara Sea

Dendronotus elegans Grenland

Dendronotus elegans Laptev Sea

Dendronotus elegans Kara Sea

Dendronotus elegans Laptev Sea

Dendronotus kalikal Kamchatka
Dendronotus kalikal Bering Strait

1/100 Dendronotus kalikal Kamchatka

Dendronotus kalikal Kamchatka

- Dendronotus kalikal Kamchatka

17

Dendronotus kalikal Kamchatka

- Dendronotus kalikal Kamchatka

Dendronotus kalikal Kuril Islands

Dendronotus kalikal Kuril Islands

Dendronotus kalikal Kuril Islands

Dendronotus kalikal Kuril
$1 / 100 /$ Dendronotus robilliardi
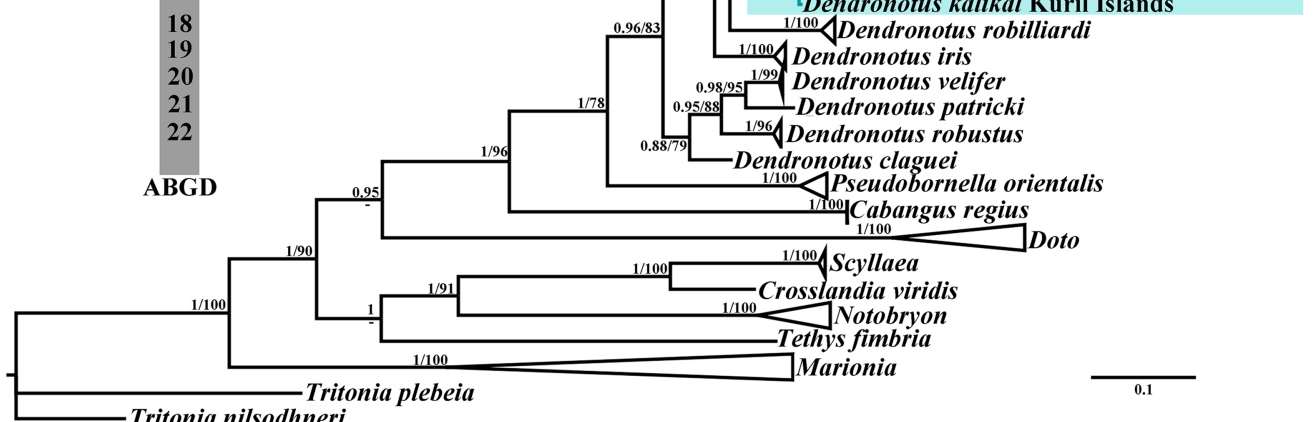

-Tritonia nilsodhneri

FIGURE 1 Phylogenetic relationships of the species of the genus Dendronotus based on COI $+16 \mathrm{~S}+28 \mathrm{~S}+\mathrm{H}_{3}$ concatenated dataset inferred by Bayesian Inference (BI). Numbers represent posterior probabilities from B I and bootstrap values for Maximum Likelihood. Some branches are collapsed at species level. Dendronotus elegans from the type region (North Atlantic) are highlighted in dark purple. Abbreviations: $\mathrm{h}$ - holotype; $\mathrm{p}$ - paratype. Summary of species delimitation results from ABGD analyses for the cor dataset is shown. 
COI
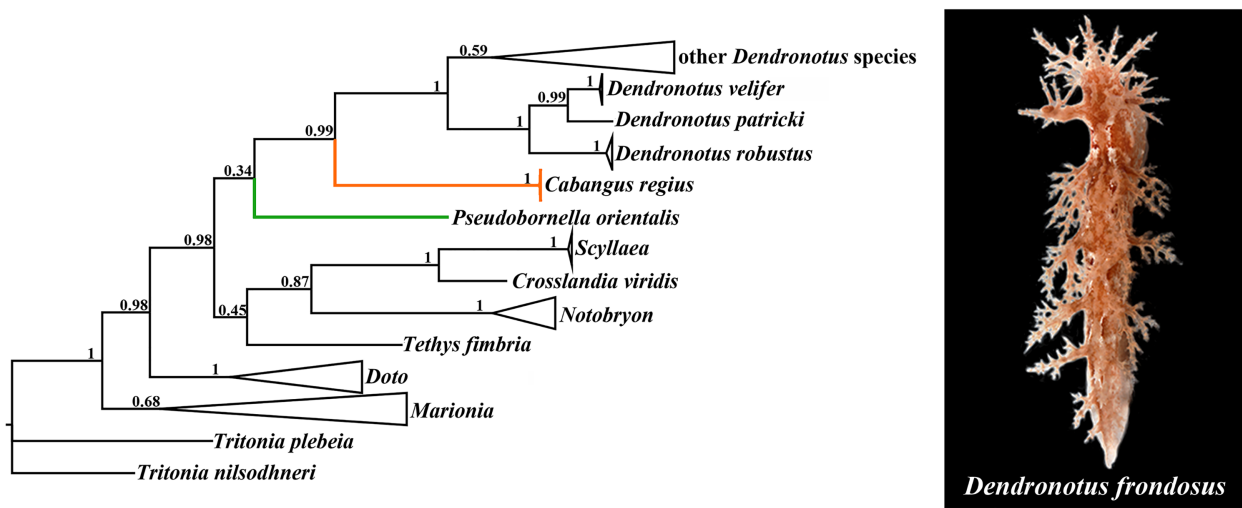

$16 S$
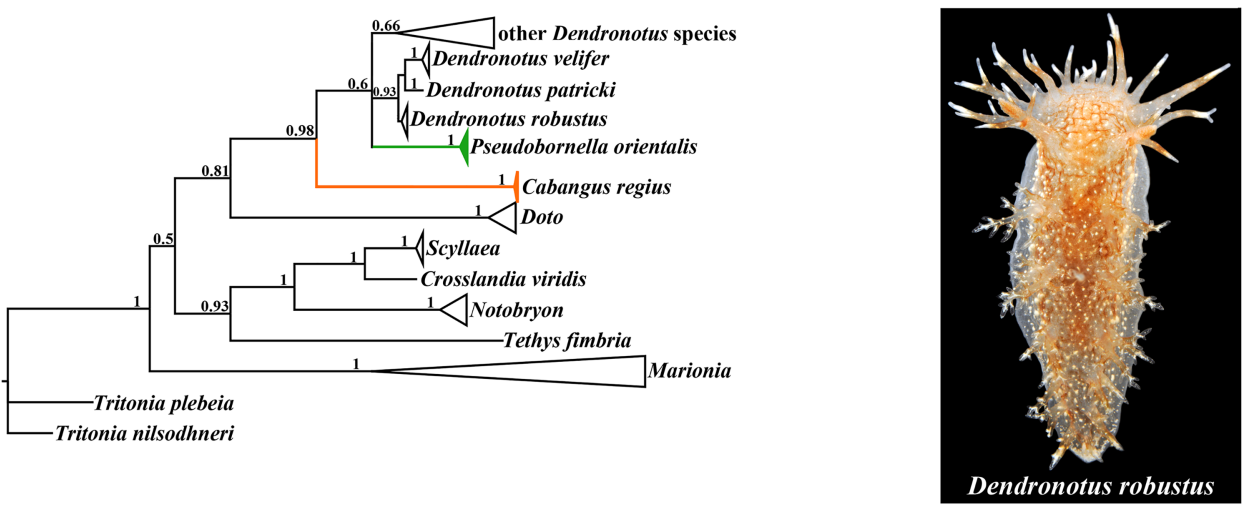

$28 \mathrm{~S}$
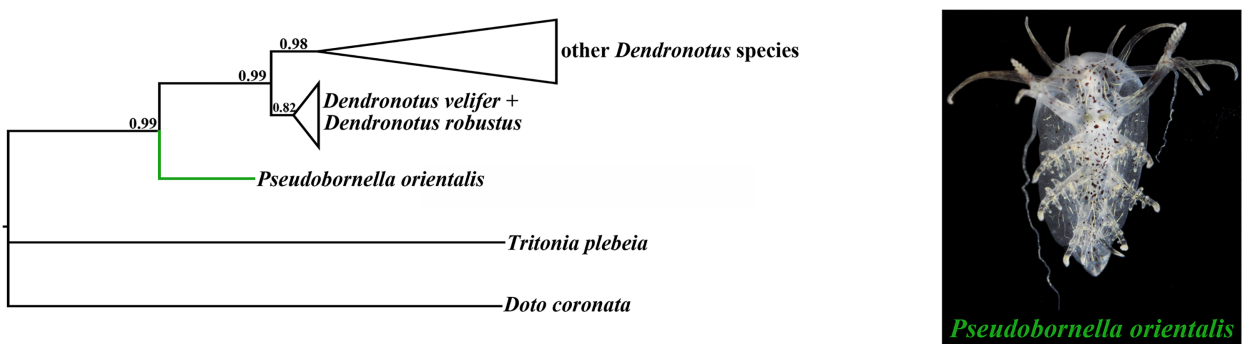

H3
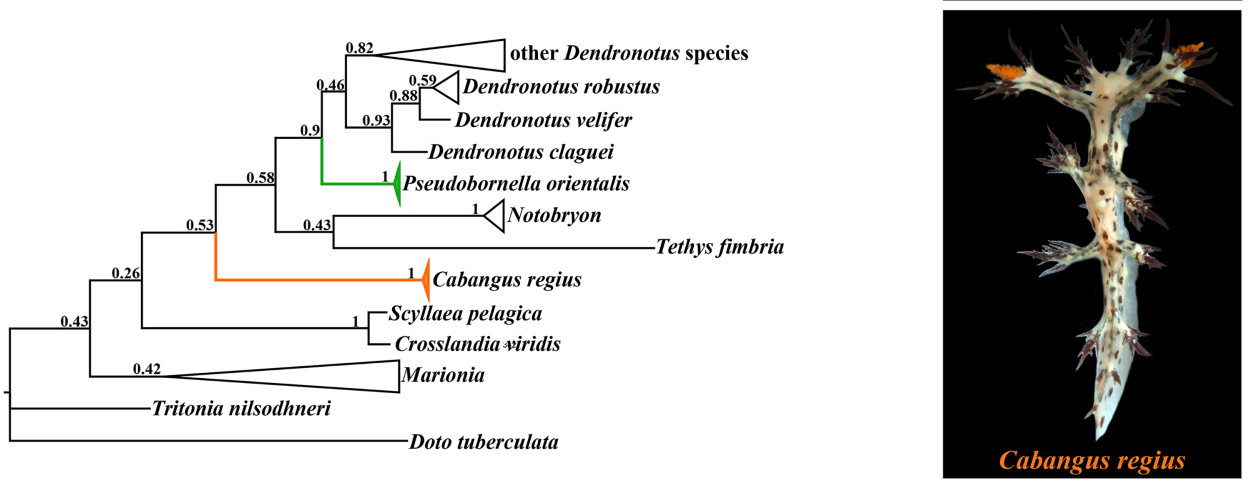

FIGURE 2 Phylogenetic relationships of the species of the genera Dendronotus, Pseudobornella and Cabangus in single COI, $16 \mathrm{~S}, 28 \mathrm{~S}$, and $\mathrm{H}_{3}$ gene trees inferred by Bayesian Inference (ві). Some branches are collapsed. Positions the Pseudobornella orientalis highlighted green; positions the Cabangus regius highlighted orange. Numbers represent posterior probabilities from BI.

PHOTOGRAPHS BY A. MARTYNOV AND T. KORSHUNOVA 
sp. nov., D. kalikal, D. rufus, D. lacteus, and D. elegans from the North Atlantic, together with D. elegans (as "D. niveus") from the Arctic region.

Analyzing multi-locus genomic sequence data under the multispecies coalescent model was conducted for D. elegans (2 specimens), former D. "niveus" (16 specimens), D. yrjargul sp. nov (11 specimens). and D. kalikal (1o specimens). In analysis $A$, the three species model (D. elegans combined with the former " $D$. niveus", separate D. yrjargul sp. nov. and separate $D$. kalikal) is preferred with a mean PP of o.94. In analysis B, the same three species model is also preferred with a higher mean PP of 0.99 .

Results obtained by PopART for the COI and ${ }_{16 S}$ genes showed a network of haplotypes that clearly clustered into three groups coincident with D. elegans combined with former "D. niveus", D. yrjargul sp. nov. and $D$. kalikal (fig. 3).

Regarding the supposedly fast-evolving CoI marker, genetic distance values between D. elegans from Newfoundland and D. elegans from Greenland is o.61\%. Maximal intragroup distance among specimens formerly identified as "D. niveus" from the White, Barents, Kara, and Laptev seas is $1.42 \%$, whereas distances between the D. elegans and specimens formerly identified as " $D$. niveus" range from o to $0.94 \%$, indicating without doubt that D. elegans and former " $D$. niveus" are the same species. Mean intragroup distance within the $D$. elegans clade is $0.59 \%$ whereas minimal intergroup distance (7.6\%) was found between $D$. elegans and D. dalli (Appendix, table A2).

The molecular phylogenetic results confirm the morphological analysis data (see Systematic section and figs 1-8). Thus, $D$. elegans and "D. niveus" are the same species, whereas D. kalikal, D. yrjargul sp. nov, and $D$. nordenskioeldi sp. nov. are three separate species in the genus Dendronotus.

\section{Systematic account}

Descriptions of the new species of the genus

\section{Dendronotus}

\section{Dendronotus yrjargul sp. nov.}

Figs 1-4, 6, 7

ZooBank: http://urn:lsid:zoobank.org:act: D44EDB5D-9C27-4D38-A18B-AD6DA5ACE43D

Etymology. From Norwegian yrjar (= old name for the type locality in Ørland) and gul (= yellow) meaning "yellow/golden of Ørland" in reference to the remarkable habitus of this species.

Type locality. Norwegian Sea, Norway, Ørland.

Material examined. Holotype. NTNU-VM76306, live length $95 \mathrm{~mm}$ (48 $\mathrm{mm}$ preserved), Norwegian Sea, mouth of Trondheimsfjord, Ørland, Breivika, 12.03.2018, depth 20-25 m, collector Viktor V. Grøtan. Paratypes with same provenance data: NTNU-VM-76307, 1 specimen, live length $75 \mathrm{~mm} \quad$ (40 mm preserved); NTNU-VM-76308, 1 specimen, live length $60 \mathrm{~mm}$ (40 $\mathrm{mm}$ preserved); paratypes with same provenance data but collected o8.01.2018, depth 20-25 m, collector Viktor V. Grøtan, Kjetil B. Johnson: NTNU-VM-76302, 1 specimen, preserved length $18 \mathrm{~mm}$; NTNU-VM76305, 1 specimen, preserved length $17 \mathrm{~mm}$; NTNU-VM-76303, 1 specimen, preserved length 14 mm; NTNU-VM-76304, 1 specimen, preserved length $19 \mathrm{~mm}$; ZMMU Op-718, 1 specimen, preserved length $19 \mathrm{~mm}$.

Description. Body elongate, living specimens up to $95 \mathrm{~mm}$ in length (fig. 4). Five to six main branched appendages on oral veil. Five appendages on rhinophoral stalks; $18-30$ rhinophoral lamellae. Branched lateral papilla on rhinophoral sheath present. Seven to eight pairs of dorsolateral appendages present in large adult specimens. Lip papillae 10 to 20. Dorsolateral 


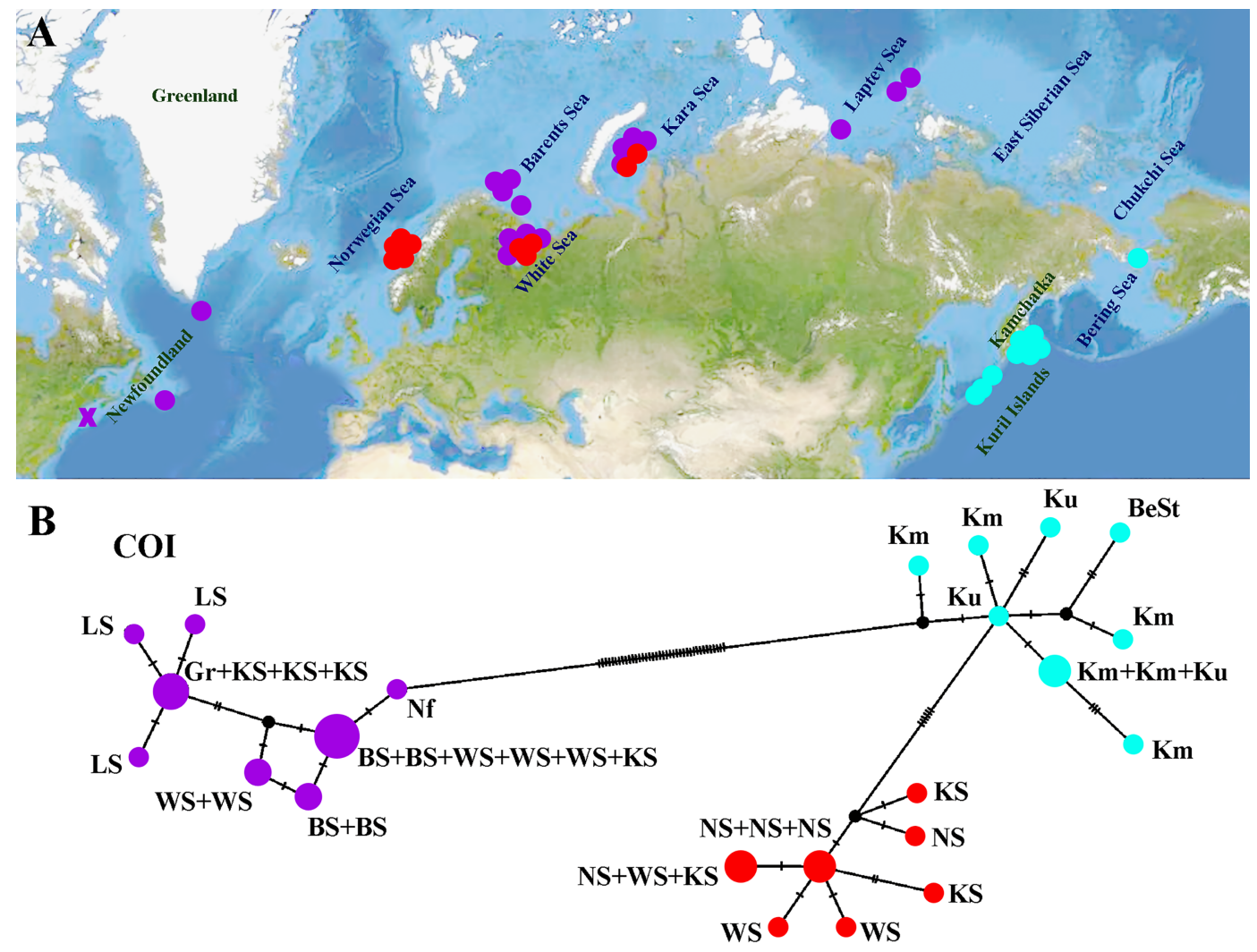

$16 S$

$\mathbf{K m}+\mathbf{K m}+\mathbf{K m}+\mathbf{K m}+$

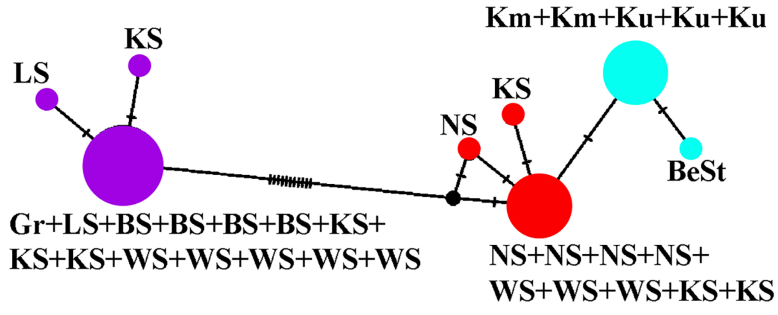

Gr+LS+LS+LS+KS+
KS+WS+WS+WS+WS+
WS+BS+BS+BS+BS

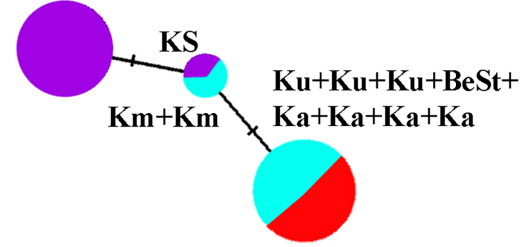

Dendronotus elegans + Dendronotus "niveus"

NS+NS+NS+WS+WS+ Dendronotus kalikal

$\mathbf{W S}+\mathrm{KS}+\mathrm{KS}+\mathrm{KS}$

\section{- Dendronotus yrjargul sp. nov}

FIGURE 3 A. Map of the Northern Hemisphere showing the distribution of D. elegans (including "D. niveus"), $D$. kalikal, and D. yrjargul sp. nov. The type locality of $D$. elegans is indicated by crossed lines. B. The haplotype networks based on cytochrome c oxidase subunit I (COI), 16S rRNA (16S), and $28 \mathrm{~S}$ rRNA (28S) molecular data showing genetic mutations occurring within D. elegans ("D. niveus"), $D$. kalikal, and D. yrjargul sp. nov. specimens. Abbreviations: BeSt - Bering Strait; BS - Barents Sea; Gr Greenland; Km - Kamchatka; KS - Kara Sea; Ku - Kuril Islands; LS - Laptev Sea; Nf - Newfoundland; Ns - Norwegian Sea; ws - White Sea. Type locality of D. elegans is marked on the map by " $\mathrm{x}$ ". 

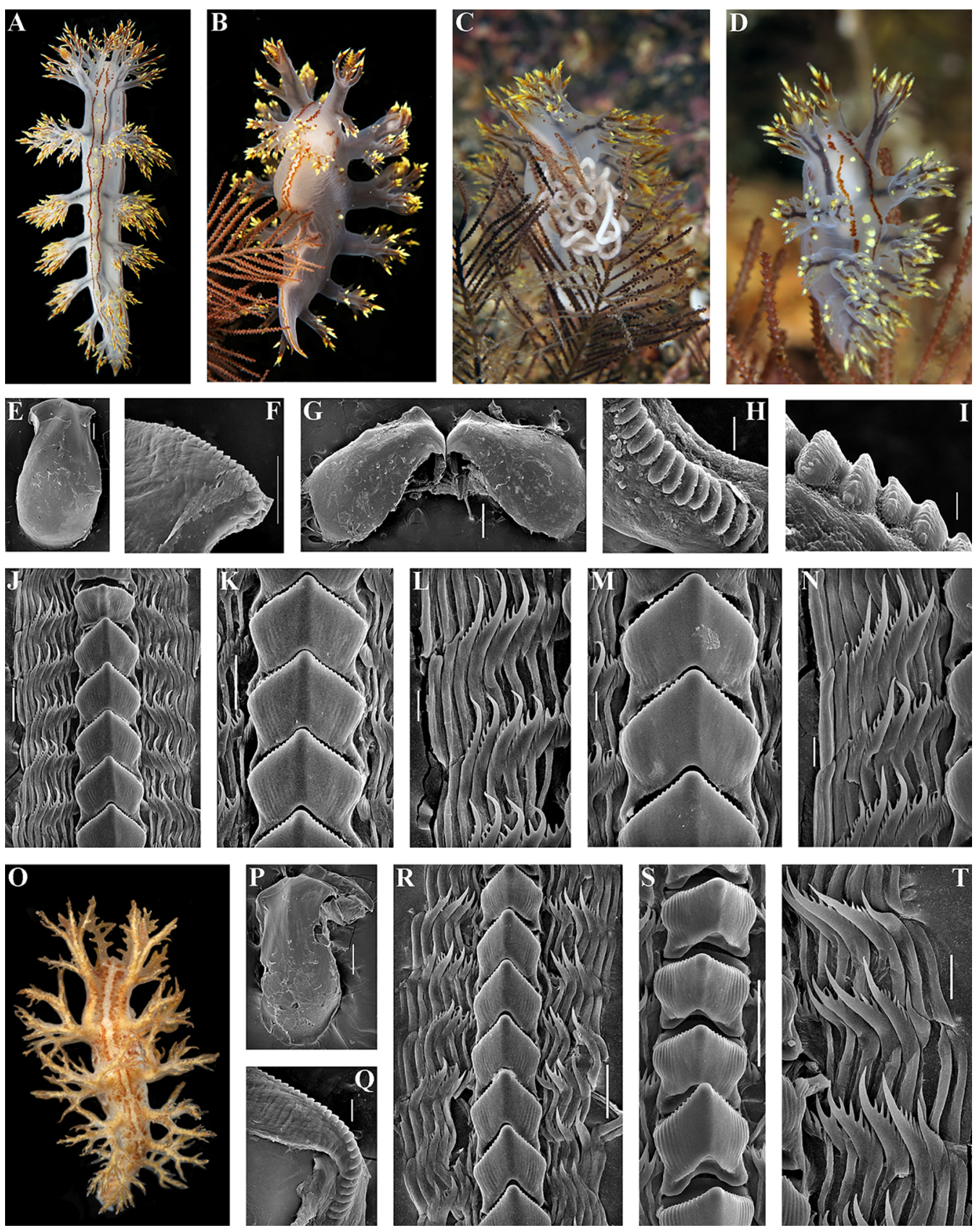

FIGURE 4 Dendronotus yrjargul sp. nov. (a-n) and D. kalikal (o-t), external and internal morphology. a-c: living holotype of $D$. yrjargul NTNU-VM-76306 (a) and its habitat (b, c), dorsal, ventral and lateral views with egg mass and associated hydroid Abietinaria fusca, respectively; d: Dendronotus yrjargul, habitat of living paratype NTNU-VM-763o2; e: jaw of holotype; f: denticles on the masticatory edge of the holotype; g: jaws of paratype NTNU-VM-76302; h: discoid ridge-like structures on the masticatory edge of paratype NTNU-VM-763o2; i: details of discoid structures on the masticatory edge of paratype NTNU-VM-76302; j: anterior part of radula of holotype; k: central teeth of radula of holotype; l: lateral teeth of radula of holotype; m: central teeth of radula of paratype NTNU-VM-763o2; n: lateral teeth of radula of holotype; o: living holotype of $D$. kalikal; p: jaw of $D$. kalikal, specimen from Kurile Islands; 
appendages with relatively short primary stalk, strongly branched secondary branches and elongate tertiary branches (fig. 4A-D). Basal colour is semitransclucent white to greyish, with characteristic two thin wavy subparallel brownish-orange to brownish lines running from the head nearly to the tail. There are no specimens with brownish basal colour. Upper part of the dorsolateral appendages covered with bright golden yellow to yellowish pigment. Foot bordered with thin brownish-orange line. Dorsal processes of jaws inclined posteriorly at approximately $40-48^{\circ}$ to the longitudinal axis of the jaw body and 0.4 of its length (fig. $\left.{ }_{4} \mathrm{E}-\mathrm{I}\right)$. Masticatory border of jaw with evident ridge-like denticles (fig. $4 \mathrm{H}, \mathrm{I}$ ). Radular formula: 38-50 $\times$ o-9.1.9-0. Central (rachidian) tooth moderately denticulated and bearing up to 16 distinct denticles (fig. 4J-M). Denticles with deep furrows. Lateral teeth elongate, slightly curved, bearing up to 7 denticles (fig. $4 \mathrm{~J}-\mathrm{N}$ ). Ampulla thickened kidney-shaped (fig. 6A). Prostate discoidal, consisting of up to 50 alveolar glands. Distal part of vas deferens moderate in length, transitioning to long, thick, curved copulatory organ. Bursa copulatrix large, rounded, with seminal receptaculum placed distally.

\section{Distribution. From Norwegian Sea to Kara Sea.}

\section{Habitatandecologicalobservations. Dendronotus} yrjargul sp. nov. is closely associated with the hydroid Abietinaria fusca (Johnston, 1847) (see Vervoort, 1942) which forms dark brown colonies that resemble small dry fir branches (personal observations of VG and KJ). The hydroid usually inhabits somewhat deeper water, but currents and other conditions in the Norwegian waters make it reachable by scuba diving at circa $20 \mathrm{~m}$.
We have only rarely observed the new species on other hydroids. Dendronotus yrjargul sp. nov. appears quite abundant in this location, up to 10 individuals per $\mathrm{m}^{2}$. The new species appears to have a one-year life cycle. Mating and egg laying occurs around March, and the large adult individuals eventually disappear throughout the spring, as does the hydroid they live on. During the summer, small individuals begin to reappear, along with the new growing phase of $A$. fusca. The new generation of D. yrjargul sp. nov. grow throughout autumn and winter.

Remarks. Externally, D. yrjargul sp. nov. readily differs from all known species of the genus Dendronotus (synopsis given below), including the sister species from the North Pacific, D. kalikal (description for comparison is given below), by a combination of off-white semitransparent body with two thin dorsal subparallel brownish lines and dorso-lateral appendages golden-yellow to yellowish (fig. 4A-D). Instead, D. kalikalinvariably possesses a basal body colour covered with numerous brownish speckles and small spots, which make subparallel dorsal lines considerably blurred and indistinct (fig. 4O). Importantly, we investigated more than ten $D$. kalikal specimens from very distantly placed localities in the Bering Strait, Kamchatka and Kurile Islands (fig. $3^{\mathrm{A})}$ and not one specimen possessed a mostly whitish semitransparent body with distinct thin subparallel dorsal lines, as in D. yrjargul sp. nov. (fig. 4A-D). The whitish colouration in D. kalikal consists of a background colour represented by areas in between the numerous basal brownish spots and stripes. Furthermore, considerable differences in the reproductive system and the maturation process between D. yrjargul sp. nov. and $D$. kalikal were revealed in course of the

FIGURE 4 q: details of the masticatory edge of the same specimen; r: anterior part of radula of the same specimen;

(cont.) s: central teeth of radula, same specimen; t: lateral teeth of radula, same specimen. Scale bars: e: 300

$\mu \mathrm{m}$; f: $100 \mu \mathrm{m}$; g: $500 \mu \mathrm{m}$; h, m, n, q, t: $20 \mu \mathrm{m}$; i: $5 \mu \mathrm{m}$; j, k, r, s: $50 \mu \mathrm{m}$; l, t: $20 \mu \mathrm{m}$; p: $200 \mu \mathrm{m}$.

PHOTOGRAPHS BY V. GRØTAN (A-D) AND T. KORSHUNOVA (O). SEM MICROGRAPHS BY A.

MARTYNOV 
present study. All studied specimens of D. kalikal have an elongated bursa copulatrix (fig. 6B), whereas in all studied specimens of $D$. yrjargul sp. nov. (fig. 6A) the bursa copulatrix is rounded.

Furthermore, we discovered that there is considerable difference in the patterns of maturation (and hence, ontogenetic patterns) between D. yrjargul sp. nov. and D. kalikal. Dendronotus yrjargul sp. nov. reaches a big size of $95 \mathrm{~mm}$ (live) in the adult state, and in specimens of $20-30 \mathrm{~mm}$ (live) the reproductive system was still very weakly developed. Instead, $D$. kalikal has a maximum length of $17 \mathrm{~mm}$ when preserved and already at lengths of 7-10 mm live specimens show a well-developed reproductive system. The molecular differences between $D$. yrjargul sp. nov. and D. kalikal are as follows. Regarding the coI marker, the maximal intragroup distance within D. kalikal is $1.74 \%$ and within D. yrjargul sp. nov. it is $0.85 \%$ (mean intragroup distances are $0.80 \%$ and $0.39 \%)$. The mean intergroup distance between $D$. kalikal and D. yrjargul sp. nov. groups is $2.1 \%$ (Appendix, table A2). Thus, intragroup distances within $D$. yirargul sp. nov. are smaller than the distance between $D$. yirargul sp. nov. and D. kalikal. Thus, $D$. yrjargul sp. nov. and D. kalikal demonstrate considerable differences in morphological, molecular and, to a very large degree, ontogenetic levels. Dendronotus yrjargul sp. nov. thus represents a well-separated species, although possibly recently diverged, as indicated by the slight molecular divergence.

\section{Dendronotus nordenskioeldi sp. nov.}

Figs 1-3, 5-7

ZooBank: http://urn:lsid:zoobank.org:act: 9FB63o88-BF8A-499o-B292-7E26DEAoFDCF

Etymology. In honour of Baron Nils Adolf Erik Nordenskiöld, outstanding Arctic explorer, geologist, and mineralogist. The Laptev Sea had been originally named "Nordenskiöld Sea", after this Arctic explorer.

\section{Type locality. Laptev Sea.}

Type material. Holotype. ZMMU Op-665. Arctic region, Laptev Sea, sta. 10o, $69 \mathrm{~m}$ depth, collector Olga Zimina.

Description. Body relatively narrow, preserved holotype $19 \mathrm{~mm}$ length (fig. 5). Five to six main branched appendages on oral veil. Five appendages on rhinophoral stalks; 12-14 rhinophoral lamellae. Lateral papilla on rhinophoral sheath present. Five pairs of dorsolateral appendages. Circa 20 lip papillae. Dorsolateral appendages with relatively short primary stalk, moderately branched secondary branches and tertiary branches (fig. $5 \mathrm{~A}, \mathrm{~B})$. Basal colour is semitranslucent white. No additional pigment. Dorsal processes of jaws inclined posteriorly at approximately $53^{\circ}$ to the longitudinal axis of the jaw body and 0.42 of its length (fig. $5 \mathrm{D}$ ). Masticatory border of jaw with fine denticles (fig. $5 \mathrm{E}$ ). Radular formula: $43 \times 3^{-11.1 .11-3}$. Central (rachidian) tooth bears very weak denticulation that are difficult to separate into individual denticles (up to 20 and more variously varied denticles at least) (fig. 5 F, G). Denticles without deep furrows. Lateral teeth elongate, slightly curved, bearing up to seven denticles $(+2-3$ reduced denticles may present) (fig. $4 \mathrm{~F}-\mathrm{H}$ ). Ampulla thickened, kidney-shaped. Prostate discoidal, consisting of up to 20 alveolar glands. Distal part of vas deferens moderate in length, transitioning to long, thick, curved copulatory organ. Bursa copulatrix large, distinctly elongated, with seminal receptaculum placed distally.

Distribution. So far known only from the Laptev Sea. 

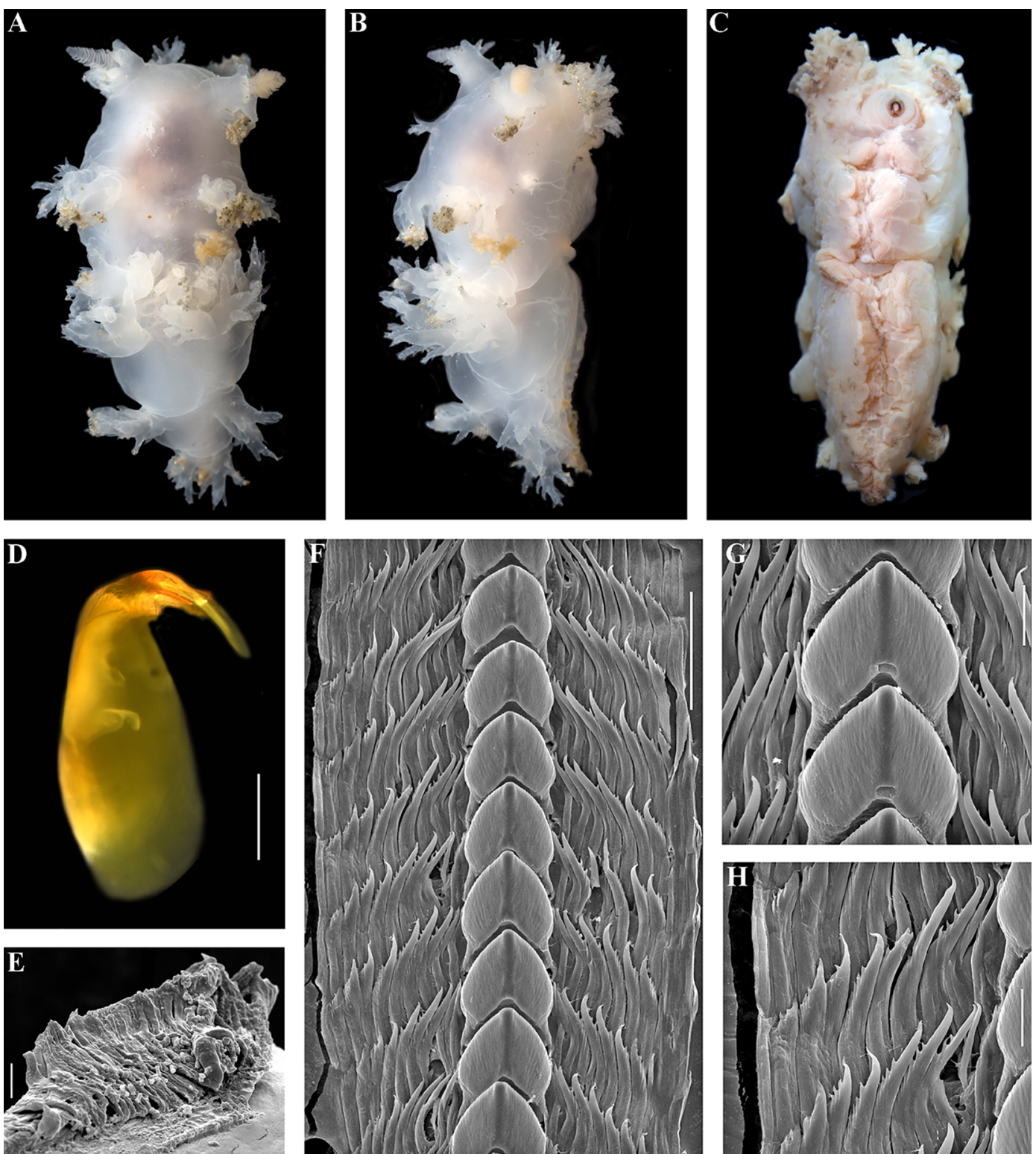

FIGURE 5 Dendronotus nordenskioeldi sp. nov. ZMMU Op-665, external and internal morphology. a-b: living holotype, dorsal and lateral views respectively; c: ventral view of preserved holotype; d: jaw of holotype; e: irregular denticles on the masticatory edge of the holotype; f: posterior part of radula; g: central teeth of radula; h: lateral teeth of radula of holotype. Scale bars: d: 1mm; e: $20 \mu \mathrm{m}$; f: $100 \mu \mathrm{m}$; g, h: $30 \mu \mathrm{m}$. PHOTOGRAPHS BY O. ZIMINA (A, B) AND T. KORSHUNOVA (C). SEM MICROGRAPHS BY A. MARTYNOV

Remarks. Externally, Dendronotus nordenskioeldi sp. nov. resembles white forms of $D$. lacteus but differs by the absence of a distinct reticulation and peculiar ribs on the central teeth, which is a common characteristic of $D$. lacteus (Korshunova et al., 2017a). According 


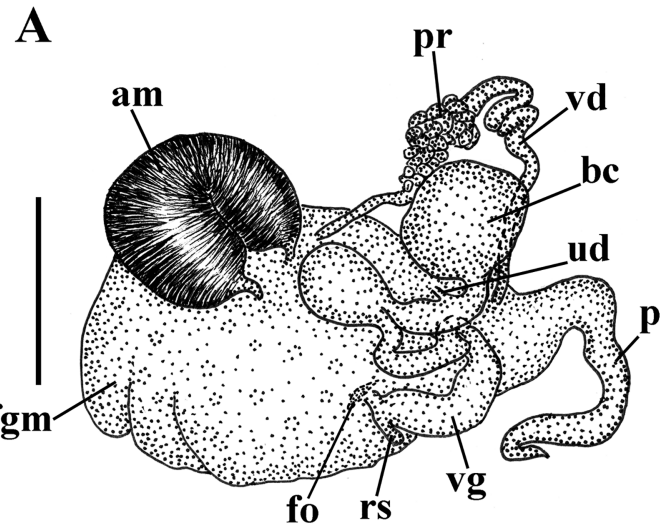

C

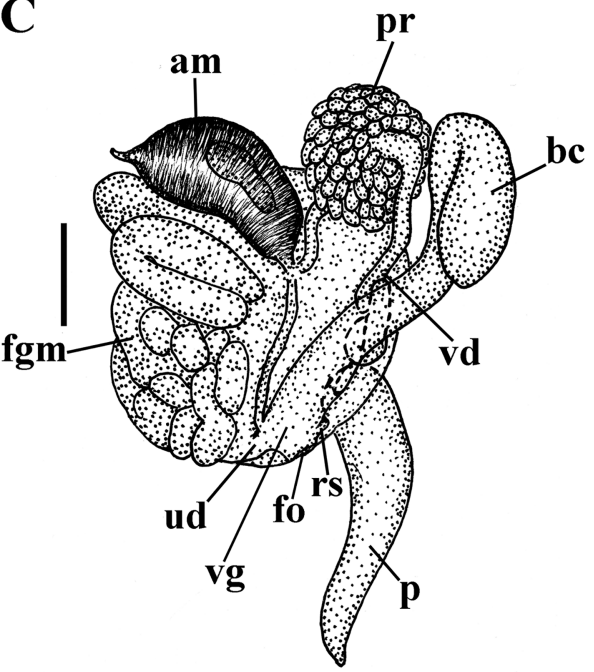

B

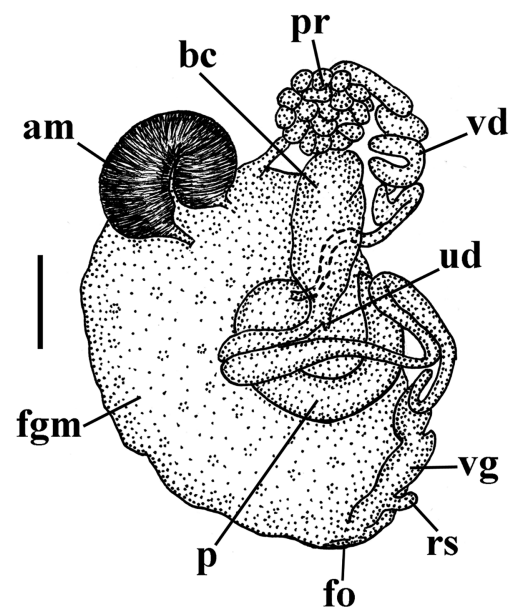

D

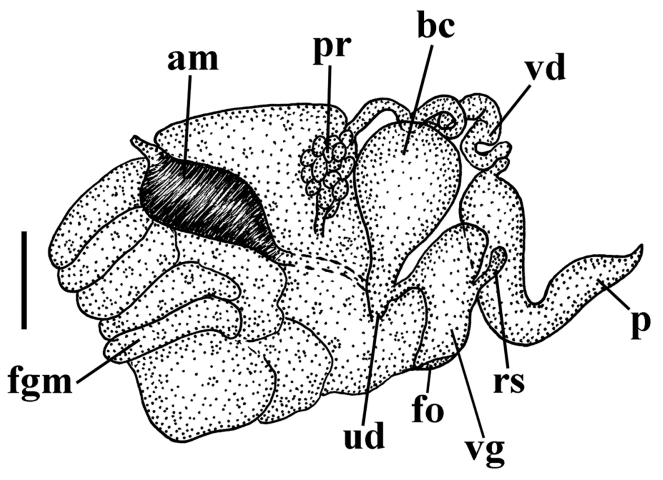

FIGURE 6 Reproductive systems. a, Dendronotus yrjargul sp. nov.; b, D. kalikal; c, D. elegans; d, D. nordenskioeldi sp. nov. Scale bars: a-d 1mm. Abbreviations: am, ampulla; bc, bursa copulatrix; fgm, female gland mass; fo, female opening; p, penis; pr, prostate; rs, receptaculum seminis; ud, uterine duct; vd, vas deferens; vg, vaginal duct.

to the molecular differences, a minimal intergroup distance for the cor gene $(7.9 \%)$ is found between $D$. nordenskioeldi sp. nov and $D$. europaeus. The mean intergroup distances between $D$. nordenskioeldi sp. nov. and $D$. rufus, D. lacteus, and D. kamchaticus are $8.3 \%, 8.3 \%$, and $8.8 \%$ respectively. A maximal intergroup distance $(15.0 \%)$ is found between D. nordenskioeldi sp. nov and D. patricki (Appendix, table A2).
Synopsis of the previously described valid taxa of the family Dendronotidae

Genus Dendronotus Alder \& Hancock, 1845 Type species. Dendronotus frondosus (Ascanius, 1774)

Diagnosis. Dorsolateral appendages with distinct tertiary branches. Oral veil with branched appendages. Jaws commonly with set of tightly 


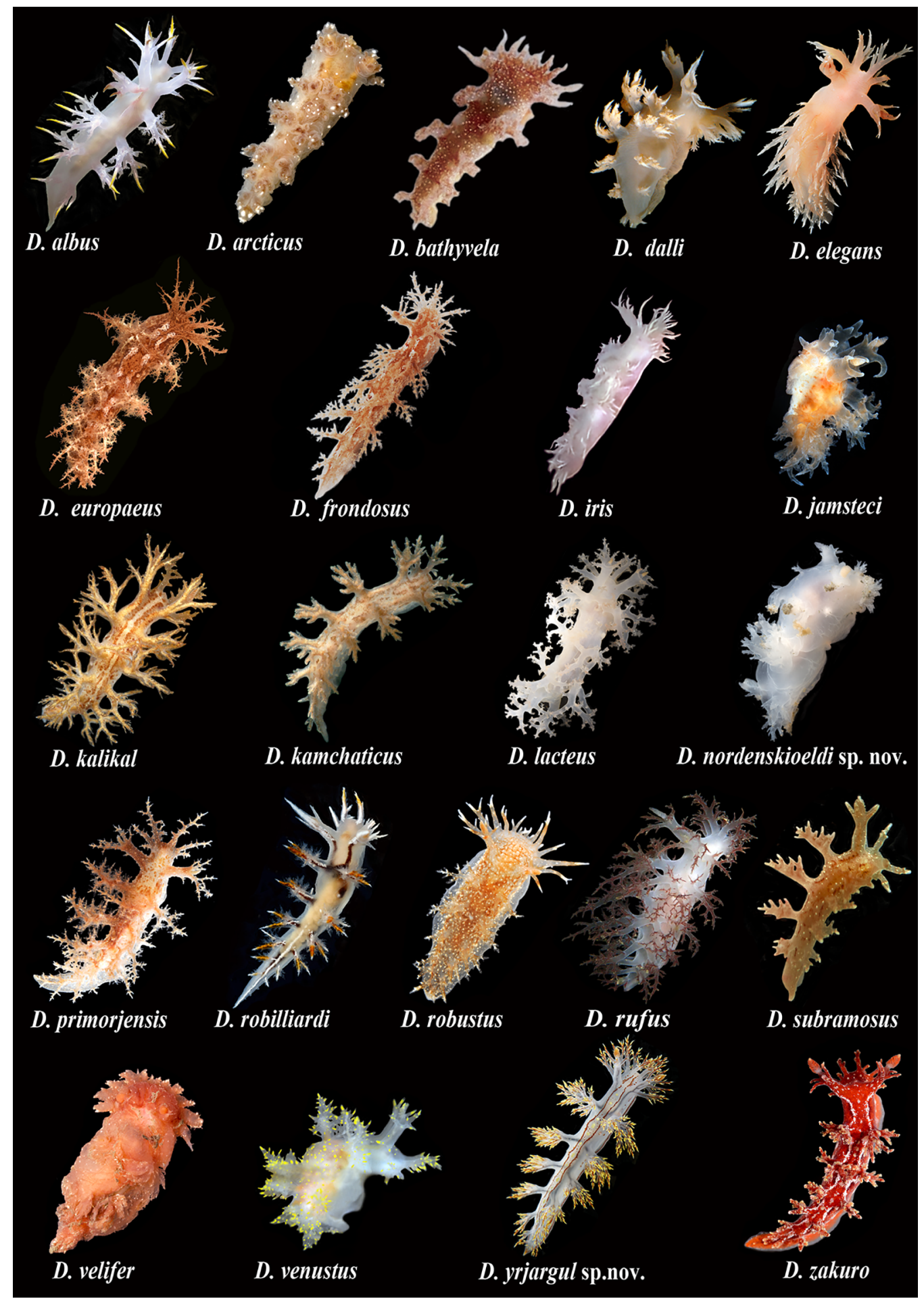

FIGURE 7 Representaives of the genus Dendronotus (living specimens). PHOTOGRAPHS BY T. KORSHUNOVA, A. MARTYNOV, K. FLETCHER, D. MILLER, Y. FUJIWARA, K. HASEGAWA, K. SANAMYAN, N. SANAMYAN, AND O. ZIMINA 
packed ridge-like semi-discoid structures and also with denticles. Radula with at least more than eight lateral teeth in adult specimens. Central teeth with cusp integrated within lateral denticles (or within teeth body if denticles absent), the central cusp is not protruding. Denticle-bear part of central teeth separated from lateral sides by usually distinct shoulder, thus central teeth with squarish base and triangular top. Prostate with evident, conspicous alveolar glands, commonly represent by a discoid structure (varies from a flattened disk to a compressed spherical structure), or very rarely non-discoid, linear (in this case alveolar glands also present). Copulative organ basically conical, with various ratios of length and width and degrees of apical tapering.

Natural history. Representaives of the genus Dendronotus inhabit a broad bathymetric range, from intertidal to depths over $3000 \mathrm{~m}$, and a variety of substrates (including stony and soft benthic environments). A majority of the Dendronotus species feed on hydroids (Robilliard, 1970; Thompson \& Brown, 1984; Martynov \& Korshunova, 2011). There as a few notable exceptions, such as $D$. iris Cooper, 1863 from the northeastern Pacific, which is an active predator of ceriantharian cnidarians (Wobber, 1970; Shaw, 1991), whereas for the wide-bodied species D. robustus Verrill, 1870, D. velifer G.O. Sars, 1878 and D. bathyvela Martynov et al., 2020a less specific prey spectrum (including polychaetes and hydroids) has been recorded (Roginskaya, 1990, 1997).

Remarks. The genus Dendronotus is restricted here since some species have been moved to other genera. See discussions and remarks under the genera Cabangus gen. nov. and Pseudobornella.

Species composition. Diagnoses and remarks for 27 included species are listed below. For each species, an extended diagnosis is provided when possible. The fine-scale diagnostics of the genus Dendronotus is a complex task since variation patterns of habitus and anatomical characters overlap in various species. By a careful listing it is possible to step-by-step fulfill the task and present a mutilelevel organismal diversity, though not in a strictly defined form, as was targeted previously (e.g., Odhner, 1936; Robilliard, 1970), but in a complex form that is best suited to the evolutionary mosaic in character evolution. There are also still uncertanties regarding some particular characters as well as previous overinterpretations. First of all, previously the pattern of branching in the dorsolateral appendages was claimed to be of considerable taxonomic importance (Ekimova et al., 2015: Fig. 8). In this respect, it is necessary to state, that while some trends exist in a few species, importance of these characters were considerably overestimated partly due to the use of preserved specimens in the analysis. This can be illustrated by the $D$. kamchaticus case, when according to Ekimova et al. (2015: Fig. 8D), D. kamchaticus has bulbous short branches that differ considerably from those in any other Dendronotus species. This resulted from the use of preserved specimens with considerably contracted branches, whereas the living adult specimens of $D$. kamchaticus have elongated branches of dorsolateral appendages, which are not fundamentally different from the type species of the genus, D. frondosus (Korshunova et al., 2016a). The description of $D$. zakuro (similar to $D$. kamchaticus by radula morphology) is based on recently collected specimens with both shorter "bulbous" (see Martynov et al., 2020a: Fig. 3A) and elongate dorsolateral appendages (Martynov et al., 202Oa: Fig. 3D, E), which is due to differences in physiological conditions. The preserved specimen of D. zakuro (see Martynov et al., 2020a: Fig. 3C) demonstrates very similar 
"bulbous" branches, which were incorrectly depicted as specific for D. kamchaticus in its original description (Ekimova et al., 2015: Fig. 8D) (see details in Synopsis under $D$. kamchaticus). Dendronotus lacteus apparently has shorter tertiary branches, and a "curly" appearance of the dorsolateral appendages. However, variation in D. lacteus does not only concern ontogenetic stages, but also occurs among different adult specimens. So, some large specimens of $D$. lacteus have quite long elongate branches of dorsolateral appendages, similar to those in $D$. frondosus (Korshunova et al., 2017a). Most species of the genus Dendronotus possess considerably branched dorsolateral appendages with distinct tertiary branches (MacFarland, 1966; Robilliard, 1970; Korshunova et al., 2016a, b, 2017a, 2019b; Martynov et al., 2020a). Unbranched dorsolateral appendages were recently reported only for $D$. claugei from the deep-sea (Valdes et al., 2018), but due to the most basal position of this species (fig. 1) the generic position of $D$. claugei needs to be evaluated with more data. For another deep-sea species, $D$. comtet $i$, the unbranched dorsolateral appendages were also indicated (Valdes et al., 2018: 413), however, according to the original description of $D$. comteti, it possesses both branched and unbranched dorsolateral appendages (Valdes \& Bouchet, 1998: 320). Unbranched dorsolateral appendages can occur in posterior parts of some other Dendronotus species (e.g., in D. robilliardi, see Korshunova et al., 2016a). For some species, e.g., for D. dalli in Ekimova et al. (2015: 862), the indication of absent tertiary branches of dorsolateral appendages is incorrect. Dendronotus dalli definitely has tertiary branches (Robilliard, 1970: 453; present study, fig. 7). Instead, in the genus Pseudobornella the general appearance of dorsolateral appendages does not show as branches, but it is ctenidiumlike, because of very indistinct (or truly absent) tertiary branches (fig. 2). More details about the genus Pseudobornella are mentioned after the diagnoses of the species of the genus Dendronotus.

There are also various uncertainties and misinterpretations regarding internal characters that need to be addressed before diagnoses can be provided. For example, Robilliard (1970) suggested to apply several coefficients of jaw proportions. However, it is easy to incorrectly apply respective angle of measurements and receive very different results, as for example in Ekimova et al. (2015) compared to the same species which jaws by Robilliard (1970). As an example, for D. dalli in Ekimova et al. (2015: 863) an angle of dorsal processes to the longitudinal axis of $25^{\circ}$ was indicated, whereas in Robilliard (1970: 454) this was $60^{\circ}$. In the present study we re-checked jaw proportions and presented updated values for the majority of species with sufficient available information. This character still needs further testing, but some characteristic patterns for different species are likely to occur. Similarly, the number of the prostatic alveoles once was thought to be a character that well characterizes different species (Robilliard, 1970; Ekimova et al., 2016). However, our previous (Korshunova et al. 2016a, b) and present study show that this character is much more variable, and while there are clear trends in some species, it should generally be used with care. In the species diagnoses below, differences in shape, length and proportions of the copulative organ (penis) are indicated. While in some species the differences in penial morphology are clear, in other species this can be partly due to different degrees of contraction after preservation. This character needs further investigation.

In the present study we show that the shape and size of the bursa copulatrix, at least among several Dendronotus species (e.g., between D. kalikal and D. yrjargul), are rather constant and can be used as a reliable diagnostic 
character. However, the exact position of the commonly very small receptaculum seminis can be very difficult to determine, but despite that, it will be given further attention in the diagnoses below.

Different terms were applied for the structures on the masticatory edge within different species of the genus Dendronotus. For example, MacFarland (1966) used "denticles" or "ridge-like" denticles and Robilliard (1970) applied "denticles", whereas Ekimova et al. (2015) used "rodlets". In this respect, the term "rodlets" was used for rod-like structures that constitute the body of jaws in other nudibranch groups. In the genus Dendronotus, the elements on the masticatory edges are usually termed as "denticles" when the bodies of jaws are entire. However, in the genus Dendronotus there is a special set of structures in addition to the denticles that appears as broad semidisks or ridges, which can additionally be covered with smaller spine- or denticle-like structures. It is likely that most species of the genus Dendronotus possess such structures. In addition to the semi-disks/ridges at the masticatory edges, more normally looking denticles can occur. Transitive denticles on masticatory edges were also occasionally reported for juveniles of D. frondosus s.l. (Colgan, 1914; Wägele \& Willan, 2000). Therefore, in the present study we use two different terms "ridge-like structures" and "denticles" when characterizing the masticatory edges of Dendronotus species. The few denticles seen in many cases are likely a precursor that further transits into semi-disk structures on the masicatory edges (see e.g., this clearly for D. kalikal, fig. 4Q). Because the full row of denticles and/or ridges is not documented for all species due to difficulties during preparation, the exact number for these structures can be uncertain. Though whenever possible, we already presented the number of denticles/ridges, for example the recently described Dendronotus species (e.g.,
Martynov et al., 2020a), in the diagnoses below we do not provide the number because it can be misleading, because only a part of the row was counted in various species. True rodlets can occur in addition, as part of the thin labial cuticle, which is separated from the masticatory edges. Such true rodlets have been well documented for the tropical representatives of the family Dendronotidae (Pola \& Stout, 2008), and possibly also occur in many Dendronotus species, since the labial cuticle with rodlets were already described for several representatives (see e.g., MacFarland, 1966). However, these characters remain largely untested by modern methods and we do not include it in the diagnoses below. As an additional complication, denticles and especially ridge-like structures on the masticatory edges can be easily discarded during preparation, and therefore in some previous descriptions it was inappropriately indicated that masticatory edges are devoid of any denticles or ridges. For example, the absence of the denticles on the masticatory edges of $D$. frondosus were incorrectly mentioned in Ekimova et al. (2015), which was further used as a putative difference between $D$. frondosus and D. primorjensis (Ekimova et al., 2016). However, in both species denticles on the masticatory edges are definitely present (Korshunova et al., 2016a). The same is true also for other species, such as D. kamchaticus and D. kalikal. For D. kamchaticus the absence of any structures on the mascticatory edges was indicated in the original description. For D. kalikal the presence of merely "rodlets" was reported in the original description (Ekimova et al., 2015). However in reality denticles and ridge-like structures are present in both of these species (Korshunova et al., 2016a, 2019b; for $D$. kalikal see fig. 4Q). Therefore, when the original descriptions denticles or ridge-like structures was not indicated for species that we could not check, we suppose the presence 
of at least one of these structures and indicate that in the diagnoses.

Though a pair of salivary glands indeed inserts into the pharynx on the sides of the oesophagus, the knowledge of these is limited only to a few species (e.g., MacFarland, 1966; Valdes \& Bouchet, 1998; Pola \& Stout, 2008). The salivary glands are usually not figured in the original descriptions (an exception: Valdes and Bouchet, 1998) and were never consistently used for taxonomic diagnostics. We therefore do not include salivary glands in the diagnoses of the species of the genus Dendronotus.

The radular patterns within the genus Dendronotus still offer one of the best diagnostic characters (Korshunova et al., 2017a). However in several species groups quite similar patterns of the central tooth can be observed. These similarities occur between groups/clades of closely related species (for example between species that closely related to $D$. frondosus, e.g., D. primorjensis and $D$. venustus, between $D$. lacteus and D. rufus, between $D$. dalli and $D$. elegans), but also among apparently more distantly related species such as D. kamchaticus and D. zakuro, and between D. albus and D. robilliardi (see fig. 1). Despite these similarities, in a majority of these cases fine-scale differences in morphology of radula can be detected. At the same time, different species which are grouped in the same subclade (fig. 1) can demonstrate considerably different radular patterns, as for example the clade consisting of D. jamsteci, D. subramosus and D. albus (Robilliard, 1970; Pola \& Stout, 2008; Korshunova et al., 2016a; Martynov et al., 2020a). Furthermore, the radulae of the morphologically very different $D$. robilliardi and D. gracilis demonstrate similar patterns in the presence of a widened central tooth with numerous small lateral denticles without furrows (Baba, 1949; Korshunova et al. 2016a, 2019b). The radula undergoes remarkable transformation during the development from early juvenile to adult. The central tooth in earlier juveniles is low and bears few distinct lateral denticles. The lateral teeth in early juveniles are very few in number (1-3) or absent, showing an indistinct denticulation or they are almost smooth. In individuals approaching the adults stage, the central teeth become elongate-triangular with distinct shoulders, lateral denticles become relatively smaller and numerous or completely reduced. Meanwhile, the lateral teeth increase in number and the denticles become more conspicuous. Since parts of juvenile radula may persist in some adults, this may create a considerable confusion regarding the taxonomic importance of radular characters. For instance, $D$. dalli usually has a smooth central teeth without denticles in adult stage, whereas for adults of $D$. dalli also denticles on central teeth were reported, which led to the incorrect synonymyzation of $D$. dalli with $D$. frondosus (Odhner, 1936; MacFarland, 1966). This decision was later changed in favour of the validity of $D$. dalli, but uncertanties over the taxonomic application of the putatively variable radula remained (Robilliard, 1970; Roginskaya, 1987). Such "variations" can be overcome by a consistent application of general ontogenetic principles in taxonomy, using the attribution of a particular set of characters to a particular ontogenetic stage (Martynov et al., 2015b, 202ob). Thus, the application of a multilevel diagnostic within the genus Dendronotus (one that combines morphological characters of various levels and molecular data) instead of a search for immediate and clearly distinctive differences, requires a fine-scale, complex approach.

Dendronotus albopunctatus Robilliard, 1972 Dendronotus albopunctatus Robilliard, 1972: 421-430, Figs 1-6; Behrens, 1980: 72; Behrens 
and Hermosillo, 2005: 93; Lamb and Hanby, 2005: 264.

Extended diagnosis. Body wide. Four to five (plus one-two posterior) pairs of dorsolateral appendages. Six to 12 appendages of oral veil. Three to seven appendages (equal in size) of rhinophoral stalks. Lateral papilla of rhinophoral sheaths absent. Rhinophores with 9-17 lamellae. No lip papillae reported in the first description. Basal colour yellowwhite, pale pink to red-brown, with red-brown spots and tiny opaque white spots scattered over whole body, solid white line along edge of foot and oral veil. Dorsal processes of jaws inclined posteriorly at approximately $5^{\circ}$ to the longitudinal axis of the jaw body. Masticatory processes bear distinct denticles which increase in size towards the distal end of the process. Radula with up to 41 rows of teeth. Central tooth with up to 25 denticles. Up to 14 lateral teeth with up to 12 denticles. Ampulla voluminous, folded. Bursa copulatrix large, oval. Seminal receptaculum very small and placed distally at a short distance from the vaginal opening. Prostate discoid with about 11-16 alveolar glands. The vas deferens is long, penis short, conical. Body length up to 6 o mm.

Distribution. NE Pacific, Washington and Oregon, USA.

Bathymetry. Depths of $18-40 \mathrm{~m}$ (soft substratum).

Remarks. Externally, D. albopunctatus is somewhat similar to other species that also inhabit soft substrata, such as $D$. robustus and D. velifer. However, its radular characters are more similar to those of the majority of Dendronotus species.

\section{Dendronotus albus MacFarland, 1966}

Fig. 7

Dendronotus albus MacFarland, 1966: 275279, Pl. 40, Fig. 1; Pl. 46, Figs 1-4; Pl. 47, Figs 8-11; Pl. 48, Figs 7, 8; Pl. 49, Fig, 5; Pl. 50, Fig. 4; Pl. 51, Figs 6, 7 .

Dendronotus diversicolor Robilliard, 1970: 470-474, Figs 4-6, 25-28, Pl. 64, Figs 35, 36.

Not D. albus sensu Robilliard, 1970: 466-470; Behrens, 1980: 72; Behrens and Hermosillo, 2005: 93; McDonald, 1983: 172; McDonald, 2009: $463=$ D. robilliardi Korshunova, Sanamyan, Zimina, Fletcher, Martynov, 2016.

Extended diagnosis. Body relatively narrow. Four to five pairs of branched dorsolateral appendages, digestive gland penetrates only two pairs of dorsolateral appendages. Up to six appendages of oral veil. Three to seven appendages (external longest) of rhinophoral stalks. Lateral papilla of rhinophoral sheaths present. Rhinophores with 12-21 lamellae. Two to eight lip papillae. Basal colour translucent white to violet, dorsolateral appendage variable opaque orange or opaque white, including tip. Dorsal processes of jaws inclined posteriorly at approximately $50-60^{\circ}$ to the longitudinal axis of the jaw body and $0.4-0.47$ of its length. Masticatory borders apparently with ridge-like structures and denticles. Radula with up to 38 rows of teeth. Central tooth with up to 25 small distinct denticles without furrows. Up to nine lateral teeth with up to 14 denticles. Ampulla voluminous, folded. Bursa copulatrix large, oval. Seminal receptaculum very small and placed distally at a short distance from the vaginal opening. Prostate discoid with about 10-30 alveolar glands. The vas deferens is relatively short, bent, penis short, nearly straight, tapering to a blunt tip. Body length up to $73 \mathrm{~mm}$. 
Distribution. NE Pacific: California to southern Alaska, Canada and US. Records from Baja California, Mexico, need verification.

Bathymetry. Intertidal to at least $30 \mathrm{~m}$ depth.

Remarks. Dendronotus albus has for almost 5 o years persistently been confused with $D$. robilliardi. Despite this, D. albus is readily distinguished from $D$. robilliardi by the number of dorsolateral appendages (four to five in D. albus vs. five to eight in D. robilliardi) and the number of dorsolateral appendages into which the digestive gland branches penetrate (only in two anterior pairs in $D$. albus vs. three to six pairs including posterior ones in $D$. robilliardi). See Korshunova et al. (2016a) for discussion.

\section{Dendronotus arcticus Korshunova,}

Sanamyan, Zimina, Fletcher \& Martynov, 2016

Fig. 7

Dendronotus arcticus Korshunova et al., 2016a: 26-28, Figs 1, 3A.

Extended diagnosis. Body relatively narrow. Five to six pairs of dorsolateral appendages. Six to eight appendages of oral veil. Five to six appendages (apparently equal in size) of rhinophoral stalks. Lateral papilla of rhinophoral sheaths present. Rhinophores with $15^{-18}$ lamellae. Lip papillae $15^{-25}$. Basal colour brownish with scattered distinct opaque white dots. Dorsal processes of jaws inclined posteriorly at approximately $55^{\circ}$ to the longitudinal axis of the jaw body and 0.47 of its length. Masticatory processes apparently bear indistinct denticles (may possess ridge-like structures). Radula with up to 39 rows of teeth. Central tooth with up to 14 small denticles and reduced furrows. Up to nine lateral teeth with up to nine denticles. Ampulla folded twice. Bursa copulatrix is large and rounded. Seminal receptaculum small placed distally at a moderately short distance from the vaginal opening. Prostate discoid with about $25-30$ alveolar glands. The vas deferens is moderate in length, penis long and twisted. Body length up to $19 \mathrm{~mm}$.

Distribution. Arctic - Kara Sea to Laptev Sea, Russia.

Bathymetry. 10-20 m depth, occasionally deeper.

Remarks. This recently described species is easily distinguished from its congenerics (Korshunova et al., 2016a). This is a true Arctic species that so far has been recorded only from the Laptev Sea and Kara Sea.

\section{Dendronotus bathyvela Martynov, Fujiwara, Tsuchida, R. Nakano, N. Sanamyan, K. Sanamyan, Fletcher \& Korshunova, 2020}

Fig. 7

Dendronotus bathyvela Martynov et al. 2020a: 507-510, Figs 4, 5 .

Extended diagnosis. Body wide. Six to seven pairs of branched dorsolateral appendages. 10 to 15 appendages of oral veil. Five appendages of rhinophoral stalks. Lateral papilla of rhinophoral sheaths absent. Rhinophores

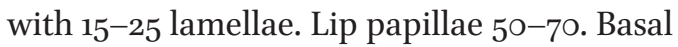
colour dull reddish-brownish with numerous distinct opaque white dots on notum, tips of lateral appendages, oral appendages. Dorsal processes of jaws inclined posteriorly at approximately $5^{\circ}$ to the longitudinal axis of the jaw body and 0.56 of its length. Masticatory processes apparently bear indistinct denticles (may possess ridge-like structures). Radula with up to 41 rows of teeth. Central tooth with high cusp and up to 35 small distinct denticles without furrows. Up to 14 lateral teeth without or with few weak 
lateral denticles. Ampulla voluminous, with approximately three loops. Bursa copulatrix large, rounded to oval. Seminal receptaculum small placed distally at a short distance from the vaginal opening. Prostate discoid with about 21-25 alveolar glands. The vas deferens is long, penis elongate, narrow, curved. Body length up to $45 \mathrm{~mm}$.

Distribution. Pacific coast of Northern Honshu, Japan, possibly may occur further in NW Pacific.

Bathymetry. A shelf to deep-sea (bathyal) species, so far recorded at depths of $249^{-510}$ m.

Remarks. This species has recently been described by Martynov et al. (2O2Oa). Until recently, only the single species $D$. robustus was recognized among the wide-bodied, shallow-water dendronotids of the North Atlantic and the North Pacific shelf (Ekimova et al., 2015). However, most recent data showed that " $D$. robustus" is a species complex, which was already separated into D. robustus s.str., D. velifer and D. bathyvela (Lundin et al., 2017; Martynov et al., 2020a).

\section{Dendronotus claguei Valdés, Lundsten \& Wilson, 2018}

Dendronotus claguei Valdés, Lundsten, Wilson, 2018: 412-415, Figs 3B, 9.

Diagnosis (original description). Body very narrow. Four to six pairs of dorsolateral appendages (reported as unbranched). Four appendages of oral veil. Four appendages of rhinophoral stalks (innermost appendages from each side longest). Lateral papilla of rhinophoral sheaths absent. Rhinophores with 11 lamellae. Lip papillae not reported in original description. Basal colour uniformly translucent white. Masticatory processes of jaws with irregular denticles and possibly with ridge-like structures. Radula with up to $3^{2}$ rows of teeth. Central tooth with deep furrows and with up to 13 distinct denticles. Up to eight lateral teeth with up to ten denticles. Ampulla with three loops. Prostate compact with about nine alveolar glands. Bursa copulatrix large, rounded. Seminal receptaculum large placed distally at considerable distance from the vaginal opening. The vas deferens is moderate in length, penis relatively long, narrow. Body length up to $18 \mathrm{~mm}$.

Distribution. Alarcón Rise, Gulf of California, Mexico, NE Pacific Ocean.

Bathymetry. $2369 \mathrm{~m}$ depth.

Remarks. For this recently described deep-sea species there is no additional morphological information and molecular data is very limited. In particular, the dorsolateral appendages need a further detailed study.

Dendronotus comteti Valdés \& Bouchet, 1998 Dendronotus comteti Valdés and Bouchet, 1998: 320-323, Figs 1-3.

Diagnosis (original description). Body narrow. Two or four pairs of partially branched, partially unbranhed dorsolateral appendages. Four to six appendages of oral veil. Four appendages (similar in size) of rhinophoral stalks. Rhinophores with seven to eight lamellae. Lateral rhinophoral papilla possibly absent. Lip papillae probably absent. Basal colour uniformly pale cream (preserved). Jaws reported as devoid denticles. Radula with up to 28 rows of teeth. Central tooth with deep furrows and with up to ten distinct denticles. Up to six lateral teeth with up to five denticles. The reproductive system was not studied in the original description. Body length up to $5.5 \mathrm{~mm}$ (preserved). 
Distribution. Middle Atlantic, Lucky Strike area in the Mid-Atlantic Ridge.

Bathymetry. $1685 \mathrm{~m}$ depth.

Remarks. This is the only known species that originated from deep-sea hydrothermal habitats, and which was considered as belonging to the genus Dendronotus according to its external and internal characters. Molecular data is necessary to determine its phylogenetic position.

\section{Dendronotus dalli Bergh, 1879}

\section{Fig. 7}

Dendronotus dalli Bergh, 1879: 94, Pl. 1, Fig. 21; Pl. 2, Figs 9-12; Pl. 3, Figs 2-6; Robilliard, 1970: 452-455, Figs 13-15; McDonald, 2009: 463 (bibliography); Martynov \& Korshunova, 2011: 155-157 (verified photographs of living specimens, description and biology in NW Pacific); Ekimova et al., 2015: 86o-863, Figs 6C, $8 \mathrm{G}, 11,12,13 \mathrm{~A}$.

Dendronotus frondosus var. dalli Bergh, 1879 - Odhner, 1907: 19.

Not D. dalli sensu Bergh, 1886, Knipowitsch, 1902, Roginskaya, 1987 (= D. elegans Verril, 1880).

Extended diagnosis. Body relatively narrow. Four to eight pairs of branched dorsolateral appendages. Four to five appendages of oral veil. Four to 12 appendages (equal in size or few posterior ones longer) of rhinophoral stalks. Lateral papilla of rhinophoral sheaths present. Rhinophores with 16-33 lamellae. Lip papillae $15^{-40}$ (and more). Basal colour uniform translucent gray, light yellow to orange, brownish or pinkish, with external opaque white pigment on tips of dorsolateral appendages. Dorsal processes of jaws inclined posteriorly at approximately $60^{\circ}$ to the longitudinal axis of the jaw body and 0.45 of its length. Masticatory processes apparently bear denticles (may possess ridge-like structures). Radula with up to $5^{1}$ rows of teeth. Central tooth completely smooth in adults. Up to 16 lateral teeth with up to 19 denticles. Ampulla relatively narrow with several (at least three) loops. Bursa copulatrix very large, oval. Seminal receptaculum small placed distally at a moderately short distance from the vaginal opening. Prostate discoid with up to 50 (and more) alveolar glands. The vas deferens is moderate in length, penis large, wide, with a blunt tip. Body length up to $14 \mathrm{~cm}$.

Distribution. North Pacific (The Sea of Japan in the west and at least Washington State, USA in the east to at least Chuckchii Sea; Russia, in the Arctic (may possibly penetrate further to the west in the Arctic).

Bathymetry. Verified records from 5 to $5^{\circ} \mathrm{m}$ depth.

Remarks. Until recently, the North Atlantic $D$. elegans (see below) has been confused with the North Pacific D. dalli. The best external feature to distinguish these two closely related species is the presence of an external opaque white pigment on the apical parts of the dorsolateral processes in $D$. dalli, whereas in D. elegans such a pigment, if present, is internal. These species may co-occur in some Arctic localities, but this needs to be further investigated. For D. dalli an absence of tertiary branches of the dorsolateral appendages was incorrectly mentioned by Ekimova et al. (2015). There is a possibility that light-coloured varieties of $D$. kamchaticus were depicted under $D$. dalli, judging from photographs in for example Behrens (1980) (see also Korshunova et al., 2016a). In some studies, Dendronotus dalli was incorrectly considered a synonym of D. frondosus (Odhner, 1936; MacFarland, 1966) due to an underestimation of the importance of ontogenetic radula data (central teeth are 
denticulated in juveniles and usually smooth in adults).

We have investigated a considerable number of specimens and sequences of D. elegans from the North Atlantic and neighbouring subarctic regions. There are no confirmed records of true $D$. dalli in the North Atlantic and neighbouring regions. The indication of D. dalli from the North Atlantic (Genbank COI AF24980o) in a table of the paper of Wollscheid-Lengeling et al. (2001) is due to a mix-up of localities, in this case with the North Pacific. The same can be said about Cadlina luteomarginata from the North Atlantic in the same paper (Wollscheid-Lengeling et al., 2001) for which Johnson (2010: 142) explained that they originated from the North Pacific.

\section{Dendronotus elegans Verrill, 1880}

Figs 7, 8

Dendronotus elegans Verrill, 1880: 385-386.

Dendronotus "elongatus": Roginskaya, 1987: 175 (lapsus calami for D. elegans Verrill, 1880).

Dendronotus niveus Ekimova, Korshunova, Shepetov, Neretina, Sanamyan \& Martynov, 2015: 864-869, Figs 6D, 8F, 13B, 14, 15 syn. nov.; Valdés et al., 2017: 6-7, 4B, 5B.

Dendronotus dalli sensu Bergh, 1886 (non Bergh, 1879); Robilliard, 1970: 452; Bleakney, 1996: 109 (D. elegans incorrectly mentioned as synonym of $D$. dalli).

Extended diagnosis. Body relatively narrow. Five to ten pairs of branched dorsolateral appendages. Six to nine appendages of oral veil. Four to five appendages (equal in size or few posterior ones longer) of rhinophoral stalks. Lateral papilla of rhinophoral sheaths present. Rhinophores with 8-23 lamellae. Lip papillae ${ }^{8}-5$ o. Basal colour uniform, pinkish to light orange, with internal opaque white pigment of tips of dorsolateral appendages. Dorsal processes of jaws inclined posteriorly at approximately $40^{\circ}$ to the longitudinal axis of the jaw body and 0.43 of its length. Masticatory processes apparently bear denticles (which may possess ridge-like structures). Radula with up to 42 rows of teeth. Central tooth completely smooth in adults. Up to at least 13 lateral teeth with up to eight denticles (can be more). Bursa copulatrix large, oval. Seminal receptaculum small placed distally at a moderately short distance from the vaginal opening. Prostate discoid with up to 60 and more alveolar glands (their number was considerably underestimated in the original description of its new synonym $D$. niveus (see remarks below). The vas deferens is moderate in length, penis strong, conical. Body length up to $70 \mathrm{~mm}$.

Distribution. North Atlantic (known southern limit - Cape Cod, USA) to the Arctic (including Barents Sea and White Sea, known northeastern limit is the Laptev Sea, Russia).

Bathymetry. 10-25 m (White Sea) to $258 \mathrm{~m}$ depth (western North Atlantic).

Remarks. Ekimova et al. (2015) overlooked important details in the original description of D. elegans Verrill, 1880, for which a big animal with uniform salmon-coloured body was used, and a special mentioning was made of the completely smooth central teeth (Verrill, 1880: $385-386$ ). These characters are identical to those of the recently described D. niveus Ekimova et al., 2015. The available molecular data (Valdés et al., 2017; present study, figs 1-3) also show that specimens identified as $D$. niveus from off the east coast of North America (relatively close to the type locality of $D$. elegans) are identical to specimens from the type locality of $D$. niveus in the White Sea. The holotype of $D$. elegans in the Smithsonian Institution (NMNH, 202O) is not suitable for molecular study. However, a microslide with radula of the holotype is 

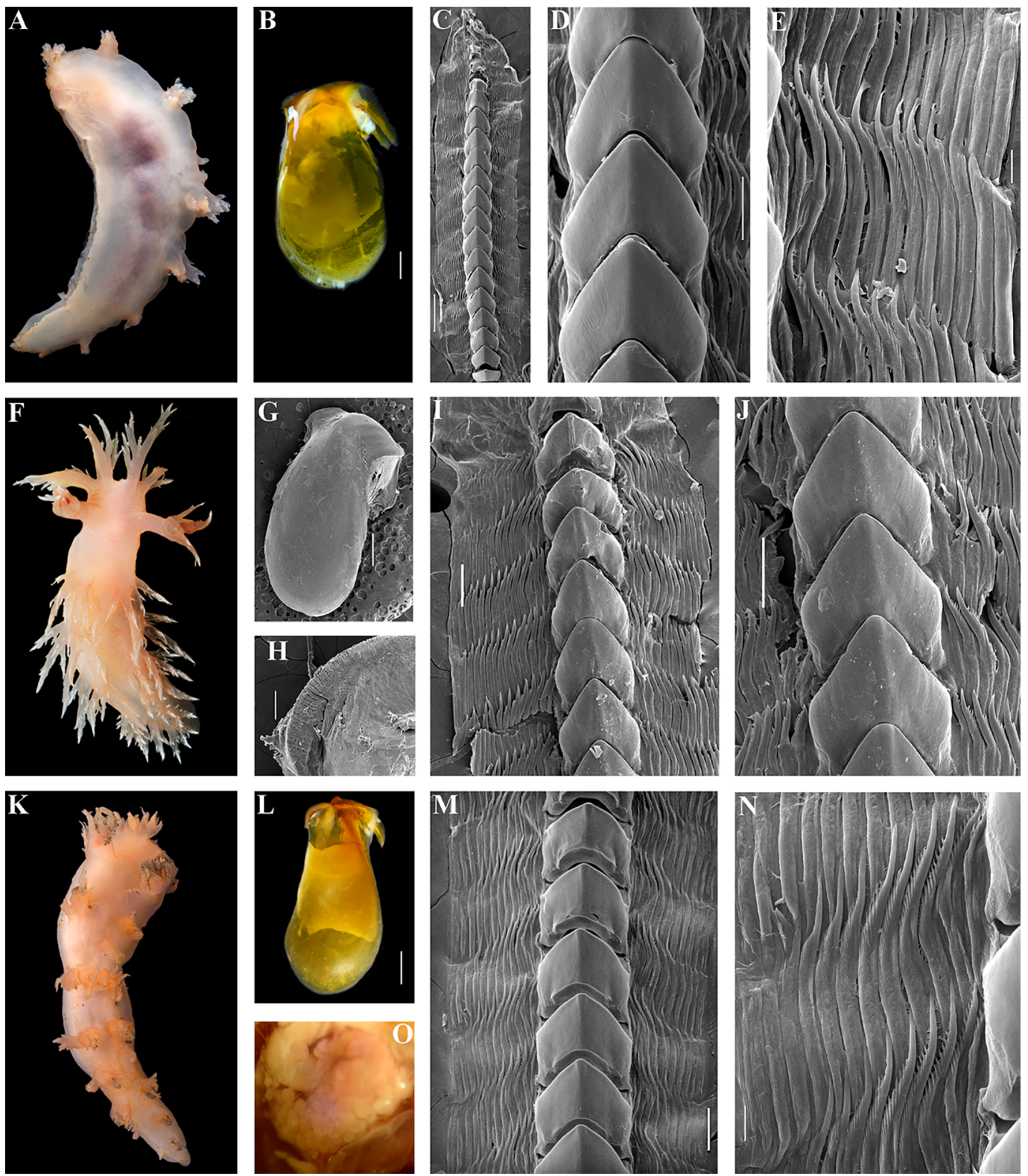

FIGURE 8 Dendronotus elegans. External and internal morphology. a: living specimen ZMMU Op-713 from

Greenland, near East Atlantic North American coast; b: jaw, same specimen; c; posterior part of radula, general overview, same specimen; d: close up of smooth central teeth, same; e: close up of lateral teeth, same; f: living specimen ZMMU Op-714 (as "D. niveus") from the White Sea (subarctic); g: jaw, same specimen; h: masticatory edge of the jaws, same; i: posterior part of radula, general overview, same specimen; j: close up of smooth central teeth, same; k: living specimen ZMMU Op-715 from the Laptev Sea (Arctic); l: jaw, same specimen; m: posterior part of radula, close up of smooth central teeth, same; n: lateral teeth, same. o: discoid prostate with numerous alveols (which considerably exceed the considerably underestimated number presented in the first description of D. niveus), same specimen; Scale bars: b, l, 1mm; c: $300 \mu \mathrm{m}$; d, h-j, m: $100 \mu \mathrm{m}$; g: $1000 \mu \mathrm{m} ; \mathrm{e}, \mathrm{n}: 30 \mu \mathrm{m}$. PHOTOGRAPHS BY O. ZIMINA (A, K) AND T. KORSHUNOVA (F). SEM MICROGRAPHS BY A. MARTYNOV 
kept separately in the Yale Peabody Museum of Natural History (YPM IZ o10761.GP) and available as online images (Yale Peabody Museum, 202O), which confirm the presence of massive smooth central teeth. The date (6 September 1879$)$, the depth $(26$ fathoms $=48$ meters) and locations (Stellwagen Bank, off Cape Cod) for collecting data of the holotype of D. elegans exactly match radula YPM IZ o10761.GP, the preserved body USNM 842116 and the original description of D. elegans in Verrill (1880). Additional morphological information of the molecularly investigated specimens of $D$. elegans of the present study is given in fig. 8. It is evident that specimens from the Atlantic North American coast and from the Arctic Eurasian regions are morphologically similar according to their external and internal features. We therefore synonymize Dendronotus niveus Ekimova et al., 2015 with D. elegans Verrill, 1880. Another species with smooth central teeth at the adult stage is $D$. dalli Bergh, 1879 (see above, figs 1,2), but this one is found predominantly in the North Pacific and differs from $D$. elegans in habitus morphology (apical parts of dorsolateral appendages with external opaque white pigment vs. with internal or absent white pigment in D. elegans) and molecular data.

\section{Dendronotus europaeus Korshunova,}

Martynov, Bakken \& Picton, 2017

Fig. 7

Dendronotus europaeus Korshunova, Martynov, Bakken, Picton, 2017: 1-8, Figs. 1-2; Supplementary information, text and figure.

Dendronotus frondosus sensu Thompson and Brown, 1984 (partim.); not Ascanius, 1774.

Extended diagnosis. Body relatively narrow. Six to nine pairs of branched dorsolateral appendages, including two to three posterior ones. The dorsolateral appendages can generally be described as highly branched, giving this species a fluffy appearance. Eight to 15 appendages of oral veil. Five to six appendages (posterior one very long) of rhinophoral stalks. Lateral papilla of rhinophoral sheaths present. Rhinophores with 11-17 lamellae. Lip papillae 20-49. Basal colour reddish-brown with opaque white stripes between dorsolateral processes to uniform light yellow with small brown spots. Dorsal processes of jaws inclined posteriorly at approximately $60^{\circ}$ to the longitudinal axis of the jaw body and 0.43 of its length. Masticatory processes apparently with fine denticles. Radula with up to 37 rows of teeth. Central tooth with up to 20 small denticles without furrows, rarely completely smooth. Up to 11 (usually 9-10) lateral teeth with up to seven denticles. Ampulla with at least two loops. Bursa copulatrix large, rounded. Seminal receptaculum small placed distally at a short distance from the vaginal opening. Prostate discoid with a range of $35^{-40}$ alveolar glands. The vas deferens is very long, penis relatively narrow, bent. Body length up to $100 \mathrm{~mm}$.

Distribution. NE Atlantic, so far known from the Netherlands, Norway, Sweden and the UK.

Bathymetry. $15^{-15}$ o m depth.

Remarks. This species has been separated from from $D$. frondosus and $D$. lacteus based on both morphological and molecular evidence (Korshunova et al., 2017b).

\section{Dendronotus frondosus (Ascanius, 1774)}

Fig. 7

Amphitrite frondosa Ascanius, 1774: 155-158, Pl. 5, Fig. 2 (neotype selected in Ekimova et al. 2015).

Dendronotus frondosus (Ascanius, 1774) Odhner, 1936: 1105-1109, Fig. 39 (mixture of several species); Robilliard, 1970: 441-446, Pl. 63, Fig. 29, text and Figs 4, 7, 8, 9 (partim, 
mostly referred to $D$. venustus); Ekimova et al. 2015: 848-857, Figs 1-5, 6A, 7A, 8A.

Doris arborescens Müller, 1776: 229 (mixture of several species).

Doris cervina Gmelin, 1791: 3105, no. 12.

Tritonia reynoldsii Couthouy, 1838: 74-80, Pl. 2, Figs 1, 2, 3, 4.

Tritonia felina Alder \& Hancock, 1842: 33.

Tritonia pulchella Alder \& Hancock, 1842: $33-34$.

Tritonia ascanii Møller, 1842: 5 .

Amphitridea fabricii Kröyer, 1847: 114.

Campaspe pusilla Bergh, 1863: 471-478, Pl.

12, Figs 28-35.

Campaspe major Bergh, 1886: 21-24; Pl. 1, Figs. 23-26; Pl. 2, Figs 1-11.

Dendronotus luteolus Lafont, 1871: 267.

Dendronotus junior Mörch, 1875: 125.

Dendronotus arborescens var. aurantiaca Friele, 1879: 284 .

NB: Mixture of several species under the name Dendronotus frondosus in the literature before 2015 .

Extended diagnosis. Body narrow. Five to six pairs of branched dorsolateral appendages. Four to seven appendages of oral veil. Four to five appendages (middle and posterior ones can be longer) of rhinophoral stalks. Lateral papilla of rhinophoral sheaths present. Rhinophores with six to 12 lamellae. Lip papillae four to 12. Basal colour brownish to reddish-brown, often with small white and yellow specks, but usually without opaque white stripes between dorsolateral processes to completely white translucent specimens. Dorsal processes of jaws inclined posteriorly at approximately $60^{\circ}$ to the longitudinal axis of the jaw body and 0.4 of its length. Masticatory processes apparently bear ridgelike structures and denticles. Radula with up to 42 rows of teeth. Central tooth with deep furrows and with up to 14 (common range 8-12) distinct denticles. Up to 10 (usually up to eight) lateral teeth with up to seven denticles. Ampulla voluminous, folded. Bursa copulatrix large, oval to rounded. Seminal receptaculum small placed distally at a moderately short distance from the vaginal opening. Prostate discoid with range $16-30$ alveolar glands. The vas deferens is moderate in length, penis relatively long, curved. Common body length no more than $50 \mathrm{~mm}$.

Distribution. North Atlantic, both east and west parts, not distributed to the Arctic further than the easternmost border of the Barents Sea.

Bathymetry. Intertidal to 20-30 m depth.

Remarks. Three common North Atlantic shallow water species, namely $D$. europaeus Korshunova et al., 2017b, D. frondosus (Ascanius, 1774), and D. lacteus, show an extremely similar range of habitus variation (see Korshunova et al., 2017b) and have been confused in older literature. Therefore, the verified distribution of $D$. frondosus can only be assessed using recent data (Korshunova et al., 2017b) that covers at least the North East Atlantic from Norway and also the Barents Sea and the White Sea to possibly France/ northern Spain. The range of $D$. frondosus does not extend further than the the true Arctic. Also, several deep-water records of D. frondosus (e.g., Odhner, 1939; Swennen, 1961; Thompson \& Brown, 1984) most likely refer to $D$. lacteus, since according to our data D. frondosus was usually found shallower than 20-30 m depth. We have examined an extensive collection of various Dendronotus from the NW Pacific and NE Pacific and have so far not found any specimen from the North Pacific for which the identity could be confirmed as $D$. frondosus despite the presence of a few published records (e.g., Ekimova et al., 2016). In this respect, the 
common occurrence of true $D$. frondosus in the North Atlantic and the extreme rarity of D. frondosus in the North Pacific, with the simultaneous common presence in the North Pacific of other species formerly considered as "D. frondosus", (e.g., D. kalikal, D. kamchaticus, D. primorjensis, D. venustus), clearly suggests that true $D$. frondosus does not occur naturally in the North Pacific. Here, it is largely substituted by other species from the $D$. frondosus species complex. In particularly, $D$. primorjensis endemic to the Sea of Japan, is morphologically similar to $D$. frondosus and sister to it according to our molecular phylogenetic analysis (fig. 1). $D$. primorjensis has several traceable diagnostic features in radula and reproductive system (see Korshunova 2016a and Synopsis below). By such features and molecular data $D$. primorjensis could be excellent candidate for an example of a relict species, with close relatives with ranges extending to the Arctic, which afterwards formed a separate species, D. frondosus, in the North Atlantic. As a result of such an evolutionary history, $D$. primorjensis and $D$. frondosus are evidently naturally separated from from closely related North Pacific and North Atlantic species, because true $D$. frondosus does not occur in the Arctic. On the contrary, the potentially disrupted populations of $D$. frondosus in the North Atlantic and the North Pacific do not reveal morphological and molecular differences. Most reliable explanations for such an occurrence of few of so far known specimens of $D$. frondosus in the North Pacific can be an anthropogenic introduction or a mistake in the sorting or processing of collection material. Dendronotus frondosus does not occur naturally in the North Pacific.

In this study we also evidently show that the North Pacific D. kalikal and the North Atlantic and Arctic D. yrjargul sp. nov. are invariably placed in two distinct clades (figs
1-3) with stable distinct differences in external and internal morphology (fig. 4) and without any gene flow between each other. Dendronotus kalikal thus does not occur naturally in the North Atlantic. A potential future introduction of some North Pacific species from the " $D$. frondosus megacomplex" may take place, but so far there are no reliable records of any North Pacific species in the North Atlantic. At least recently, a case of evident anthropogenic transportation of the dendronotid Pseudobornella orientalis was reported from Japan or China to NE Pacific (Agarwal et al., 2017) (for taxonomy of Pseudobornella see below). Thus, most previous records of this species from the Northwest Pacific refer to one of three recently described species, D. kamchaticus Ekimova et al., 2015, D. kalikal Ekimova et al., 2015, or D. primorjensis Martynov et al., 2015, and in the Northeast Pacific, previous records refer to $D$. venustus Stout et al., 2010 or D. kamchaticus Ekimova et al., 2015 (see also Korshunova et al., 2016a, b).

\section{Dendronotus gracilis Baba, 1949}

Dendronotus gracilis Baba, 1949: 167, Pl. 35, Fig. 127, text-fig. 109; Robilliard, 1970: 461-462; Nakano, 2018: 385 .

Diagnosis (original description). Body narrow. Four pairs of branched dorsolateral appendages. Four veil appendages. Five to six processeses of the rhinophoral stalks. Rhinophores with 18 lamellae. Basal colour bluish-white, with numerous scattered yellow spots, various processes opaque white. Masticatory processes of jaws with denticles. Radula with up to 41 rows of teeth. Central tooth with up to 20 small denticles without furrows, rarely completely smooth. Up to eight lateral teeth with up to nine denticles. Reproductive system unknown. Body length $25 \mathrm{~mm}$ (living, original description). 
Distribution. Japan, Pacific side of Honshu, Japan.

Bathymetry.16o m depth (original description).

Remarks. This species is insufficiently known. Information on the internal morphology of specimens from the type locality is restricted to the original description (Baba, 1949). Additional data in Pola and Stout (2008) referring to $D$. gracilis specimens are from considerably remote locations off the tropical island of Okinawa, whereas the type locality of D. gracilis is in the temperate Sagami Bay. Their study lacks molecular data and may represent a separate species. The Okinawan specimen indicated in Pola and Stout (2008) has eight pairs of dorsolateral processes, six processess of the oral veil, and 12 rhinophoral lamellae, whereas according to the original description in Baba (1949) there are four pairs of dorsolateral processes, four processesses of the oral veil, and 18 rhinophoral lamellae, respectively. Taking into consideration that details of colour patterms between the original description of $D$. gracilis and Okinawan specimens are also different as indicated by Pola and Stout (2008: 65), we cannot confirm the conspecificity of the Okinawan specimens with the original $D$. gracilis, even if we consider the potentially cooler waters in Okinawa at 69 $m$ depth and that only a few specimens were involved in the comparison. Furthermore, Pola and Stout (2008) considered specimens from New Zealand as belonging to D. gracilis as well, which also show differences in colouration. However, in the light of a modern emerging paradigm of multilevel organismal diversity that challenges the previously concept of widely claimed polytypic species with broad ranges in favour of considerably smaller, often geographically restricted species, a potential presence of true $D$. gracilis in New Zealand can only be the result of an anthropogenic transportation, which is hard to explain in this case and needs verification.

\section{Dendronotus iris Cooper, 1863}

Fig. 7

Dendronotus iris Cooper, 1863: 59; MacFarland, 1966: 257-265, Pl. 47, Figs 1218; Plate 48, Figs 1-6; Pl. 49, Fig. 4; Pl. 50, Fig. 1; Pl. 51, Figs 1-5; Robilliard, 1970: 446-450, Figs 4-6, 10-12, Pl. 63, Fig. 30; Behrens, 198o: 74; Behrens \& Hermosillo, 2005: 94.

Dendronotus giganteus O'Donoghue, 1921: 187-19o; Pl. 4, Fig. 47; Pl. 5, Figs 57-59.

Extended diagnosis. Body relatively narrow. Four to eight pairs of branched dorsolateral appendages. Two to four oral veil appendages. Two to five appendages (longest internal) of rhinophoral stalks. Lateral papilla of rhinophoral sheaths present. Rhinophores with 15-31 lamellae. 20-40 lip papillae. Basal colour grayish to reddish-orange, with white line bordered foot edge. Dorsal processes of jaws inclined posteriorly at approximately $40^{\circ}$ to the longitudinal axis of the jaw body and 0.35 of its length. Masticatory processes bear denticles (possibly including ridge-like structures and denticles). Radula with up to 61 rows of teeth. Central tooth quite narrow, with deep furrows and with up to 18 distinct denticles. Up to 21 lateral teeth commonly smooth, occasionally with up to eight denticles. Ampulla relatively narrow with numerous loops. Bursa copulatrix moderate in size, oval, bent. Seminal receptaculum small, placed distally at a moderately short distance from the vaginal opening. Prostate very long, non-discoid, linear, with numerous alveolar glands. The vas deferens is short, penis moderately short, straight, with blunt tip. Body length of live specimens may reach more than $20 \mathrm{~cm}$. 
Distribution. NE Pacific, from southern Alaska to California (but records from Baja California need to be confirmed). As an adult it feeds on cerianthid anthozoans (Wobber, 1970; Shaw, 1991), quite different to other Dendronotus species.

Bathymetry. 10-30 m depth.

Remarks. This species is clearly distinguished by a combination of external characters (uniform grayish to reddish-orange colour, massive dorsal appendages) and internal characters (linear instead of discoid prostate - unique for the genus), and also by adult behavioral patterns (special "rearing attack" feeding on species of Ceriantharia, e.g., Shaw, 1991). Dendronotus nanus Marcus et Marcus, 1967 was considered a synonym of D. iris (Stout et al., 2010), but in the absence of molecular data and presence of morphological differences (see below) we prefer to retain $D$. nanus as a separate species (see details below). Dendronotus iris possibly is the largest species of its genus.

\section{Dendronotus jamsteci Martynov, Fujiwara,} Tsuchida, R. Nakano, N. Sanamyan,

\section{K. Sanamyan, Fletcher \& Korshunova, 2020}

Fig. 7

Dendronotus jamsteci Martynov, Fujiwara, Tsuchida, Nakano, Sanamyan, Sanamyan, Fletcher, Korshunova, 2020a: 500-505, Figs 2, 5 A.

Extended diagnosis. Body narrow. Six to seven pairs of branched dorsolateral appendages. Six to nine appendages of oral veil. Four to five appendages (posterior ones longest) of rhinophoral stalks. Lateral papilla of rhinophoral sheaths present. Rhinophores with 12-15 lamellae, 20-25 lip papillae. Basal colour whitish with brownish spots and streak. Dorsal processes of jaws inclined posteriorly at approximately $5^{6^{\circ}}$ to the longitudinal axis of the jaw body and 0.47 of its length. Masticatory processess with ridge-like structures. Radula with up to 38 rows of teeth. Central tooth with up to 17 small, distinct denticles with furrows. Up to eight lateral teeth with up to nine denticles. Ampulla moderately narrow, with several loops. Bursa copulatrix large, oval. Seminal receptaculum small, placed distally at a moderately short distance from the vaginal opening. Prostate discoid with $5^{\mathrm{O}-60}$ alveolar glands. The vas deferens is moderate in length, penis conical, relatively thin. Body length up to $21.5 \mathrm{~mm}$.

Distribution. Pacific coast of Northern Honshu, Japan.

Bathymetry. A deep-sea (bathyal) species, so far recorded at $670-761 \mathrm{~m}$ depth (for discussion of the different usage of the term "bathyal", see Rybakova et al., 2020).

Remarks. This species is recently described in detail (Martynov et al., 2O2Oa).

\section{Dendronotus kalikal Ekimova, Korshunova, Shepetov, Neretina, Sanamyan \& Martynov, 2015}

Fig. 7

Dendronotus kalikal Ekimova, Korshunova, Shepetov, Neretina, Sanamyan \& Martynov, 2015: 872-874, 6F, 8E, 16C, 18B, 19; Korshunova et al., 2019b: 8-9, Figs 1, 3M-Q.

Extended diagnosis. Body narrow. Four to five pairs of branched dorsolateral appendages (plus 2-3 posterior smaller processes). Four to five oral veil appendages. Five appendages (apparently similar in size) of rhinophoral stalks. Lateral papilla of rhinophoral sheaths present. Rhinophores with 8-14 lamellae. Four to six lip papillae. Basal colour brownish, with creamy to whitish areas, dorsum, dorsolateral 
appendages, and upper sides of foot bear brownish orange lines and dots, partly arranged in blurred subparallel pattern. Dorsal processes of jaws inclined posteriorly at approximately $35-40^{\circ}$ to the longitudinal axis of the jaw body and 0.45 of its length. Masticatory processes bear denticles (possibly including ridge-like structures). Radula with up to 31 rows of teeth. Central tooth with deep furrows and with up to 18 distinct denticles. Up to eight lateral teeth with up to eight denticles. Ampulla moderately voluminous, folded. Bursa copulatrix large, considerably elongate, narrowly-oval. Seminal receptaculum small placed distally at a short distance from the vaginal opening. Prostate discoid with circa 20 alveolar glands. The vas deferens is moderate in length, penis relatively long, slightly curved. Body length up to $15 \mathrm{~mm}$ (preserved).

Distribution. NW Pacific from Kamchatka to northern Kurile Island and Bering Strait, Russia.

Bathymetry. 14-6o m depth.

Remarks. Although this species was previously confused with $D$. frondosus, D. kalikal is very distinct from it by morphological features (mottled body, brownish colouration with indistinct but commonly present dorsal blurred subparallel stripes), radular patterns and molecular phylogenetic data. In the present study we provide evidence that in the North Atlantic to the Kara Sea there is a sister species, $D$. yrjargul sp. nov., separate from $D$. kalikal, see above.

\section{Dendronotus kamchaticus Ekimova,}

Korshunova, Shepetov, Neretina, Sanamyan \& Martynov, 2015

Fig. 7

Dendronotus kamchaticus Ekimova, Korshunova, Shepetov, Neretina, Sanamyan
\& Martynov, 2015: 869-872, Figs 6E, 8D, 16A, B, 17, 18A; Korshunova et al., 2016a: 32-36, Figs ${ }_{4} \mathrm{C}, \mathrm{D}, 5$.

Extended diagnosis. Body narrow. Five to six pairs of branched dorsolateral appendages. Four to six oral veil appendages. Five to six appendages (apparently similar in size or posterior longer) of rhinophoral stalks. Lateral papilla of rhinophoral sheaths present. Rhinophores with $5^{-11}$ lamellae. Lip papillae 4-15. Basal colour semitransparent to brownish with irregularly scattered small brownish dots. Dorsal processes of jaws inclined posteriorly at approximately $70^{\circ}$ to the longitudinal axis of the jaw body and 0.37 of its length. Masticatory processes possibly bear denticles and ridge-like structures. Radula with up to 44 rows of teeth. Central tooth with almost completely reduced denticles and furrows at adult stages, subadults may bear small denticles. Up to eleven lateral teeth with up to nine denticles. Ampulla moderately voluminous with several (at least two or three) folded loops. Bursa copulatrix large, rounded. Seminal receptaculum small, placed distally at a moderately short distance from the vaginal opening. Prostate discoid with circa 7-25 alveolar glands. The vas deferens is moderate in length, penis relatively long, slightly curved. Body length up to $30 \mathrm{~mm}$.

Distribution. NW Pacific from Kamchatka to Japan Sea, Russia, and NE Pacific in Salish Sea, Canada and USA.

Bathymetry. 7-17 m depth.

Remarks. Though this species previously was confused with $D$. frondosus, $D$. albus and $D$. venustus, D. kamchaticus is well delineated from those species according to the morphological features (semitransparent grayish with white-tipped dorsolateral 
appendages and digestive gland often penetrating all branches of all dorsolateral appendages to body brownish colouration without dorsal subparallel stripes), radular patterns (usually almost smooth central teeth in adults) and molecular phylogenetic data (figs 1,2). In the original description branches of the dorsolateral appendages were incorrectly described as bulbous and short (see Ekimova et al., 2015: Fig. 8D), despite the presence of this species in the same paper (Ekimova et al., 2015: Fig. 16A, B) represented by photos of live paratypes with more elongated, not exactly bulbous, though still shortened branches. Further, in a specimen of D. kamchaticus from the Sea of Japan the branches were described as elongated and also very different from the original description and Fig. 8D in Ekimova (2015). This significant discrepancy compared with the original description was explained: "because different ontogenetic stages were used in the description and this study, as well as cerata morphology may be altered in preserved specimens" (Ekimova et al., 2016: 38). However, this discrepancy was not due to the different ontogenetic stages. In the original description of $D$. kamchaticus, the type specimens were represented by an almost adult holotype (12 $\mathrm{mm}$ preserved length) with a mature reproductive system whereas seven paratypes were subadults $(2-10 \mathrm{~mm}$ of preserved length). Most importantly, the drawing in Ekimova (2015: Fig. 8D) depicted the largest holotype, with an adult reproductive system and the artificially bulbous branches were only seen in the preserved specimen, without any considerable ontogenetic modifications. The largest specimen so far known of D. kamchatcius (adult, $30 \mathrm{~mm}$ ) from the NE Pacific, also has considerably elongated branches (Korshunova et al., 2016a). This fully confirms that the branches were described and figured incorrectly in the original description.

\section{Dendronotus lacteus (Thompson, 1840)}

Fig. 7

Tritonia lactea Thompson, 1840: 88-89, Pl. 2, Fig. 3 .

Dendronotus lacteus Eliot, 1910: 161; Nordsieck, 1972: 68; Pruvot-Fol, 1954: 356; Thollesson, 1998: 191-193, Figs 1-3; Evertsen and Bakken, 2005: 18; Korshunova et al., 2017: 2-7, Figs 1, 2.

not Becher, 1886: 14.

not Eliot, 1910:112 (= D. dalli). = D. frondosus auct. non Ascanius, 1774 .

Extended diagnosis. Body relatively narrow. Four to eight pairs of branched dorsolateral appendages which in adults commonly show specific "curly" pattern though other specimens with more "typical" for genus Dendronotus elongated appendages may occur. Four to ten oral veil appendages. Four to six appendages (inetrnal middle and posterior ones longest) of rhinophoral stalks. Lateral papilla of rhinophoral sheaths present. Rhinophores with 10-14 lamellae. At least more than 15 lip papillae. Basal colour from uniformly dark red to uniform white, often with small brownish dots. Redddish and brownish specimens may have white stripes between cerata, white specimens milky, non-transparent in appearance. Dorsal processes of jaws inclined posteriorly at approximately $55^{-60^{\circ}}$ to the longitudinal axis of the jaw body and $0.5^{2}$ of its length. Masticatory processes possibly bear denticles and ridge-like structures. Radula with up to 43 rows of teeth. Central tooth with up to $40-50$ small denticles (commonly smaller), often with peculiar ribs, never completely smooth. Up to 16 lateral teeth with up to five denticles. Ampulla moderately narrow with several windings or folded loops. Bursa copulatrix large, rounded to oval. Seminal receptaculum small placed distally at considerable distance from the vaginal opening. Prostate discoid with a range from 12 to more than 30 alveolar glands. 
The vas deferens is relatively long in length, penis relatively long, bent. Body length up to $150 \mathrm{~mm}$.

Distribution. North Atlantic and Arctic (eastern limit at least Laptev Sea, Russia).

Bathymetry. From circa 5 to $427 \mathrm{~m}$ depth; common at shallow, subtidal depths at around $10-20 \mathrm{~m}$.

Remarks. Dendronotus lacteus together with $D$. frondosus and D. europaeus form a species complex that is difficult to distinguish based on external characteristics, but in which it is still possible to find fine-scale morphological differences. In contrast, the radulae of these three species demonstrate distinctly different patterns (Korshunova et al., 2017b).

\section{Dendronotus nanus Marcus \& Marcus, 1967} Dendronotus nanus Marcus \& Marcus, 1967: 210-214, Figs 64-65; Farmer, 1980: 72; Robilliard, 1972: 428-430.

Diagnosis (original description). Body narrow. Six pairs of branched dorsolateral appendages. Circa six oral veil appendages. Five appendages (posterior ones the longest) of rhinophoral stalks. Lateral papilla of rhinophoral sheaths present. Rhinophores with about 15 lamellae. Circa 20 lip papillae. Basal colour semitransparent grayish with a slight reddish hue and a little brown pigment, with white line bordered foot edge, white tipped dorsolateral appendages with blackish brown subapical rings and an orange base. Masticatory processeses with crested pointed denticles. Radula with up to 26 rows of teeth. Central tooth quite narrow, with deep furrows and with up to 10 distinct denticles. Up to 14 lateral teeth commonly smooth, occasionally with up to 12 denticles.
Ampulla was not described in the original description. Bursa copulatrix large, rounded to oval. Seminal receptaculum small placed distally at considerable distance from the vaginal opening. Glandular part of prostate was reported in the original description as in early development of differentiation. The vas deferens is extremely long, with numerous loops, penis moderately short, straight, with blunt tip. Body length up to $13 \mathrm{~mm}$.

Distribution. NE Pacific, Baja California, Puerto Peñasco, Sonora, Mexico.

Bathymetry. Floating on seawater surface.

Remarks. Dendronotus nanus was considered a synonym of $D$. iris by Stout et al. (2010), but in the absence of molecular data we prefer to keep them separate. Furthermore, despite the fact that Stout et al. (2010) mentioned only minor morphological differences between D. iris and D. nanus, Marcus and Marcus (1967) in their original description specially highlighted that $D$. nanus differs from $D$. iris by a considerably longer vas deferens in animals of only $13 \mathrm{~mm}$ length (an considered to be not fully mature), whereas $D$. iris that was studied anatomically by Robilliard (1970) had a considerably larger average body length $65^{-120} \mathrm{~mm}$ but a significantly shorter vas deferens. In the BOLD database there is a sequence of $D$. nanus (in GenBank identified as $D$. iris), but from a very remote location in British Columbia whereas the type locality of D. nanus is Baja California, Sonora, thus this available sequence does not represent a true $D$. nanus. Even if taken into account that the glandular part of vas deferens likely is underdeveloped in D. nanus (see Marcus \& Marcus, 1967), the non-glandular muscular part of vas deference of $D$. nanus is considerably longer than in $D$. iris. Robilliard 
(1972) compared D. iris and D. nanus in detail and mentioned similarity of both species but did not synonymize them. All these characters need to be re-analysed before any further attempts at synonymizing these species should be done.

\section{Dendronotus patricki Stout, Wilson \&}

\section{Valdés, 2011}

Dendronotus patricki Stout et al., 2011: 63-67, Figs 2-4.

Diagnosis (original description). Body broad. Three to four pairs of branched dorsolateral appendages. Six appendages of oral veil. Four appendages (posterior ones long) of rhinophoral stalks. Lateral papilla of rhinophoral sheaths absent. Number of rhinophoral lamellae and lip papillae not indicated in the original description. Colour uniformly reddish brown (appears in original description as rather pinkish) with a semitransparent body. Masticatory processeses with ridge-like structures. Radula with up to 31 rows of teeth. Central tooth with up to 20 small denticles without furrows. Up to eight lateral teeth without denticles. Ampulla moderately voluminous with two folded loops. Bursa copulatrix very large, rounded to oval. Seminal receptaculum moderate in size placed distally near the vaginal opening. Prostate discoid with range at least 10 alveolar glands. The vas deferens is very long, penis relatively long, straight, conical. Body length up to $25 \mathrm{~mm}$.

Distribution. Whalefall 'Patrick' area ( $36^{\circ} 42^{\prime}$ $30.31^{\prime \prime} \mathrm{N}, 122^{\circ}$ o6' 18.72"W), Monterey Canyon, USA.

Bathymetry. 1819-1822 m depth.

Remarks. So far only known from three specimens collected at the type locality.

\section{Dendronotus primorjensis Martynov,} Sanamyan \& Korshunova, 2015

Fig. 7

Dendronotus primorjensis Martynov et al., 2015a: 6o, Fig. 5A-G; Martynov et al., 2015c: 75-76; Korshunova et al., 2016b: $15^{-28}$, Figs 1, 2; Korshunova et al., 2016a: 2O-32; Korshunova et al., 2019b: 6-8, Fig. 3A-F.

Dendronotus dudkai Ekimova et al. (2016): 33-38, Figs 9-11 (synonym of D. primorjensis).

Extended diagnosis. Body narrow. Five to nine pairs of branched dorsolateral appendages (including 2-3 smaller pairs). Five to twelve oral veil appendages. Four to five appendages (internal middle and posterior ones longest) of rhinophoral stalks. Lateral papilla of rhinophoral sheaths present. Rhinophores with 8-12 lamellae. Five to 12 lip papillae. Basal colour nonuniformly reddish brown with few opaque white stripes between dorsolateral processes to more uniformly olive almost without white pigment, or almost lacking general pigmentation. Dorsal processes of jaws inclined posteriorly at approximately $45^{-47^{\circ}}$ to the longitudinal axis of the jaw body and 0.48 of its length. Masticatory processes bear denticles and ridge-like structures. Radula with up to 41 rows of teeth. Central tooth with deep furrows and with up to 18 (common range 12-14) distinct denticles. Up to nine lateral teeth with up to eight denticles. Ampulla moderately narrow with several windings or folded loops. Bursa copulatrix large, rounded. Seminal receptaculum small placed distally at a moderately short distance from the vaginal opening. Prostate discoid with range 1219 alveolar glands. The vas deferens is moderate in length, penis relatvely long, curved. Reported body length up to $35 \mathrm{~mm}$.

Distribution. NW Pacific, common in the northern part of the Sea of Japan, at both the Russian coast and at Hokkaido on the Japanese coast (Korshunova et al., 2016b, 2019b). 
Bathymetry. 3-20 $\mathrm{m}$ depth.

Remarks. Dendronotus dudkai Ekimova et al. (2016) is a synonym of $D$. primorjensis according to morphological, molecular and geographical data. For discussion see Korshunova et al. (2016b, 2019b).

\section{Dendronotus purpureus Bergh, 1879}

Dendronotus purpureus Bergh, 1879: 89-93, Pl. I, Figs 18-20; Pl. 3, Figs 7-12.; Bergh, 1904:15; MacFarland, 1966: 254; Odhner, 1936:1108.

Non Dendronotus purpureus var. aurantiaca Friele, 1879 (=D. frondosus or D. lacteus).

Diagnosis (original description). Exact number of pairs of branched dorsolateral appendages unknown (at least, more than three). Living colour purple, preserved reddish brown. Circa seven oral veil appendages. Five appendages (described as equal in size, likely due to preservation) of rhinophoral stalks. Lateral papilla of rhinophoral sheaths present. Rhinophores with circa 20 lamellae. Several lip papillae (no exact count present in original description). Masticatory processes of jaws with small denticles. Radula with up to 44 rows of teeth. Central tooth with a very fine denticulation. Up to 14 lateral teeth with up to six denticles. Prostate and vas deferens unknown, penis long, straight, conical. Body length up to $20 \mathrm{~mm}$.

Distribution. North Pacific, Bering Sea. Port Moller, Alaska, USA.

Bathymetry. $31 \mathrm{~m}$ depth.

Remarks. According to its original description (Bergh, 1879), D. purpureus has 14 lateral radula teeth and is thus similar in this respect to the North Atlantic and Arctic species D. lacteus. However, D. lacteus of such a size has usually less than 14 lateral teeth, and also the central teeth usually have more distinct denticles. We therefore retain the North Pacific D. purpureus as a separate species, potentially a sister species to D. lacteus, until further studies are done.

\section{Dendronotus robilliardi Korshunova,} Sanamyan, Zimina, Fletcher \& Martynov, 2016 Fig. 7

Dendronotus robilliardi Korshunova, Sanamyan, Zimina, Fletcher \& Martynov, 2016: 28-32, Figs 2, 3, 5 .

Extended diagnosis. Body narrow. Five to eight pairs (commonly more than six) of branched dorsolateral appendages, digestive gland penetrates at least three pairs of dorolateral appendages. Four to six appendages of oral veil. Four to six appendages of rhinophoral stalks. Lateral papilla of rhinophoral sheaths present. Rhinophores with 11-15 lamellae. Five to ten lip papillae. Basal colour white, dorsolateral appendage variable opaque orange or opaque white, including tip. Dorsal processes of jaws inclined posteriorly at approximately $50-60^{\circ}$ to the longitudinal axis of the jaw body and $0.43^{-0.45}$ of its length. Radula with up to 43 rows of teeth. Masticatory processes with ridge-like structures and smaller denticles. Central tooth with up to 17 small, distinct denticles without furrows. Up to nine lateral teeth with up to eight denticles. Ampulla is hook-shaped to swollen kidney-shaped, with various degrees of folding. Bursa copulatrix large, rounded, with small seminal receptaculum placed distally at a short distance from the vaginal opening. Prostate discoid with about 19-30 alveolar glands. The vas deferens is short, penis relatively short, curved. Body length up to $35 \mathrm{~mm}$.

Distribution. NW (from South Korea to Commander Islands) and NE Pacific (from Alaska to at least Washington State, Canada 
and USA). Northern Japan (photographic record only, Korshunova et al., 2019b).

Depth. circa 5-30 m.

Remarks. See Remarks for D. albus.

\section{Dendronotus robustus Verrill, 1870}

Fig. 7

Dendronotus robustus Verrill, 1870: 405; Lundin et al., 2017: 303, 306, 309-315, Figs 3, 4.

Non auct., not Ekimova et al. (2015) (mix-up with $D$. velifer G.O. Sars, 1878).

Extended diagnosis. Body wide. Six to seven pairs of branched dorsolateral appendages. 10 to 15 appendages of oral veil. Four to five appendages of rhinophoral stalks. Lateral papilla of rhinophoral sheaths absent. Rhinophores with 7-14 lamellae. More than 20 lip papillae. Basal colour light grayish to yellowish with scattered opaque white and yellow spots. Dorsal processes of jaws inclined posteriorly at approximately $47^{\circ}$ to the longitudinal axis of the jaw body and 0.55 of its length. Masticatory processes apparently bear denticles (may possess ridgelike structures). Radula with up to 31 rows of teeth. Central tooth with high cusp and up to 20 small distinct denticles without furrows. Up to nine lateral teeth with up to seven denticles. Ampulla moderately narrow, with approximately three to four irregular loops. Bursa copulatrix moderate in size, rounded to pear-shaped, with small seminal receptaculum placed distally near the vaginal opening. Prostate discoid with about 10 alveolar glands. The vas deferens is moderate in length, penis massive, broad, slightly curved. Body length of verified specimens up to $50 \mathrm{~mm}$.

Distribution. North Atlantic (both western and eastern, Canada, Norway, Russia and USA), very shallow waters only, in the Arctic, the range does not extend further eastward than the Barents Sea.

Bathymetry. Intertidal to less than 20 m deep.

Remarks. T.A. Korshunova's and A.V. Martynov's pre-2015 analysis has showed that there are at least two species in the " $D$. robustus complex", namely D. robustus Verrill, 1870 and D. velifer G.O. Sars, 1878. However, this analysis was unfortunately not included in the final version of the publication by I.A. Ekimova (Ekimova et al., 2015). This detailed morphological and molecular analysis has shown that $D$. robustus and $D$. velifer are well differentiated morphologically, bathymetrically and according to the molecular analysis (Lundin et al., 2017). In the previous literature these two species have been mixed.

\section{Dendronotus rufus O'Donoghue, 1921}

Fig. 7

Dendronotus rufus O'Donoghue, 1921:19o192; Pl. 3, Figs 25-27; Pl. 4, Fig. 48; O'Donoghue, 1922:125; Robilliard, 1970: 456-46o, Figs 4-6, 16-18, Pl. 63, Fig. 32.

Behrens, 198o:76; Behrens \& Hermosillo, 2005:95; Lamb \& Hanby, 2005: 262.

Dendronotus frondosus sensu Odhner, 1936 (part.) non Ascanius, 1774.

Extended diagnosis. Body relatively narrow. Six to nine pairs of branched dorsolateral appendages. Five appendages of oral veil. Five appendages of rhinophoral stalks. Lateral papilla of rhinophoral sheaths present. Rhinophores with 19-24 lamellae. More than 30 lip papillae. Basal colour from red to grayish white, white specimens commonly have remarkable differences in colour of dorsolateral appendages (which can be brick red to dark red). Dorsal processes of jaws inclined posteriorly at approximately $70^{\circ}$ 
to the longitudinal axis of the jaw body and 0.45 of its length. Masticatory processess with ridge-like structures and smaller denticles. Radula with up to 35 rows of teeth. Central tooth with up to 28 small denticles (usually smaller) with ribs or shallow furrows, never completely smooth. Up to 16 lateral teeth with up to seven denticles. Ampulla relatively narrow, long, with several windings and loops. Bursa copulatrix large, oval. Seminal receptaculum small, placed distally at a moderately short distance from the vaginal opening. Prostate discoid with numerous alveolar glands (at least more than $5^{\circ}$ ). The vas deferens is very long, penis long, narrow, looped several times. Body length up to $170 \mathrm{~mm}$.

Distribution. NE Pacific, from southern Alaska to Washington state, Canada and USA.

Bathymetry. $7-38 \mathrm{~m}$ depth.

Remarks. This is among the largest Dendronotus species. According to the radular formula it is similar to $D$. lacteus and molecular data confirm $D$. rufus as a sister species to $D$. lacteus (fig. 1). In its biogeographical pattern it reveals quite narrow endemism, so far known only from southern Alaska to Washington state.

\section{Dendronotus subramosus MacFarland, 1966} Fig. 7

Dendronotus subramosus MacFarland, 1966: 265-270, Pl. 40, Fig. 3; Pl. 46, Figs 5-8; Pl. 47, Figs 3-7; Pl. 49, Figs 1-3; Pl. 5o, Fig. 2; Pl. 52, Figs 1, 2; Robilliard, 1970: 462-466, Figs 3, 4, 6, 19-21, Pl. 64, Fig. 33; Behrens, 1980:76; Behrens \& Hermosillo, 2005:95; McDonald, 1983: 177.

Extended diagnosis. Body narrow. Three to six pairs of branched dorsolateral appendages. Four to six appendages of oral veil. Three to seven appendages (posterior and medial ones longest) of rhinophoral stalks. Lateral papilla of rhinophoral sheaths absent. Rhinophores with 3-14 lamellae. o-4 lip papillae. Basal colour opaque white, solid orange, brownish, ranges from pale yellow to dark brown, scattered small yellow spots, often with four thin subparallel lines (two on each side) next to the dorsolateral appendages. Dorsal processes of jaws inclined posteriorly at approximately $65^{\circ}$ to the longitudinal axis of the jaw body and 0.33 of its length. Masticatory processess with ridge-like structures. Radula with up to 72 rows of teeth. Central tooth with up to 10 small distinct denticles with furrows. Up to seven lateral teeth with up to seven denticles. Ampulla voluminous, folded. Bursa copulatrix large, oval. Seminal receptaculum small placed distally at a moderately short distance from the vaginal opening. Prostate discoid with up to 12 alveolar glands. The vas deferens is moderate in length, penis thin, long, winded. Body length up to $40 \mathrm{~mm}$.

Distribution. North Eastern Pacific, Canada and USA.

Bathymetry. From intertidal to $20 \mathrm{~m}$ depth.

Remarks. Dendronotus subramosus is unique among the clades of narrow-bodied species since it has no lateral papillae on the rhinophoral sheath. However, phylogenetically D. subramosus is more closely related to the externally similarlooking deep sea species D. jamsteci (with the presence of rhinophoral sheath papillae), which was recently described off Pacific Honshu (Japan) and also to the externally different-looking NE Pacific shallow water species D. albus (figs 1, 2). Such a morphological and molecular evolutionary mosaic is remarkable and contribute for the 
fulfilling of the term "mutlilevel fine-scale organismal diversity".

\section{Dendronotus velifer G.O. Sars, 1878}

Fig. 7

Dendronotus velifer G.O. Sars, 1878: 238-239, Pl. 15, Fig. 4, Pl. 28, Fig. 2; Lundin et al., 2017: 303-309, 310-318, Figs 1, 2, 4.

Non D. velifer auct. (mix-up with $D$. robustus and D. bathyvela).

Extended diagnosis. Body wide. Four to six pairs of branched dorsolateral appendages. Six to twelve main appendages on oral veil. Four to five appendages on rhinophoral stalks. Lateral papilla of rhinophoral sheaths absent or very small. Rhinophores with 12-15 lamellae. 30-35 lip papillae. Basal colour commonly light-to bright red with scattered white dots. Dorsal processes of jaws inclined posteriorly at approximately $65^{\circ}$ to the longitudinal axis of the jaw body and 0.55 of its length. Masticatory processes with denticles. Radula with up to 36 rows of teeth. Central tooth with low to moderate cusp and up to 26 small distinct denticles without furrows. Up to 15 lateral teeth with which is smooth or with up to four rudimentary denticles. Ampulla twolooped. Bursa copulatrix large, rounded, with small seminal receptaculum placed distally at some distance from the vaginal opening. Prostate discoid with more than 50 alveolar glands. The vas deferens is moderate in length, penis thin, long. Body length up to $90 \mathrm{~mm}$.

Distribution. North Atlantic (southern limit Gullmarfjord, Sweden) and Arctic (at least to the Laptev Sea), Norway and Russia.

Bathymetry. Commonly found below $50 \mathrm{~m}$ depth, in the Arctic not shallower than $10 \mathrm{~m}$.

Remarks. See Remarks for D. robustus.

\section{Dendronotus venustus MacFarland, 1966}

Fig. 7

Dendronotus venustus MacFarland, 1966: 271275, Pl. 40, Fig. 2; Pl. 46, Figs 9-12; Pl 47, Figs 1, 2; Pl. 49, Fig. 6; Pl. 50, Fig. 3; Pl. 52; Figs 3-6; Stout et al. 2010: 7 .

D. frondosus sensu Robilliard, 1970 and auctorum non Ascanius, 1774.

Diagnosis. Body narrow. Four to eight pairs of branched dorsolateral appendages. Four to eight appendages of oral veil. Four to six appendages (posterior and medial ones longest) of rhinophoral stalks. Lateral papilla of rhinophoral sheaths present. Rhinophores with 8-14 lamellae. Lip papillae absent or up to eight. Colour forms include white specimens with yellow spots and brownish or reddish specimens with yellow dots and/or tubercles or large amount of white pigment, but with no white-tipped appendages. Dorsal processes of jaws inclined posteriorly at approximately $55^{-60^{\circ}}$ to the longitudinal axis of the jaw body and 0.41 of its length. Masticatory processess with ridge-like structures and smaller denticles. Radula with up to 48 rows of teeth. Central tooth with up to 12 small distinct denticles with furrows. Up to eight lateral teeth with up to five denticles. Ampulla voluminous, folded. Bursa copulatrix large, pear-shaped. Seminal receptaculum small placed distally at considerable distance from the vaginal opening. Prostate discoid with few $\left(5^{-12}\right)$ alveolar glands. The vas deferens is long, possibly also partly prostatic since thickened on considerable length and then distally narrowed, penis thin, long. Body length up to $42 \mathrm{~mm}$.

Distribution. NE Pacific, Canada and USA.

Bathymetry. Common in shallow waters, at depths of circa $5^{-20} \mathrm{~m}$. 
Remarks. Despite MacFarland's (1966) detailed description of D. venustus, it was almost universally considered a synonym of D. frondosus (Robilliard, 1970; McDonald, 1980; Behrens \& Hermosillo, 2005) until molecular data showed that it is distinct from D. frondosus (Stout et al., 2010; Korshunova et al., 2019b). Robilliard (1970) did not doubt the synonymy of $D$. venustus, although he rarely observed more than 12 of the prostatic alveolar glands in the NE Pacific specimens, whereas in true $D$. frondosus their number is usually up to at least 30 . There are also minor differences in the radular patterns and some details of colouration between $D$. frondosus and $D$. venustus (e.g., common presence of white forms with small yellow spots in $D$. venustus). There is a possibility of the presence of hidden diversity within $D$. venustus. However, a specimen from Alaska included in our present study (fig. 7) matches the original description of $D$. venustus very well by external and internal features (MacFarland, 1966: 271-275, pl. 40 fig. 2, pl. 46, fig. 9, pl. 5 o fig. 3). These characters include the presence of yellow-greenish spots on a greyish to whitish body, a specifically broadened, somewhat cheliform first lateral tooth, and a long, broadened, apparently partly prostatic vas deferens in addition to a small discoid alveolar prostate. We therefore surely refer to this specimen as a true $D$. venustus in our present phylogenetic analysis (fig. 1).

\section{Dendronotus zakuro Martynov, Fujiwara,}

Tsuchida, R. Nakano, N. Sanamyan,

K. Sanamyan, Fletcher \& Korshunova, 2020

Fig. 7

Dendronotus zakuro Martynov, Fujiwara, Tsuchida, Nakano, Sanamyan, Sanamyan, Fletcher, Korshunova, 2020a: 505-507, Figs 3, $5^{\mathrm{B} .}$

Extended diagnosis. Body narrow. Six to seven pairs of branched dorsolateral appendages.
Five to seven appendages of oral veil. Circa five appendages (posterior ones the longest) of rhinophoral stalks. Lateral papilla of rhinophoral sheaths present. Rhinophores with 10-11 lamellae. Lip papillae 20-30. Basal colour bright red to reddish-brownish with thin white broken lines between dorsolateral appendages, also scattered opaque white dots and speckles on dorsal and lateral sides, and on various appendages. Dorsal processes of jaws inclined posteriorly at approximately $70^{\circ}$ to the longitudinal axis of the jaw body and 0.5 of its length. Masticatory processess with ridge-like structures. Radula with up to 36 rows of teeth. Central tooth completely devoid of denticles (except for the anteriormost juvenile radula in some specimens), only sometimes faint traces of furrows occur. Up to 12 lateral teeth with up to seven denticles. Ampulla moderately narrow, sligthly bent. Bursa copulatrix very large, oval. Seminal receptaculum small placed distally at considerable distance from the vaginal opening. Prostate discoid with circa 25 alveolar glands. The vas deferens is moderate in length, penis conical, curved. Body length up to $30 \mathrm{~mm}$.

Distribution. NW Pacific, so far recorded from Kamchatka, Russia, southern part of Hokkaido and Honshu, Japan (the Sea of Japan side).

Bathymetry. Shallow waters, at depths of circa 7-20 m.

Remarks. This species has recently been described in detail (Martynov et al., 202Oa).

\section{Genus Cabangus gen. nov.}

ZooBank: http://urn:lsid:zoobank.org:act: 3B779CBF-A310-4B47-85B1-488104FAD 541

Type species. Dendronotus regius Pola \& Stout, 2008 
Etymology. From the Indonesian word "cabang" meaning "branch" in reference to this genus as "dendronotids of the tropics" and to respect the great contribution of the Indonesian fauna to global marine biodiversity (e.g., Hoeksema, 2007).

Diagnosis. Dorsolateral appendages with distinct tertiary branches. Oral veil with branched appendages. Radula with at least up to nine lateral teeth in adult specimens. Central teeth with cusp integrated within lateral denticles. Denticle-bearing part of central teeth not separated from lateral sides, distinct shoulders absent, thus central teeth triangular in outline. Prostate represented by a thickened structure without evident alveolar glands and disk. Copulative organ conical.

Remarks. According to the present molecular phylogenetic analysis, the tropical Dendronotus regius Pola \& Stout, 2008 comes as a most basal clade, distinct from all presently known species of the genera Dendronotus and Pseudobornella. Morphologically, $D$. regius differs from any known species of the genus by the presence of a homogenous, fine prostate, which is externally smooth and does not show any alveoles. Pola and Stout (2008: Fig. 4) evidently did not indicate any alveols in the prostate of their D. regius, but in the text they (Pola \& Stout, 2008: 48) mentioned a "large prostate with the proximal limit being marked by a closely set ring of alveolar glands". To clear this contradiction between this figure and the text in the original description, we checked several adult specimens of $D$. regius and confirm that there are no externally or internally conspicous alveols, otherwise so characteristic for a majority of true Dendronotus species. There is another striking difference between both strictly tropical species of Dendronotus (D. regius plus D. noahi) and any other known species of this genus, namely that the denticle-bearing part of the central teeth is not separated from the lateral sides by a distinct shoulder. Thus the central teeth have a squarish base and a triangular top. This makes the radula of both species more similar (though not identical) to that of the family Bornellidae, whose species are also partly similar in external morphology. However, details of the stomach and the reproductive systems are different. Therefore, taking molecular and morphological evidence into account, we propose here the new genus Cabangus gen. nov. with as type species Dendronotus regius Pola \& Stout, 2008. The holotype of the only other tropical species described so far, $D$. noahi, is likely a juvenile since it possesses only four rows of lateral teeth and immature reproductive system. Although this species is now included in the genus Cabangus gen. nov., this needs further study. Externally, Cabangus spp. are different from the common external appearance of Dendronotus spp. by a combination of a very narrow body and short dorsolateral appendages. By these characters, Cabangus gen. nov. is also somewhat similar to the family Bornellidae, which is phylogenetically distant from the Dendronotidae. Cabangus gen. nov. represents a basalmost clade within the Dendronotidae and hence may retain some features of the common ancestors with phylogenetically more distantly related families. Cabangus gen. nov. is also well supported by biogeographic data because the majority of its species inhabits Arctic and temperate waters, whereas Cabangus gen. nov. represents a distinct tropical lineage.

Cabangus noahi (Pola \& Stout, 2008) comb. nov.

Dendronotus noahi Pola \& Stout, 2008: $55^{-63}$, figs $6 \mathrm{~A}, \mathrm{~B}$.

Diagnosis (original description). Body very narrow. Four pairs of branched dorsolateral appendages. Six appendages of oral veil. Four 
appendages (posterior longest) of rhinophoral stalks. Small lateral papilla of rhinophoral sheaths possibly present. Rhinophores with nine lamellae. Lip papillae not indicated in the original description. Colour semitransparent white with brownish branches of digestive gland. Masticatory processes with denticles. Radula with up to 18 rows of teeth. Central tooth quite narrow, with shallow furrows and with up to 15 distinct denticles. Up to four lateral teeth with up to eight denticles. Reproductive system reported as immature in the first description. Body length up to $4 \mathrm{~mm}$ (juvenile specimen).

Distribution. Papua New Guinea, north coast, outer barrier reef, Bagabag Island, Bismarck Sea.

Bathymetry. 30.5 m depth.

Remarks. Molecular data unavailable, as well as additional specimens. Species is in need of further study.

Cabangus regius (Pola \& Stout, 2008) comb. nov.

Fig. 2

Dendronotus regius Pola \& Stout, 2008: 4654, Figs 1-5.

Extended diagnosis. Body very narrow. Three to four pairs of branched dorsolateral appendages. Circa six appendages of oral veil. Four to five appendages (posterior ones longest) of rhinophoral stalks. Rhinophores with 10-11 lamellae. Lateral papilla of rhinophoral sheaths present. Lip papillae possibly absent. Basal colour white or yellow, with blue, brown and reddish patches. Masticatory processes with denticles. Radula with up to 36 rows of teeth. Central tooth with up to 20 small distinct denticles with furrows. Up to nine lateral teeth with up to seven denticles. Ampulla voluminous, folded. Bursa copulatrix large, pear-shaped to oval. Seminal receptaculum small placed distally at a short distance from the vaginal opening (in the original description entangled duct from ampulla was incorrectly identified as "receptaculum seminis"). Prostate non discoid, thickened, without evident alveolar glands. The vas deferens is moderate in length, penis tapered. Body length up to $15 \mathrm{~mm}$.

Distribution. Tropical Indo-west Pacific.

Bathymetry. Up to $45 \mathrm{~m}$ deep.

Remarks. See under Cabangus gen. nov.

Genus Pseudobornella Baba, $193^{2}$

Type species. P. orientalis Baba, 1932 (fig. 2)

Diagnosis. Dorsolateral appendages without distinct (or with few very short) tertiary branches. One of the rhinophoral stalk appendages from both sides is extremely long, usually exceeding body length. Oral veil with long simple unbranched appendages. Radula with very small number of lateral teeth (presently known to be no more than two rows of lateral teeth). Central teeth with protruding cusp distinctly separate from lateral denticles. Prostate represents by narrow tube, without alveols and disk. Copulative organ partly flattened and with a widened subcircular apical part.

Remarks. The genus Pseudobornella differs from both Dendronotus and Cabangus gen. nov. by a unique combination of external and internal characters. These characters include a very long appendage of the rhinophoral sheath, absence of distinct tertiary branches of the dorsolateral appendages, resulting in the general appearance of dorsolateral appendages of Pseudobornella as ctenidium-like. Instead, all species of the genus 
Dendronotus possess well-defined tertiary branches on the dorsolateral appendages, and no species has such a exceedingly long appendages of the rhinophoral sheaths. There is a deep-sea species, Dendronotus claugei (see above), for which unbranched dorsolateral appendages are reported, but this species is only known from a single specimen and needs further studies. According to the present phylogeny $D$. claugei may represent a separate genus, but more data are needed to support this. Furthermore, so far no single species of the genus Dendronotus and Cabangus gen. nov. have smooth unbranched appendages in the oral veil, whereas numerous reported Pseudobornella specimens invariably show strong unbranched appendages of the oral veil. Ultimately, the radular pattern of the genus Pseudobornella differs from that in the adult stage of species of Dendronotus and Cabangus gen. nov. by a very small number of lateral teeth (so far reported no more than two). Adult specimens of the genera Dendronotus and Cabangus gen. nov. possess at least eight lateral teeth, and only very rarely in poorly known deep-sea lineages, the number of the lateral teeth rows can reach six in number. The tropical C. noahi was reported to have only four rows of lateral teeth, but only a single juvenile specimen is known (Pola \& Stout, 2008). All investigated species of the genus Dendronotus showed the presence of $1-3$ rows of lateral teeth during the early stages of their ontogeny (e.g., Martynov et al., 202Oa), while only in the genus Pseudobornella such feature became apparent in adults stage. Furthermore, the shape of the central teeth of Pseudobornella is also different from that in any adult Dendronotus and Cabangus gen. nov. species by the presence of a strongly protruding central cusp on the central teeth, which is distinctly separated from the lateral denticles.

AsEMimage of the radulaof P.orientalisfrom the Sea of Japan was presented in Martynov et al. (2015a: 6o, fig. 5G). Radular characters coupled with the molecular data (including presenting for the first time data on cor gene for the type species Pseudobornella orientalis, figs 1, 2) show that the genus Pseudobornella represents an early offshoot of the family Dendronotidae. This evolution was fuelled by the paedomorphic reduction of the lateral teeth and juvenilization of the central teeth (for criteria of paedomorphosis (Korshunova et al., 2020a; Martynov et al., 2O2Ob). A previous morphological cladistic study (Pola et al., 2009) placed the genus Pseudobornella outside the family Dendronotidae, thus highligthing the morphological peculiarities of this genus as inconsistent with those of other dendronotid genera. However, a solely molecular study suggested to synonymize Pseudobornella with Dendronotus (Pola \& Gosliner, 2010). We confirm here the validity of the genus Pseudobornella Baba, 1932 using integrative evidences. Specimens of the type species Pseudobornella orientalis from the Sea of Japan (fig. 2) in the present study matched morphologically well with those in the original description of $P$. orientalis (Baba, 1932), including the characteristic small chocolate-brown spots and yellow lines on the dorsal side, and the shape of the radular teeth.

Species composition. This presently monospecific genus only contains $P$. orientalis Baba, 1932.

\section{Discussion}

General taxonomic and biogeographic overview of the family Dendronotidae: a revolution of fine-scale defining of species The family Dendronotidae and its type genus Dendronotus represent an emerging model for studying speciation, and ultimately for investigating general problems related to the "species concept". The total number of 
species belonging to the genus Dendronotus in restricted sense is 27 (a review of all the previously described and species considered valid with diagnoses is presented in the Synopsis section). Though some new species were recognized using morphological methods (e.g., MacFarland, 1966; Robilliard, 1970, 1972), the species composition of the genus Dendronotus remained quite conservative (Thompson \& Brown, 1984; Roginskaya 1987, 1997). The genus Dendronotus was represented by just about 10 recognised shallow-water species worldwide (plus one deep-sea and two or three species of unclear status) until a considerable amount of hidden diversity was discovered recently in the shallow waters of both the North Pacific and the North Atlantic (e.g., Korshunova et al., 2017a; Martynov, 2020a).

The conservative approach in the taxonomy of the family Dendronotidae relied considerably on Mayr's $(1942,1969)$ polytypic species concept and allowed the presence of broadly defined "species" distributed over very large geographic distances. For example, until about the year 2000 only $D$. frondosus was recognised among the North Atlantic narrow-bodied Dendronotus spp. (Thompson \& Brown, 1984). The wide geographic range of D. frondosus at that time also encompassed the entire North Pacific up to subtropical regions of the middle of Honshu (Japan) and China (e.g., Robilliard, 1970; Baba, 1993; Lin et al., 1986). Later this has showed not to be the case, and the supposedly super-polytypic and pan-geographic "species" D. frondosus has been split into at least 11 narrow-defined species (see below and figs 1, 7). Each of these species occupies a particular geographic region. The natural range of true $D$. frondosus sensu stricto is limited solely to the eastern and western parts of the North Atlantic with the subarctic Barents Sea as easternmost limit, while it is absent in the Arctic region.
Dendronotus europaeus inhabits the northerneastern Atlantic in European waters only. Dendronotus arcticus is reported only from the true Arctic, e.g., Kara and Laptev seas. Dendronotus lacteus occurs in northeastern Atlantic and Arctic with the Laptev Sea as easternmost limit. Dendronotus yrjargul sp. nov. inhabits mostly the Arctic (with the Kara Sea as easternmost limit) and the neighbouring northern European regions with middle Norway as southernmost limit. Dendronotus nordenskioeldi sp. nov. is so far only reported from the Arctic Laptev sea. Dendronotus kalikal is distributed in the northwestern Pacific until the Bering Strait. Dendronotus kamchaticus is limited to the Northern Pacific only, with scattered records from the northwestern and northeastern parts. Dendronotus zakuro is reported from the northwestern Pacific only, ranging from middle Honshu to Kamchatka Peninsula. Dendronotus primorjensis is restricted merely to the Sea of Japan and neighbouring localities in Japan. Dendronotus venustus is restricted to the northeastern Pacific. This considerable regionalisation in a majority of the species is remarkable since all of them have planctonic veliger larvae and may potentially disperse very widely. But in reality instead of a single "infinitely variable" species around whole Eurasia we have an enormously complicated radiation of evidently separate species. From these species, so far only $D$. lacteus shows a maximum range from the northern European seas to the Arctic. However, it also shows a considerable morphological variation compared to other species, which may lead to this species becoming further subdivided. A very broad geographic range (the North Atlantic, Arctic and North Pacific) was previously also indicated for Dendronotus dalli (Robilliard, 1970; Roginskaya, 1987). Mutilevel data for the putative North Atlantic and Arctic "D. dalli" show instead that it represents a 
separate species D. elegans (as "D. niveus"). Dendronotus elegans is a predominatly Arctic species, which reaches cold water masses at the Canadian and US North Atlantic coasts. Dendronotus dalli instead is a predominantly North Pacific species, which reach Arctic seas into the Bering Strait and neighbouring waters, but it is absent in the subarctic North Atlantic regions.

Importantly, many of these species could be separated by a careful application of morphological characters without aid of molecular data. The possibility of morphological separation is evident in the case of $D$. venustus from the NE Pacific. Dendronotus venustus was described in considerable detail and already became delineated from the resembling $D$. frondosus in the mid-2oth century (published in MacFarland, 1966) without use of molecular techniques and scanning electron microscopy (SEM).SEM has been available to taxonomists since the 1970s and its use would enable differentiation of some of the Dendronotus species that were described in the 21st Century. However, this did not happen because all these characters could be considered as too subtle from the perspective of the past dominant paradigm. For instance, Thompson and Brown (1984) published an SEM image of radula of a specimen identified as $D$. frondosus but which actually belongs to the recently described $D$. europaeus (Korshunova et al., 2017b). Even such morphologically well distinguished species as D. albopunctatus (Robilliard, 1972) was commented as very similar to $D$. robustus (see Rudman, 2007). While data on the multilevel diversity within Dendronotidae are currently accumulating, more and finer cases will be discovered in the future among already restricted "species". Nevertheless, a majority of the recently separated species can either be differentiated by SEM radula data or by a combination of the habitus data, radular data and features of the reproductive system.
Notably, Robilliard (1970) noted differences in the reproductive system between European D. frondosus and his NE Pacific specimens of D. venustus that he at that time identified as "D. frondosus". At the same time, apparently key reproductive features (e.g., number of prostatic alveols and shape of ampulla) can vary significantly, as in the cases of D. albus or D. elegans. The separate characters should be therefore used with considerable care to distinguish particular species.

All these cases clearly confirm that not only molecular data, per se, changed the modern landscape of biodiversity research. The fundamental changes have occurred in the dominated paradigm of the species description. A major modern feature of this is the general denial of huge polytypic and pan-geographic species in favour of fine-scale interspecific morphological differences in combination with limited geographic ranges. Within restricted "narrow species" a polymorphism (a basis for the polytypic concept) is often manifested in the occurrence of parallel morphs, which may obscure species diversity (see e.g., Korshunova et al., 2O2ob). Though Mayr was among the major developers of the population-based, variable, "non-typological" species concept, he also admitted the possible existence of a hardly detectable diversity of "sibling species" (Mayr, 1942; Yoder et al., 2005). Despite this, the gravity of "a morphologically super-variable species concept" was clearly unfavourable for seeking of fine-scale differences. This was one of the reasons why researchers for a long time omitted evidence for morphological differences in the " $D$. frondosus megacomplex". The polytypic concept became popular more than five decades ago and at that time Mayr (1942) suggested a potential solution for how to unfold the apparent "chaotic species" of "typologists" into a polymorphic "biological" species. However this concept can now be considered 
as rather an obstacle than an aid in the discovery of real patterns of biodiversity. As a clear evidence for that, until very recently only drastically different species within the genus Dendronotus have been recognised without doubts (Robilliard, 1970; McDonald, 1983), despite uncertanties in their delimitation (Robilliard, 1975). An especially remarkable example is the notorious problem of how to distinguish "D. albus" from "D. diversicolor", which has persisted since Robilliard (1970). This problem was in a profound confusion of the morphological characters rather than in the absence of molecular data and was solved only recently by the distinction of $D$. robilliardi (Korshunova et al., 2016a).

The majority of the described species of the genus Dendronotus inhabit cold and temperate regions of the Northern Hemisphere and their diversity clearly declines towards tropical localities. Pola and Stout (2008) assigned two tropical dendronotids first to the genus Dendronotus. However, the morphology of the male part of the reproductive system of the these tropical representatives is different from those in the genus Dendronotus, and available molecular data for "D. regius" show it to be a separate with a more basal placement compared to any other dendronotid (figs 1, 2). Therefore "D. regius" has become the type species of the new genus Cabangus gen. nov., which encompasses exclusively tropical dendronotids. This corroborates well with the new general agenda of the multilevel organismal diversity, which proposes narrowly defined taxa not only on a species level, but also at the genus and family levels (Korshunova et al., 2017a, b, c; 2019a). This prevents to produce non-diagnosable huge taxa that not only lack support from morphology but also from various other data, such as biogeography. The taxonomic diversity of the family Dendronotidae undergoes a process of understanding and more taxa in this family are expected to be discovered. For example, a not yet described diversity within the genus Dendronotus was discovered in the temperate waters of Southern Hemisphere (e.g., Burn, 2015).

Most of the previously recognised Dendronotus species (seven out of nine, see Robilliard, 1970, 1972) occur in the NE Pacific, while in the North Atlantic and NW Pacific only one or two species were commonly recognized. This caused a distorted picture of a biogeographic asymmetry in the Dendronotus diversity between the North Atlantic, northwestern Pacific and northeastern Pacific. One of the important results of the fine-scale species definition is a considerable reduction of the "biogeographic asymmetry" among Dendronotus spp. between NE Pacific, NW Pacific, Arctic and North Atlantic localities. The resulting numbers of shallow-water and shelf species in such regions, as the North Atlantic and the NW Pacific, are impressive. I.e., in the North Atlantic and western subarctic regions (Barents Sea as limit) there are currently seven species, in the true Arctic (Kara, Laptev and East Siberian seas) there are also seven species so far described and recorded, while in the NW Pacific (Bering Strait as northernmost limit) there are eigth species and in NE Pacific there are 10 species. In all regions the number of species will likely increase further. This analysis clearly suggests that not only geographical proximity to the rich warm water fauna (as in the case of NE Pacific) is important, but also that ecological and other factors (including the history of faunal formation) have contributed substantially to an active speciation. The presence of at least seven species of Dendronotus in the Artic as one of the world's coldest regions is a clear evidence for this. All these data and implications have contributed to rapid and revolutionary advancements in the taxonomy of the family Dendronotidae (Thollesson, 1998; Stout et al., 2010; Martynov et al. 2015a, c, 2020a; Ekimova 
et al. 2015; Korshunova et al. 2016a, b, 2017a, 2019b; Lundin et al., 2017; present study).

\section{Multilevel Dendronotidae diversity and different degrees of evolutionary separation}

The majority of dendronotids are putatively united under the genus Dendronotus, which represents a morphologically heterogenous assemblage of several distinct clades with a significant molecular divergence (see figs 1, 2; Synopsis; Appendix, table A2). The case of the family Dendronotidae is therefore particularly illustrative of multilevel differences among apparently taxonomically equally recognized "species". These apparently natural units are not equal by their morphological and molecular properties, and broader, ontogenetic properties. Hence, the term "species" is not equal over large phylogenetic distances but also among relatively small levels, such as genus and family. To make taxonomy consistent with the multilevel diversity among the family Dendronotidae, we separate a new genus Cabangus gen. nov. and confirm a separate status of the genus Pseudobornella.

Notably, even among the "core species" that is still constitute the genus Dendronotus (fig. 1) our present study demonstrates various degrees of separation from species in a state of being morphologically well distinguished but molecularly low delineated (the D. yrjargul sp. nov. - D. kalikal pair) to morphologically subtle but molecularly well distinguished species (D. frondosus $-D$. primorjensis, D. dalli-D. elegans, D. lacteus-D. europaeus and D. nordenskioeldi sp. nov.) (figs. 1-8). We can unambiguously present distinguishing characters only when these apparent groups currently known as species really belong to sufficiently distantly related subclades, as in easily recognizable species such as $D$. iris or $D$. subramosus, or D. frondosus and D. robustus (figs 1, 7). A very complicated mutilevel morphological and molecular diversity of the genus Dendronotus implies the presence of many taxa that are incomparably more close to $D$. frondosus as the type species of the genus (e.g., D. primorjensis, D. venustus) than to the much different wide-bodied D. robustus (and its closely related species, e.g., D. velifer, $D$. bathyvela). Therefore, although a direct comparison between $D$. robustus sensus strictus and $D$. frondosus sensus strictus is possible, this is not taxonomically meaningful anymore considering the presence of such hardly distinguishable complexes. The similarities between the "Dendronotus robustus complex" and the " $D$. frondosus megacomplex" are thus similarities at genus or higher level. This needs to be adressed in a further study.

The common formulation of a procedure to find differences within such multilevel organismal diversity, and hence the degree of separation between different groups of biological organisms is a "species delimitation" despite the species concept itself having no universal fundamental agreement even in recent publications (Stanton et al., 2019). In the present study we found a remarkable case when the mean cor difference of a group is slightly above $2 \%$ (normally indicative of a single species) but when morphological, ontogenetic and biogeographic evidence are examined the two Dendronotus groups deserve to be taxonomically marked as distinct species, namely D. kalikal and D. yrjargul sp. nov. (figs 1-4, 6). At the same time D. nordenskioeldi sp. nov., despite its habitus similarity with $D$. lacteus, differs substantially from that species by its central teeth with very weak denticles devoid of rib-like structures (fig. 5) and intriguingly, (fig. 1) it demonstrates significant molecular distance from all know species of the genus Dendronotus (Appendix, table A2). Despite the lack of consensus about the meaning of "species" we can observe some "groups of genetically and ecologically similar individuals" (e.g., Shapiro 
et al., 2016) in nature, even though there are no clear criteria about how to separate one similar group from another similar group. A conclusion was reached that the "population-to-species" level represents a continuum (Mallet et al., 2009; Coates et al., 2018). Using these numerous available data on different groups and our present data, we therefore disagree with the most recent suggestion to save "species" as a universal concept using a "weak realism" approach (Reydon \& Kunz, 2019). Because even in its weaker form, "species" as a reality still implies the universal application of this concept despite that it encompasses groups that have different degrees of separation, and hence different morphological and molecular properties. The big discrepance between "species" or other taxon as a systematic unit and "species/taxon" as a natural entity still persists (e.g., Ereshefsky, 1998; Zachos, 2018). The recently proposed concept of the multilevel organismal diversity (Korshunova et al., 2017b, 2019a) is helping to reduce this discrepance and make a transit from the previous paradigm of "polytypic species", by placing the organismal diversity in a broad ontogenetic framework, as a finescale complex of the morphological, genetic and epigenetic patterns and processes.

\section{Acknowledgements}

Olga Zimina is warmly thanked for providing specimens from Arctic. The team of Gulen Dive Center (Christian Skauge, Ørjan Sandnes, Monica Bakkeli, and Guido Schmitz) are generously thanked for their help during fieldwork in Norway, as these Norwegian specimens were used for comparative purposes in this study. We are thankful to Yoshihiro Fujiwara, Kazunori Hasegawa, Doug Miller, Karen Sanamyan, Nadezhda Sanamyan, and Olga Zimina for providing some photographs of live specimens. Our warm gratitude goes to Karin Fletcher for improvement of English in an earlier version of the manuscript and for providing us with the wonderful pictures of D. rufus and D. venustus. Electron Microscopy Laboratory MSU is thanked for support with electron microscopy. Reviewers are thanked for providing comments. The study was supported by the Norwegian Taxonomy Initiative project \#sneglebuss Barents Sea (1918_70184240). The work of AM was supported by the research project of MSU Zoological Museum (AAAA-A16-116o2166oo77-3). The work of TK was conducted under the IDB RAS Government basic research program in 2020 No 0108-2019-0002.

\section{References}

Agarwal, M. (2017) First record of Dendronotus orientalis (Baba, 1932) (Nudibranchia: Dendronotidae) in the temperate Eastern Pacific. BioInvasions Rec., 6, 135-138.

Alder, J. \& Hancock, A. (1842) Descriptions of several new species of nudibranchous mollusca found on the coast of Northumberland. Ann. Mag. Nat. Hist., 9, 31-36.

Ascanius, P. (1774) Beskrivelse over en Norske sneppe og et sodyr. Det Kongelige Norske Videnskabelige Selskabs Skrifter Trondhejm, 5, 153-158.

Baba, K. (1932) Pseudobornella orientalis, nov. gen. et sp. from Japan. Annot. Zoolog. Japon., 13, 4, 369-376.

Baba, K. (1949) Opisthobranchia of Sagami Bay collected by His Majesty The Emperor of Japan. Iwanami Shoten, Tokyo.

Baba, K. (1993) A northern species of Dendronotus (Mollusca: Nudibranchia: Dendronotidae) from Sado Island, Sea of Japan. Rep. Sado Mar. Biol. Stat., 23, 29-33.

Bakken, T., Hårsaker, K. \& Daverdin, M. (2020) Marine invertebrate collection NTNU University 
Museum. Version 1.414. NTNU University Museum. Occurrence dataset https://doi.org/10.15468/ ddbsi4 accessed via GBIF.org on 2020-02-25.

Becher, E. (1886) Mollusken von Jan Mayen, gesammelt von Dr. F. Fischer, Arzt der österreichishcen Expedition auf Jan Mayen. Die internationale Polarforschung, 1882/83, 3, $1-16$.

Behrens, D. \& Hermosillo, A. (2005) Eastern Pacific nudibranchs, a guide to the opisthobranchs from Alaska to Central America. Sea Challengers, Monterey.

Behrens, D. (1980) Pacific Coast Nudibranchs, a Guide to the Opisthobranchs of the Northeastern Pacific. Sea Challengers, Los Osos, CA.

Bergh, R. (1863) Campaspe pusilla, en ny Slægstform af Dendronotidernes Gruppe, samt Bemærkninger om Dotidernes Familie. Naturhist. Tidsskr. Stiftet af Henrik Kroyer, 1, 471-483.

Bergh, R. (1879) On the nudibranchiate gasteropod mollusca of the North Pacific Ocean, with special reference to those of Alaska. Proc. Acad. Nat. Sci. Philadelphia, 31, 71-132.

Bergh, R. (1886) Die Nudibranchien. Gesammelt wärhrend der fahrten des "Willem-Barents" in das Nördliche Eismeer. Bijdr. Dierk., 13, 1-37, pls. $1-3$.

Bergh, R. (1904) Malacologische Untersuchungen. Reisen im Archipel der Philippinen von Dr. Carl Gottfried Semper, 9, 1-56.

Bickford, D., Lohman, D.J., Sodhi, N.S., Ng, P.K.L., Meier, R., Winker, K. \& Das, I. (2006) Cryptic species as a window on diversity and conservation. Trends Ecol. Evol, 22, 148-155.

Bleakney, J. (1996) Sea slugs of Atlantic Canada and the Gulf of Maine. Nimbus Publishing \& The Nova Scotia Museum, Halifax.

Burn, R. (2015) Nudibranchs and Related Molluscs. Museum Victoria, Melbourne.

Coates, D., Byrne, M. \& Moritz, C. (2018) Genetic diversity and conservation units: dealing with the species-population continuum in the age of genomics. Front. Ecol. Evol., 6, 165.
Colgan, N. (1914) The opisthobranch fauna of the shores and shallow waters of County Dublin. Ir. Nat. J., 23 (8/9), 161-204.

Cooper, J. (1863) On new or rare Mollusca inhabiting the coast of California. No. II. Proc. Calif. Acad. Nat. Sci., 3, 56-6o.

Couthouy, J. (1838) Descriptions of new species of Mollusca and shells, and remarks on several Polypi found in Massachusetts Bay. Boston J. Nat. Hist., 2, 53-111.

Crossman, C., Taylor, E., \& Barrett-Lennard, L. (2016) Hybridization in the Cetacea: widespread occurrence and associated morphological, behavioral, and ecological factors. Ecol. Evol., 6, 1293-1303.

Darwin, C. (1859) On the Origin of Species by Means of Natural Selection. John Murray, London.

de Queiroz, K. (2006) Ernst Mayr and the modern concept of species. Proc. Nat. Acad. Sci. USA, 102, 660o-66o7.

de Queiroz, K. (2007) Species concepts and species delimitation. Systematic Biology, 56, 879-886.

Ekimova, I., Korshunova, T., Schepetov, D., Neretina, T., Sanamyan, N. \& Martynov, A. (2015) Integrative systematics of northern and Arctic nudibranchs of the genus Dendronotus (Mollusca, Gastropoda), with descriptions of three new species. Zool. J. Linn. Soc., 173, 841-886.

Ekimova, I., Schepetov, D., Chichvarkhina, O. \& Chichvarkhin, A. (2016) Nudibranch molluscs of the genus Dendronotus Alder et Hancock, 1845 (Heterobranchia: Dendronotina) from Northwestern Sea of Japan with description of a new species. Invertebr. Zool., 13, 15-42.

Eldredge, N. \& Gould, S.J. (1972) Punctuated equilibria: an alternative to phyletic gradualism. In Schopf T.J.M. (Ed.) Models in Paleobiology, pp. 82-115. Freeman Cooper, San Francisco.

Eliot, C. (1910) A Monograph of the British Nudibranchiate Mollusca: with Figures of the Species. pt. VIII (supplementary). Ray Society, London. 
Ereshefsky, M. (1998) Species pluralism and antirealism. Philos. Sci., 65, 103-120.

Evertsen, J. \& Bakken, T. (2005) Nudibranch diversity (Gastropoda, Heterobranchia) along the coast of Norway. Fauna Norvegica, 25, 1-37.

Farmer WM. 1980. Sea-slug Gastropods. W.M. Farmer Enterprises, Tempe, AZ.

Fraïsse, C., Belkhir, K., Welch, J. \& Bierne, N. (2016) Local interspecies introgression is the main cause of extreme levels of intraspecific differentiation in mussels. Mol. Ecol. Evol., 25, 269-286.

Friele, H. (1879) Catalog der auf der norwegischen Nordmeerexpedition bei Sptizbergen gefundenen Mollusken. Jahrb. Deutsch. Malakozool. Gesellsch., 6, 264-286.

Gmelin, J. (1791) In: Linnaeus (Ed.) Systema Naturae, per regna tria naturae. 13, 1, 6, 31033107, 3147-3148.

González, A., Thompson, P. \& Loreau, M. (2018) Spatial ecological networks: planning for sustainability in the long-term. Curr. Opin. Environ. Sust., 29, 187-197.

Harrison, R. \& Larson, E. (2014) Hybridization, introgression, and the nature of species boundaries.J. Hered., 105, 795-809.

Hoeksema, B.W. (2007) Delineation of the Indo-Malayan Centre of Maximum Marine Biodiversity: The Coral Triangle. In: Renema W. (ed.) Biogeography, Time and Place: Distributions, Barriers and Islands, pp 117-178. Springer, Dordrecht.

ICZN. (1999) International Code of Zoological Nomenclature. The International Trust for Zoological Nomenclature, London.

Jančúchová-Lásková,J.,Landová,E.\&Frynta,D.(2015) Experimental crossing of two distinct species of leopard geckos, Eublepharis angramainyu and E. macularius: Viability, fertility and phenotypic variation of the hybrids. PLoS ONE, 10, eo143630.

Johnson, R.F. (2010) Breaking family ties: taxon sampling and molecular phylogeny of chromodorid nudibranchs (Mollusca, Gastropoda). Zool. Scr., 40, 137-157.
Katoh, K., Misawa, K., Kuma, K. \& Miyata, T. (2002) MAFFT: a novel method for rapid multiple sequence alignment based on fast Fourier transform. Nucleic Acids Res., 30, 3059-3066.

Kijewski, T., Zbawicka, M., Väinölä, R. \& Wenne, R. (2006) Introgression and mitochondrial DNA heteroplasmy in the Baltic populations of mussels Mytilus trossulus and M. edulis. Mar. Biol., 149, 1371-1385.

Knipowitsch, N. (1902) Zoologische ergebnisse der russischen expeditionen nach Spitzbergen, Mollusca und Brachiopoda. Ann. Mus. Zool. Acad. Imp. Sci. St. Pétersbourg, 7, 355-459.

Korshunova, T., Fletcher, K., Picton, B., Lundin, K., Kashio, S., Sanamyan, N., Sanamyan, K., Padula, V., Schrodl, M. \& Martynov A. (2020a) The Emperor Cadlina, hidden diversity and gill cavity evolution: new insights for the taxonomy and phylogeny of dorid nudibranchs (Mollusca: Gastropoda). Zool. J. Linn. Soc., 189, 762-827.

Korshunova, T., Malmberg, K., Prkić, J., Petani, A., Fletcher, K., Lundin, K. \& Martynov, A. (2020b) Fine-scale species delimitation: speciation in process and periodic patterns in nudibranch diversity. ZooKeys, 917, 15-50.

Korshunova, T., Martynov, A. \& Picton, B. (2017c) Ontogeny as an important part of integrative taxonomy in tergipedid aeolidaceans (Gastropoda: Nudibranchia) with a description of a new genus and species from the Barents Sea. Zootaxa, 4324, 1-22.

Korshunova, T., Martynov, A., Bakken, T. \& Picton, B. $(2017 \mathrm{~b})$ External diversity is restrained by internal conservatism: New nudibranch mollusc contributes to the cryptic species problem. Zool. Scr., 46, 683-692.

Korshunova, T., Martynov, A., Bakken, T., Evertsen, J., Fletcher, K., Mudianta, I., Saito, H., Lundin, K., Schrödl, M. \& Picton, B. (2017a) Polyphyly of the traditional family Flabellinidae affects a major group of Nudibranchia: aeolidacean taxonomic reassessment with descriptions of several new families, genera, and species (Mollusca, Gastropoda). ZooKeys, 717, 1-139. 
Korshunova, T., Nakano, R., Fletcher, K., Sanamyan, N. \& Martynov, A. (2019b) First molecular confirmation of the presence of Dendronotus primorjensis Martynov, Sanamyan \& Korshunova, 2015 in Japan and new distributional records of Dendronotus species in the North Pacic (Nudibranchia: Dendronotidae). Venus, 77, 1-14.

Korshunova, T., Picton, B., Furfaro, G., Mariottini, P., Pontes, M., Prkić, J., Fletcher, K., Malmberg, K., Lundin, K. \& Martynov, A. (2019a) Multilevel fine-scale diversity challenges the 'cryptic species' concept. Sci. Rep., 9, 6732.

Korshunova, T., Sanamyan, N. \& Martynov, A. (2016b) Morphological and molecular evidence indicate Dendronotus primorjensis is a valid species that has priority over $D$. dudkai (Nudibranchia). ZooKeys, 634, 15-28.

Korshunova, T., Sanamyan, N., Zimina, O., Fletcher, K. \& Martynov, A. (2016a) Two new species and a remarkable record of the genus Dendronotus from the North Pacific and Arctic oceans (Nudibranchia). ZooKeys, 630, 19-42.

Kröyer, H.N. (1847) Zoologisches. I. Aus Königlichen Musäen. Amtlicher Bericht über die Versammlung Deutscher Naturforscher und Ärzte in Kiel, 24, 109-115.

Kumar, S., Stecher, G., \&Tamura, K. (2016) MEGA7: Molecular evolutionary genetics analysis version 7.0 for bigger datasets. Mol. Biol. Evol., $33,1870-1874$.

Lafont, A. (1871) Note pour servir a la faune de la Gironde contenant la liste des animaux marins dont la présence a été constatée a Arcachon pendant les années 1869-70. Act. Soc. Linn. Bordeaux, 28, 237-28o.

Lamb, A. \& Hanby, B.P. (2005) Marine Life of the Pacific Northwest, a Photographic Encyclopedia of Invertebrates, Seaweeds and Selected Fishes, Harbour Publishing, Madeira Park, BC.

Lin, G., Zhang, F. \& Ma, S. (1986) Opisthobranchia. In: Chinese animal atlas: Mollusca, volume 3. Science Publishing Company, China.

Lundin, K., Korshunova, T., Malmberg, K. \& Martynov, A. (2017) Intersection of historical museum collections and modern systematics: a relict population of the Arctic nudibranch Dendronotus velifer G.O. Sars, 1878 in a Swedish fjord. Contrib. Zool., 86, 303-318.

MacFarland, F.M. (1966) Studies of opisthobranchiate mollusks of the Pacific coast of North America. Mem. Calif. Acad. Sci., 6, 1-546.

Mallet, J. (2005) Hybridization as an invasion of the genome. Trends Ecol. Evol., 20, 229-237.

Mallet, J., Meyer, A., Nosil, P., \& Feder, J. (2009) Space, sympatry and speciation.J. Evol. Biol., 22, 2332-2341.

Marcus, Ev. \& Marcus, Er. (1967) American opisthobranch mollusks Part I,Tropical American opisthobranchs, Part II, Opisthobranchs from the Gulf of California. Stud. Trop. Oceanogr., Miami, $6,1-256$.

Martinsson, S. \& Erséus, C. (2018) Cryptic diversity in supposedly species-poor genera of Enchytraeidae (Annelida: Clitellata). Zool. J. Linn. Soc., 183, 749-762.

Martynov, A., Fujiwara, Y., Tsuchida, S., Nakano, R., Sanamyan, N., Sanamyan, K., Fletcher, K. \& Korshunova, T. (2020a) Three new species of the genus Dendronotus from Japan and Russia (Mollusca, Nudibranchia). Zootaxa, 4747, 495-513. Martynov, A., Ishida, Y., Irimura, S., Tajiri, R., O'Hara, T. \& Fujita, T. (2015b) When ontogeny matters: a new Japanese species of brittle star illustrates the importance of considering both adult and juvenile characters in taxonomic practice. PLOS ONE, 10, eo139463.

Martynov, A., Lundin, K., Picton, B., Fletcher, K., Malmberg, K. \& Korshunova, T. (2020b) Multiple paedomorphic lineages of softsubstrate burrowing invertebrates: parallels in the origin of Xenocratena and Xenoturbella. PLoS ONE, 15, eo227173.

Martynov, A., Sanamyan, N. \& Korshunova, T. (2015a) New data on the opisthobranch molluscs (Gastropoda: Opisthobranchia) of waters of Commander Islands and Far-Eastern seas of Russia. Conservation of biodiversity of Kamchatka and coastal waters - Proceedings 
of the XV International Scientific Conference Petropavlovsk-Kamchatsky, pp. 55-69. Kamchat Press, Petropavlovsk-Kamchatsky.

Martynov, A., Sanamyan. N. \& Korshunova, T. (2015c) Review of the opisthobranch mollusc fauna of Russian Far Eastern seas: Pleurobranchomorpha, Doridida and Nudibranchia. Bull. Kamchatka State Technol. Univ., 34, 62-87.

Martynov, A.V. \& Korshunova, T.A. (2011) Opisthobranch Molluscs of the Seas of Russia. A Colour Guide to their Taxonomy and Biology. Fiton, Moscow.

Mayer, F. \& von Helversen, O. (2001) Cryptic diversity in European bats. Proc. R. Soc. B, 268, 1825-1832.

Mayr, E. (1942) Systematics and the Origin of Species Columbia University Press, New York.

Mayr, E. (1969) Principles of Systematic Zoology. McGraw-Hill, New York.

Mayr, E. (1982) The Growth of Biological Thought: Diversity, Evolution, and Inheritance. Harvard University Press, Harvard, MA.

Mcdonald, G. (1983) A review of the nudibranchs of the California coast. Malacologia, 24, 114-276.

McDonald, G. (2009) Nudibranch Systematic Index. Second edition. Long Marine Laboratory, UC Santa Cruz.

McDonald, J., Koehn, R. (1988) The mussels Mytilus galloprovincialis and M. trossulus on the Pacific coast of North America. Mar. Biol., 99, 111-118.

Møller, H.P.C. (1842) Index Molluscorum Groenlandice.C.A. Reitzelii, Hafniae.

Mörch, O. (1875) Prodromus Faunæ Molluscorum Groenlandiæ,. In: Rupert Jones, T. (Ed.) Manual of the Natural History, Geology, and Physics of Greenland and the Neighbouring Regions, 2014 Edition, pp. 124-135. Cambride University Press, Cambridge.

Müller, O.F. (1776) Zoologiae Danicae. Prodromus seu animalium Daniae et Norvegiae ingenarum characteres, nomina, et synonyma imprimis popularium. Hallageriis, Havniae.
Nakano, R. (2018) Field Guide to Sea Slugs and Nudibranchs of Japan. Bun-ichi Co., Ltd., Tokyo.

NMNH (National Museum of Natural History, Smithsonian Institution) (2020) Dendronotus elegans Verrill, 1880 Holotype USNM 842116. Accesssed through http://n2t.net/ ark:/65665/39fc3ac7d-5caa-47ae-bocb$6 \circ 37 \mathrm{~b} 864 \mathrm{c} 4 \mathrm{~d}$

Nordsieck, F. (1972) Die europäischen Meeresschnecken (Opisthobranchia mit Pyramidellidae; Rissoacea), Vom Eismeer bis Kapverden, Mittelmeer und Schwarzes Meer. Gustav Fischer Verlag, Stuttgart.

Nylander, J., Ronquist, F., Huelsenbeck, J. \& NievesAldrey, J. (2004) Bayesian phylogenetic analysis of combined data. Syst. Biol., 53, 47-67.

O’Donoghue, C. (1921) Nudibranchiate Mollusca from the Vancouver Island region. Trans. R. Can. Inst., 13, 147-209.

O'Donoghue, C. (1922) Notes on the nudibranchiate Mollusca from the Vancouver Island region. III. Records of species and distribution. Trans. $R$. Can. Inst., 14, 145-167.

Odhner, N. (1907) Northern and Arctic invertebrates in the collection of the Swedish state museum. Det Kongelige Norske Videnskabers Selskabs Skrifter, 41, 1-114.

Odhner,N.(1936)NudibranchiaDendronotacea-A revision of the system. Mém. Mus. R. Hist. Nat. Belg. (Ser. 2), 3, 1057-1128.

Odhner, N. (1939) Opisthobranchiate Mollusca from the western and northern coasts of Norway. Det Kongelige Norske Videnskabernes Selskabs Skrifter, 1, 1-93.

Platania, L., Vodă, R., Dincă, V., Talavera, G., Vila, R. \& Dapporto, L. (2020) Integrative analyses on Western Palearctic Lasiommata reveal a mosaic of nascent butterfly species. J. Zool. Syst. Evol. Res., doi:10.1111/jzs.12356

Pola, M. \& Stout, C. (2008) Description of the first two tropical Indo-Pacific species of Dendronotus (Gastropoda: Nudibranchia) with new data of the poorly known species 
Dendronotus gracilis Baba, 1949. Zootaxa, 196o, 45-66.

Pola, M., \& Gosliner, T. M. (2010) The first molecular phylogeny of cladobranchian opisthobranchs (Mollusca, Gastropoda, Nudibranchia). Mol. Phyl. Evol., 56, 931-941.

Pola, M., Rudman,W.\& Gosliner,T.(2009)Systematics and preliminary phylogeny of Bornellidae (Mollusca: Nudibranchia: Dendronotina) based on morphological characters with description of four new species. Zootaxa, 1975, 1-57.

Potkamp, G. \& Fransen, C.H.J.M. (2019) Speciation with gene flow in marine systems. Contrib. Zool., 88, 133-172.

Pruvot-Fol, A. (1954) Mollusques Opisthobranches. Faune de France, 58, 1-46o.

Puillandre, N., Lambert, A., Brouillet, S. \& Achaz, G. (2012) ABGD, Automatic Barcode Gap Discovery for primary species delimitation. Mol. Ecol., 21, 1864-1877.

Ratnasingham, S. \& Hebert, P. (2013) A DNABased Registry for All Animal Species: The Barcode Index Number (BIN) System. PLoS ONE, 8, e66213. doi:10.1371/journal. pone.oo66213

Reydon, T. \& Kunz, W. (2019) Species as natural entities, instrumental units and ranked taxa: new perspectives on the grouping and ranking problems. Biol. J. Linn. Soc., 126, $623-636$.

Robilliard, G. (1970) The systematics and some aspects of the ecology of the genus Dendronotus. Veliger, 12, 433-479.

Robilliard, G. (1972) A new species of Dendronotus from the northeastern Pacific with notes on Dendronotus nanus and Dendronotus robustus (Mollusca: Opisthobranchia). Can. J. Zool., 50, 421-432.

Robilliard, G. (1975) The nudibranch Dendronotus frondosus - one species or four? Festivus, 6, 44-47.

Roginskaya, I.S. (1987) Order Nudibranchia Blainville, 1814. In: Molluscs of the White Sea. Keys to the Fauna of USSR, 151, 155-201.
Roginskaya, I.S. (1990) Additional data on the food and feeding of Dendronotus robustus Verrill, 1879 (Nudibranchia: Dendronotidae) from Dvinsky Bay of the White Sea. In: Kuznetsov A.P. (Eds) Feeding and Bioenergetics of Marine Bottom Invertebrates, pp. 93-110, 158. P.P. Shirshov Institute of Oceanology, Academy of Sciences of the U.S.S.R., Moscow.

Roginskaya, I.S. (1997) Predation by a nudibranch Dendronotus robustus from the Sea of Japan on Oweniid polychaetes. Opisthobranch Newsl., 23, 21-23.

Ronquist, F., Teslenko, M., van der Mark, P., Ayres, D.L., Darling, A., Höhna, S., Larget, B., Liu, L., Suchard, M.A. \& Huelsenbeck, J.P. (2012) MrBayes 3.2: Efficient Bayesian phylogenetic inference and model choice across a large model space. Syst. Biol., 61, 539-542.

Rudman, W. (2007) Comment on Dendronotus robustus from Spitzbergen, Nth Atlantic by Erling Svensen. Message in Sea Slug Forum. Australian Museum, Sydney. Available from http://www.seaslugforum.net/find/19087

Rybakova, E., Galkin, S., Gebruk, A., Sanamyan, N. \& Martynov, A. (2020) Vertical distribution of megafauna on the Bering Sea slope based on ROV survey., PeerJ, 8, e8628. doi 10.7717/ peerj. 8628

Sars, G. (1878) Bidrag til kundskaben om Norges Arktiske fauna. I. Mollusca regionis Arcticae Norvegiae, oversigtoverde iNorges Arktiskeregion forekommende. Bløddyr. Universitetsprogram, Christiania.

Shapiro, B.J., Leducq, J.-B. \& Mallet, J. (2016) What is speciation?. PLoS Genet., 12, e100586o.

Shaw, G. (1991) Chemotaxis and lunge-feeding behaviour of Dendronotus iris (Mollusca, Opisthobranchia). Can.J. Zool., 69, 2805-2810.

Stamatakis, A., Hoover, P. \& Rougemont, J. (2008) Rapid bootstrap algorithm for the RAxML webservers. Syst. Biol., 75, 758-771.

Stanton, D., Frandsen, P., Waples, R., Heller, R., Russo, I., Orozco-terWengel, P., Pedersen, C., Siegismund, H. \& Bruford, M. (2019) More grist 
for the mill? Species delimitation in the genomic era and its implications for conservation. Conserv. Genet., 20, 101-113.

Stout, C., Pola, M. \& Valdés, Á. (2010) Phylogenetic analysis of Dendronotus nudibranchs with emphasis on northeastern Pacific species. J. Mollus. Stud., 76, 367-375.

Stout, C., Wilson, N. \& Valdés, Á. (2011) A new species of deep-sea Dendronotus Alder \& Hancock (Mollusca: Nudibranchia) from California, with an expanded phylogeny of the genus. Invertebr. Syst., 25, 6o-69.

Swennen, C. (1961) Data on distribution, reproduction and ecology of the nudibranchiate molluscs occurring in the Netherlands. Neth. J. Sea Res., 1, 191-240.

Talavera, G. \& Castresana, J. (2007) Improvement of phylogenies after removing divergent and ambiguously aligned blocks from protein sequence alignments. Syst. Biol., 56, 564-577.

Thollesson, M. (1998) Discrimination of two Dendronotus species by allozyme electrophoresis and the reinstatement of Dendronotus lacteus (Thompson, 1840) (Nudibranchia, Dendronotoidea). Zool. Scr., 27, 189-195.

Thompson, T. \& Brown, G. (1984) Biology of Opisthobranch Molluscs (vol.2). The Ray Society Publishing, London.

Thompson, W. (1840) Contributions towards a knowledge of the Mollusca Nudibranchia and Mollusca Tunicata of Ireland, with descriptions of some apparently new species of invertebrata. Ann. Mag. Nat. Hist., 5, 84-102,

Valdés, Á. \& Bouchet, P. (1998) Naked in toxic fluids: a nudibranch mollusc from hydrothermal vents. Deep-sea Res. Pt II, 45, 319-327.

Valdés, Á., Lundsten, L. \& Wilson, N. (2018) Five new deep-sea species of nudibranchs (Gastropoda: Heterobranchia: Cladobranchia) from the Northeast Pacific. Zootaxa, 4526, 4, 401-433.

Valdés, Á., Murillo, F., McCarthy, J. \& Yedinak, N. (2017) New deep-water records and species of North Atlantic nudibranchs (Mollusca,
Gastropoda: Heterobranchia) with the description of a new species. J. Mar. Biol. Ass. U.K., 97, 303-319.

Verril, A. (1880) Notice of recent additions to the marine Invertebrata, of the northeastern coast of America, with descriptions of new genera and species and critical remarks on others. Part II.-Mollusca, with notes on Annelida, Echinodermata, etc., collected by the United States Fish Commission. Proc. US Nat. Hist. Mus., 3, 356-405.

Verrill, A. (1870) Contributions to zoology from the Museum of Yale College. No.8.-Descriptions of some New England Nudibranchiata. Am. J. Sci. Arts (Ser. 2), 50, 405-408.

Vervoort, W. (1942) Northern Hydroida in the Collections of the Rijksmuseum van Natuurlijke Historie and the Zoological Museum at Amsterdam, with notes on their distribution. Zool. Meded, 23, 275-312.

Wägele, H., Willan, R. (200o) Phylogeny of the Nudibranchia. Zool.J. Linn. Soc., 130, 83-181.

Wiemers, M. \& Fiedler, K. (2007) Does the DNA barcoding gap exist? - a case study in blue butterflies. Front. Zool., 4, 8.

Willis, S. (2017) One species or four? Yes!....and, no. Or, arbitrary assignment of lineage to species obscures the diversification processes of Neotropical fishes. PLoS ONE, 12, eo172349.

Wobber, D. (1970) A report on the feeding of Dendronotus iris on the anthozoan Cerianthus sp. from Monterey Bay, California. Veliger, 12, 383-387. Wollscheid-Lengeling, V., Boore J., Brown, W. \& Wägele, H. (2001) The phylogeny of Nudibranchia (Opisthobranchia, Gastropoda, Mollusca) reconstructed by three molecular markers. . Org. Divers. Evol., 1, 241-256.

Yale Peabody Museum. (2020) Dendronotus elegans Verrill, 188o YPM IZ o10761.GP. Accessed through https://collections.peabody.yale.edu/ search/Record/YPM-IZ-o1o761.GP

Yang, Z. (2015) The BPP program for species tree estimation and species delimitation. Curr. Zool., $61,854-865$. 
Yoder, A., Olson, L., Hanley, C., Heckman, K., Rasoloarison, R., Russell, A., Ranivo, J., Soarimalala, V., Praveen Karanth, K., Raselimanana, A. \& Goodman, S. (2005) A multidimensional approach for detecting species patterns in Malagasy vertebrates. In: Hey, J., Fitch, W.M., Ayala, F.J., (Eds) Systematics and the origin of species: on Ernst Mayr's 1ooth anniversary, pp. 203-228 The National Academies Press, Washington, D.C..

Zachos, F.E. (2016) Species concepts in biology. Historical Development, Theoretical Foundations and Practical Relevance. Springer Nature Switzerland, Cham.
Zachos, F.E. (2018) Mammals and meaningful taxonomic units: the debate about species concepts and conservation. Mammal Rev., 48, 153-159.

Zachos, F.E., Apollonio, M., Bärmann, E.V., Festa-Bianchet, M., Göhlich, U., Habel, J.C. et al. (2013) Species inflation and taxonomic artefacts-A critical comment on recent trends in mammalian classification. Mamm. Biol., 78, 1-6.

RECEIVED: 2 MARCH 2020 | REVISED AND

ACCEPTED: 21 JULY 2020

EDITOR: B.W. HOEKSEMA 


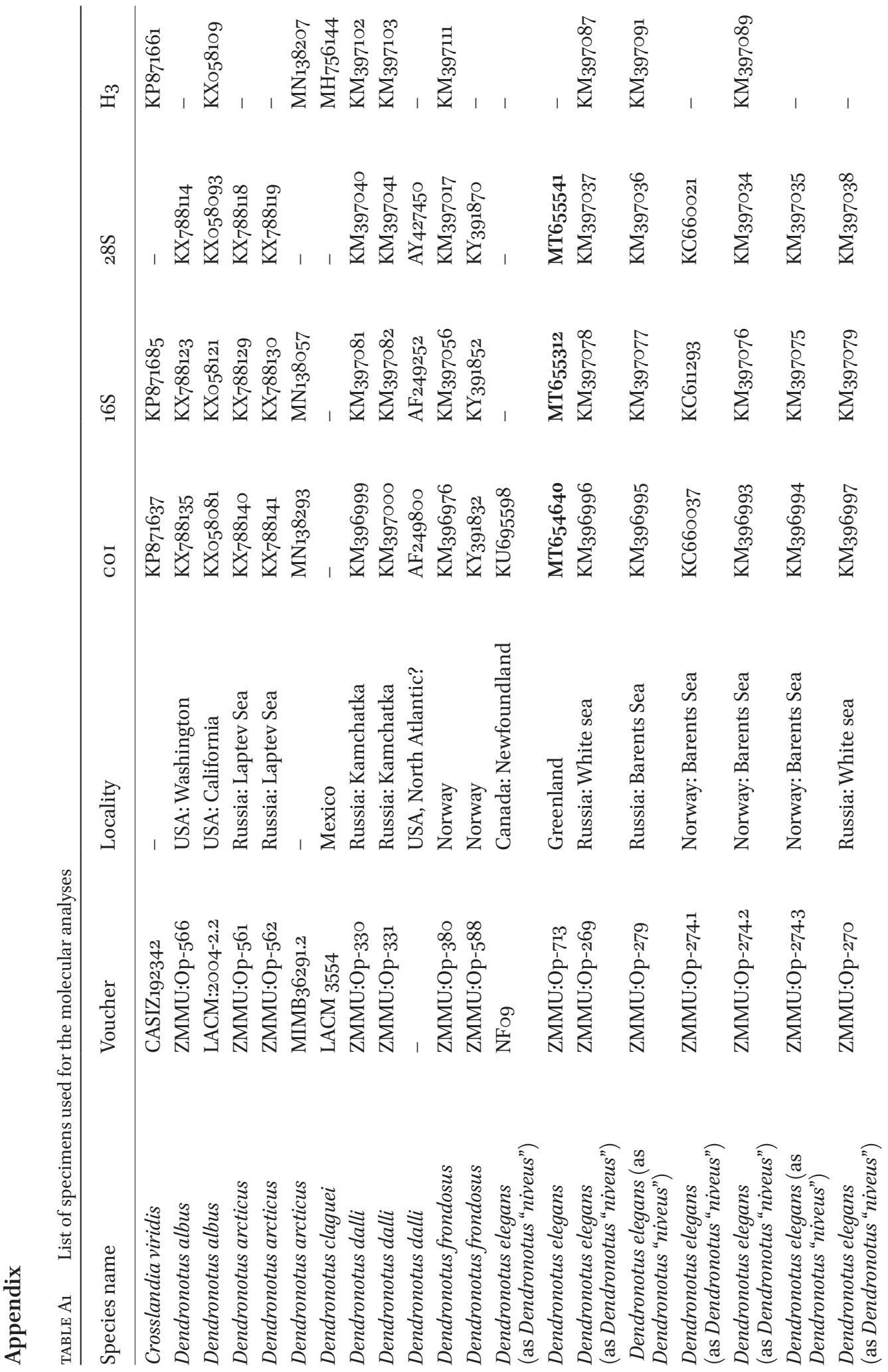




\begin{tabular}{|c|c|c|c|c|c|c|c|c|c|c|c|c|c|c|c|c|c|c|c|c|c|}
\hline$\ddot{I}$ & 1 & 1 & 1 & 1 & 1 & 1 & 1 & 1 & 1 & 1 & 1 & 1 & 1 & 1 & 1 & 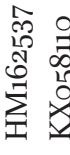 & & I & 1 & 1 & 1 \\
\hline ஷ্ & 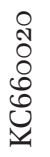 & 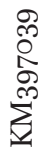 & 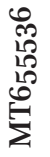 & $\begin{array}{l}\text { קి } \\
10 \\
10 \\
10 \\
\qquad \\
\Sigma\end{array}$ & 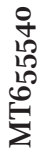 & 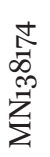 & 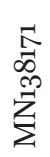 & 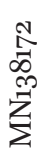 & 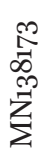 & 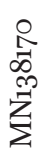 & 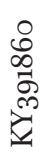 & 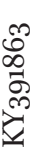 & 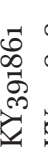 & 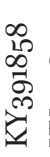 & 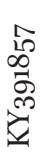 & $\begin{array}{ll}0 & 1 \\
2 & 0 \\
0 & 0 \\
10 & 1 \\
0 & 0 \\
1 & 1\end{array}$ & & 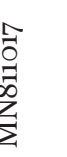 & 1 & 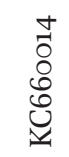 & $\begin{array}{l}m \\
\overline{0} \\
0 \\
0 \\
0 \\
ن \\
\forall\end{array}$ \\
\hline$\underset{\sim}{\mathscr{~}}$ & 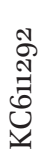 & \begin{tabular}{l}
0 \\
$\infty$ \\
0 \\
\multirow{1}{*}{} \\
$\infty$ \\
$\sum_{1}$
\end{tabular} & 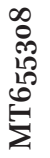 & 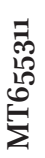 & 1 & 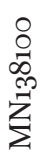 & 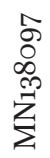 & $\begin{array}{l}\infty \\
\delta \\
\infty \\
\infty \\
\dddot{m} \\
Z_{z}\end{array}$ & 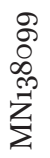 & 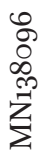 & 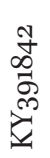 & 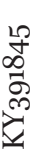 & 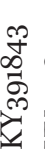 & 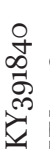 & 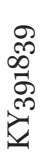 & 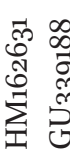 & 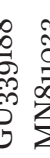 & 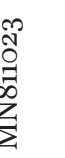 & 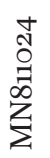 & 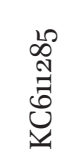 & 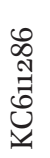 \\
\hline O & $\begin{array}{l}0 \\
m \\
0 \\
0 \\
0 \\
0 \\
ن \\
ચ\end{array}$ & $\begin{array}{l}\infty \\
\text { హ) } \\
\text { హ) } \\
\text { న } \\
\sum\end{array}$ & 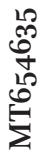 & 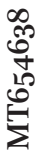 & 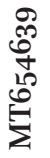 & 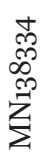 & 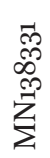 & $\begin{array}{l}\text { w్ } \\
\text { ల్ } \\
\text { m } \\
\sum_{\Sigma}\end{array}$ & 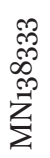 & 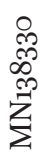 & 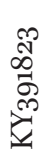 & 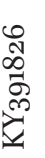 & 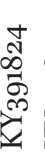 & 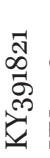 & 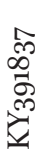 & $\begin{array}{ll}\infty & \\
\infty & \infty \\
0 & 0 \\
1 & 1 \\
0 & 1 \\
0 & 1\end{array}$ & & $\begin{array}{l}\infty \\
10 \\
10 \\
0 \\
\infty \\
\infty \\
\Sigma \\
\Sigma\end{array}$ & $\begin{array}{l}0 \\
10 \\
10 \\
\infty \\
0 \\
\infty \\
\sum \\
\sum\end{array}$ & 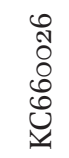 & 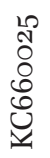 \\
\hline 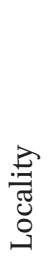 & 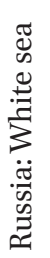 & 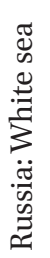 & 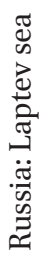 & 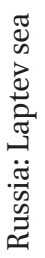 & 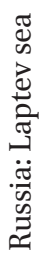 & 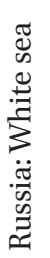 & 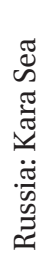 & 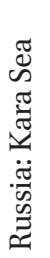 & 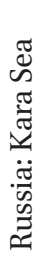 & 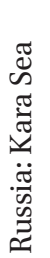 & 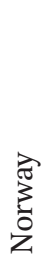 & 岁 & 光 & $\begin{array}{l}\text { ते } \\
\sum_{0} \\
0 \\
z\end{array}$ & $\begin{array}{l}\vec{\pi} \\
3 \\
0 \\
Z \\
Z\end{array}$ & 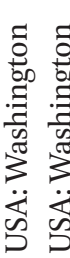 & 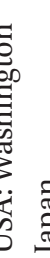 & 苂 & 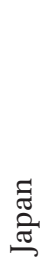 & 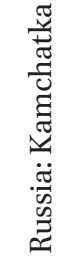 & 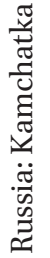 \\
\hline 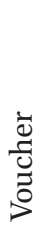 & $\begin{array}{l}\text { N } \\
\text { G } \\
\text { D } \\
3\end{array}$ & $\begin{array}{l}10 \\
0 \\
0 \\
\text { N } \\
3\end{array}$ & 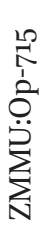 & 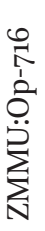 & 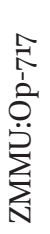 & $\begin{array}{l} \\
\infty \\
\infty \\
5 \\
5\end{array}$ & 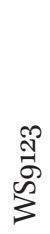 & 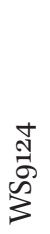 & 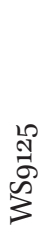 & $\begin{array}{l}\text { जี } \\
\text { 皃 }\end{array}$ & 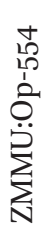 & 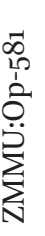 & 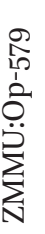 & 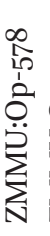 & 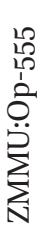 & 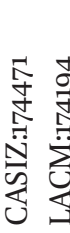 & 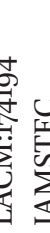 & 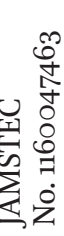 & $\sum_{\substack{U \\
\infty}}^{\infty}$ & 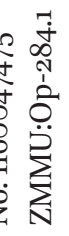 & 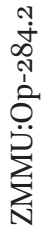 \\
\hline
\end{tabular}




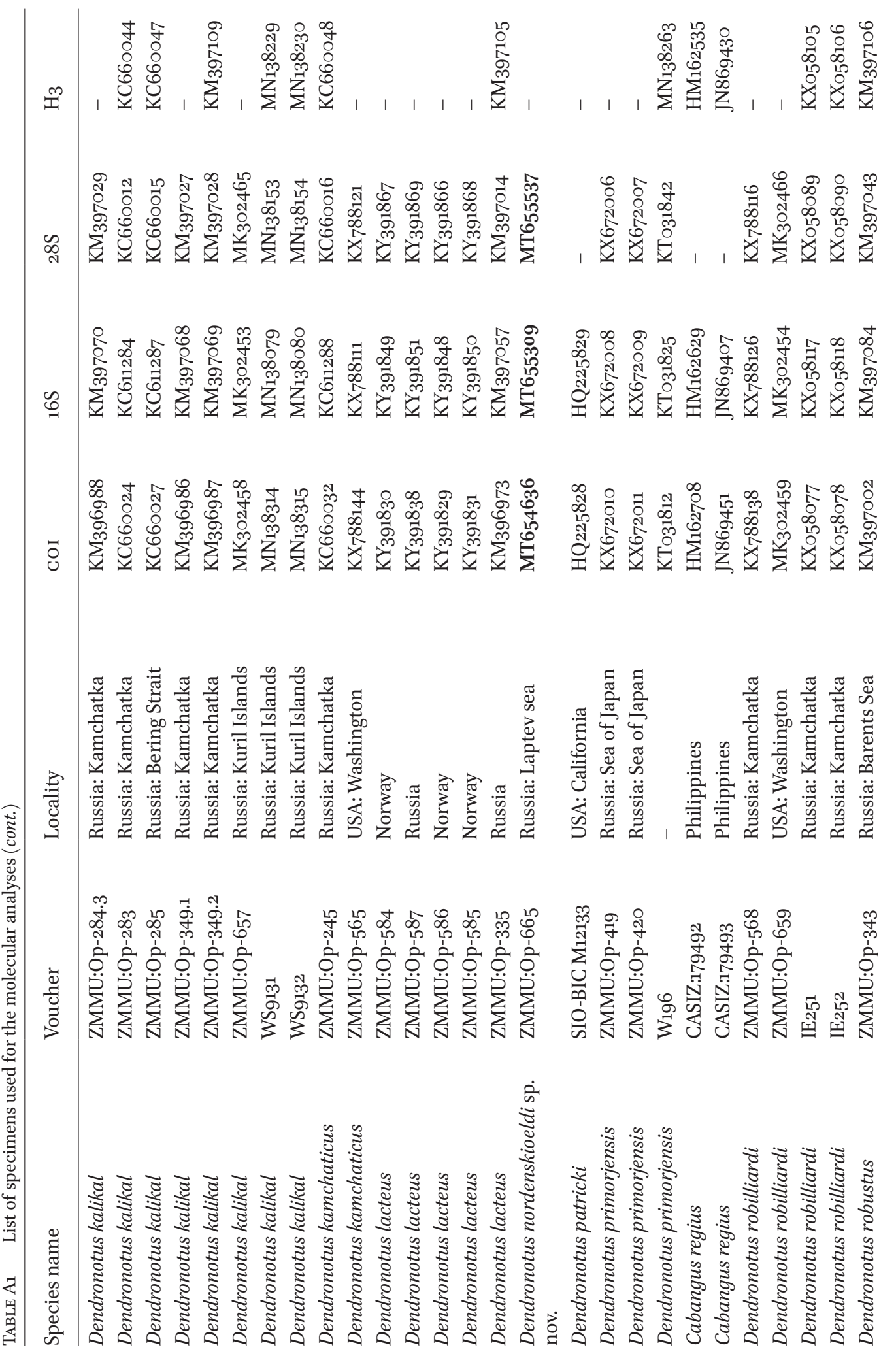




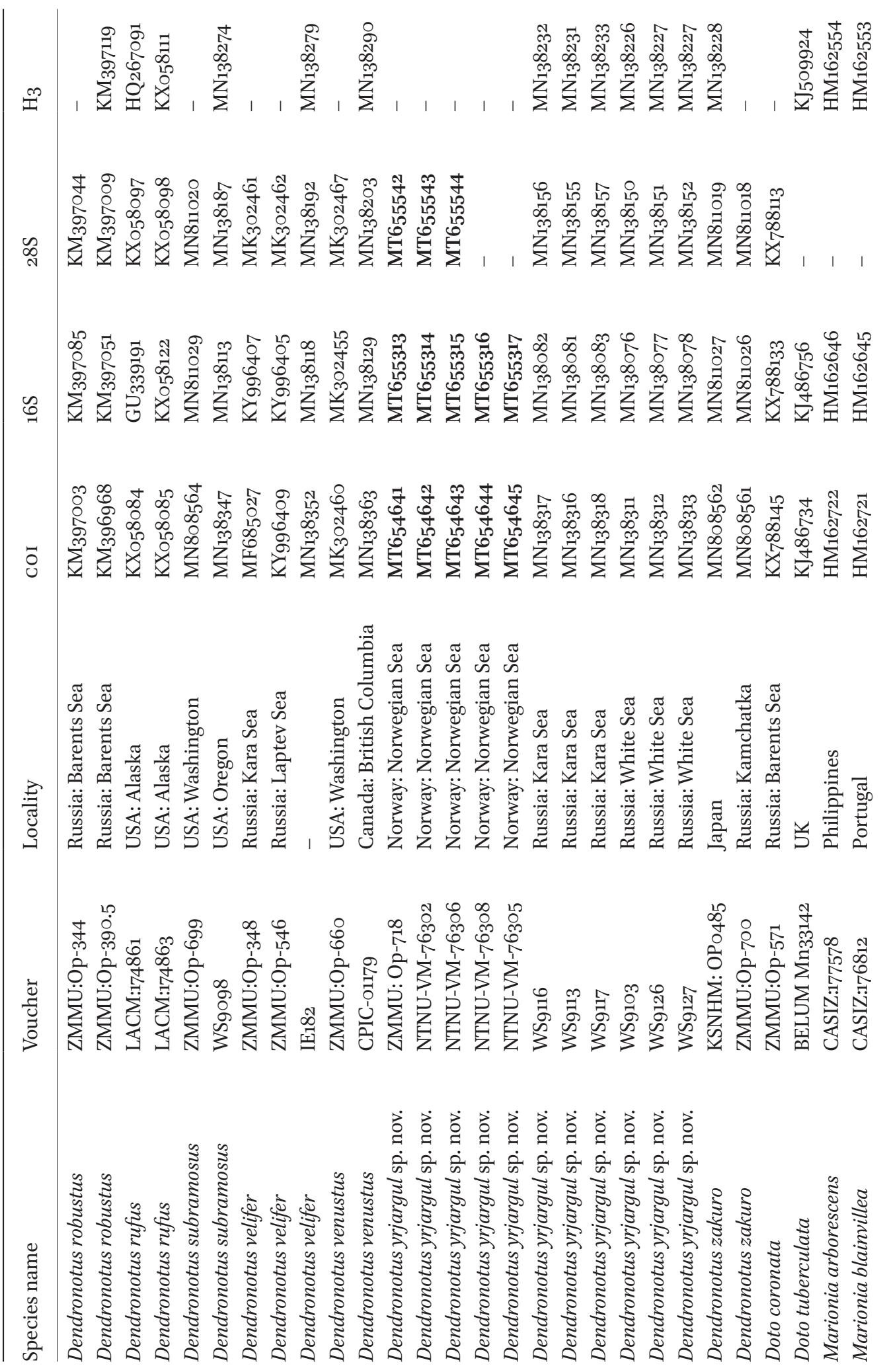




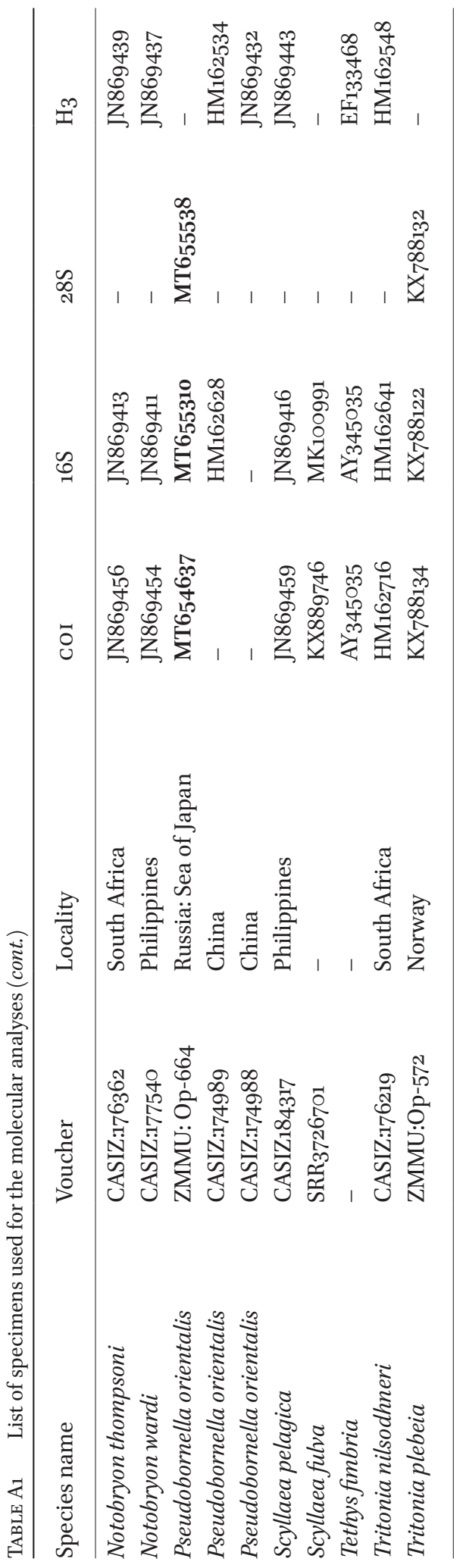




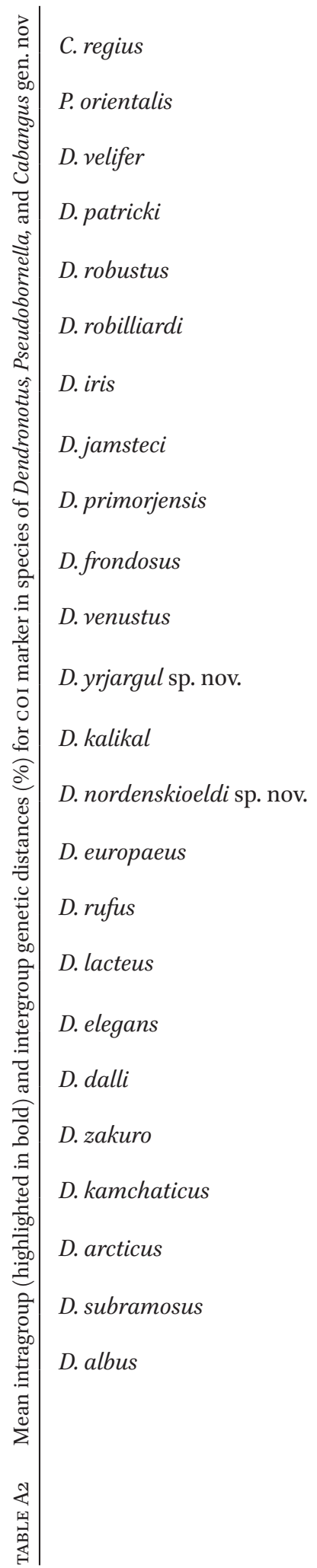

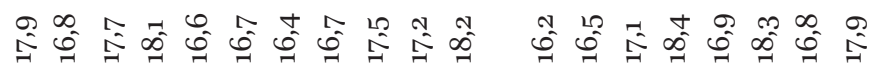

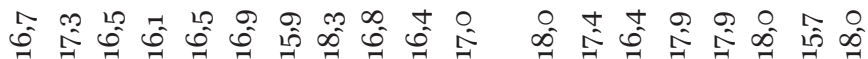

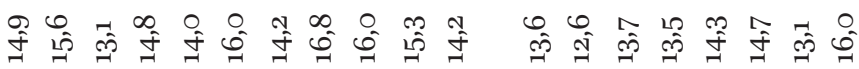

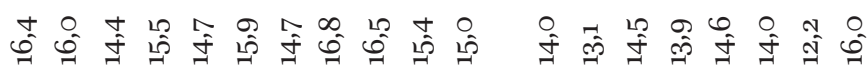

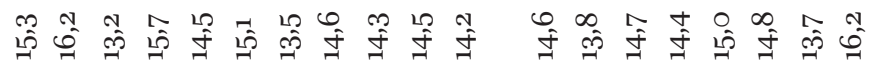

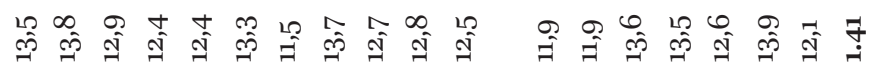

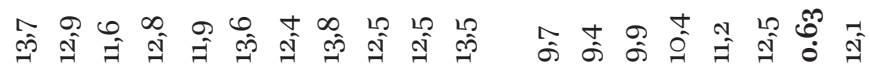

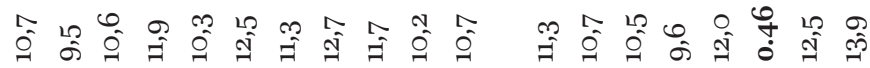
जิ

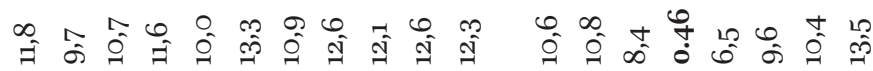
I

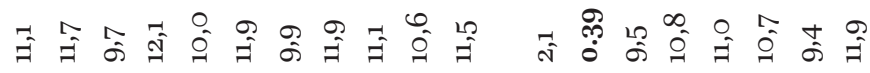

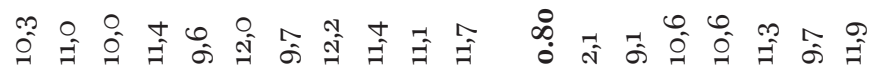
ิิ

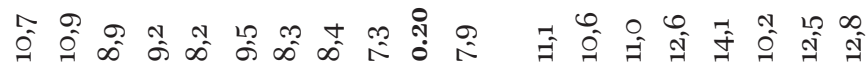
पै

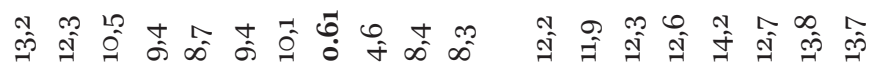

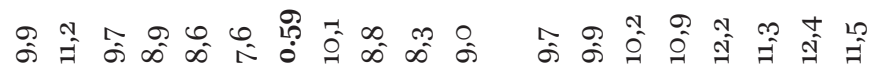
की

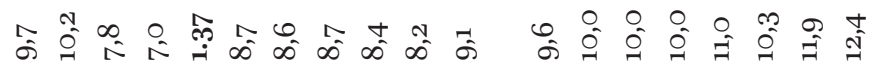

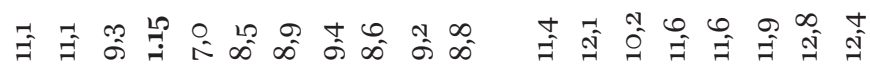

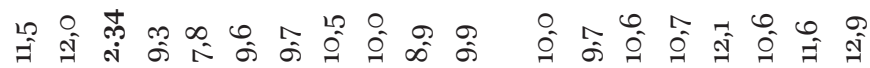
के बैं की

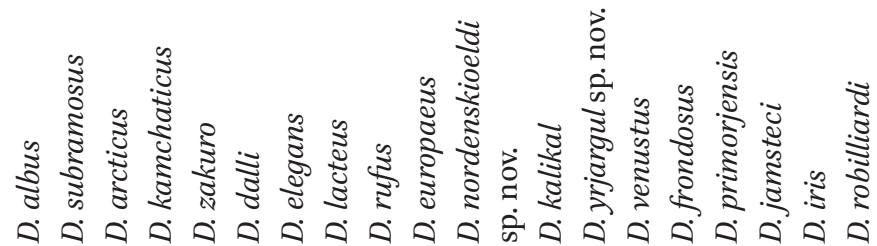




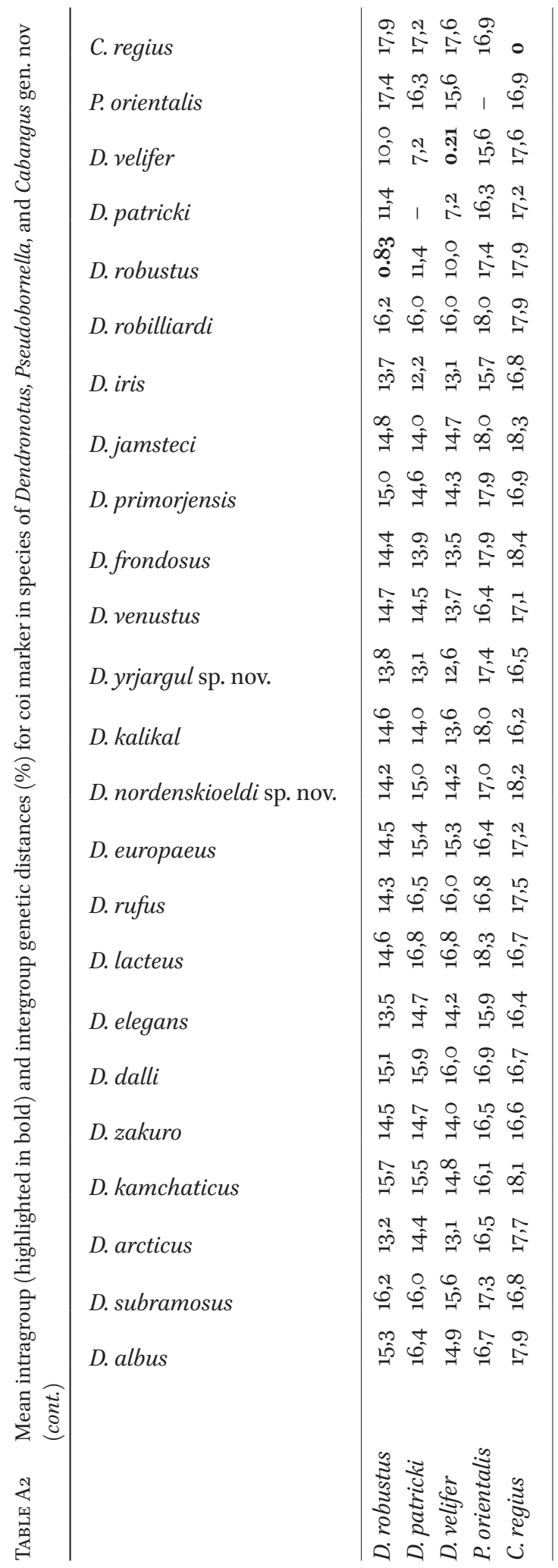

